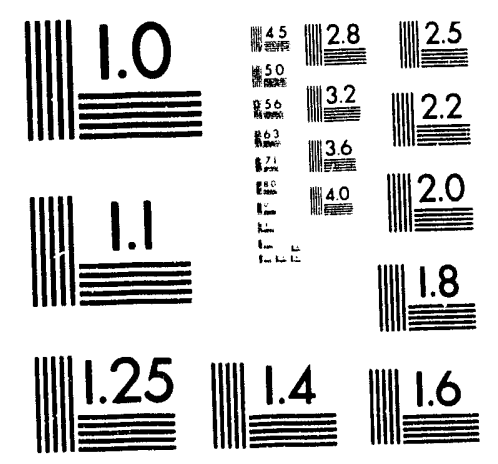



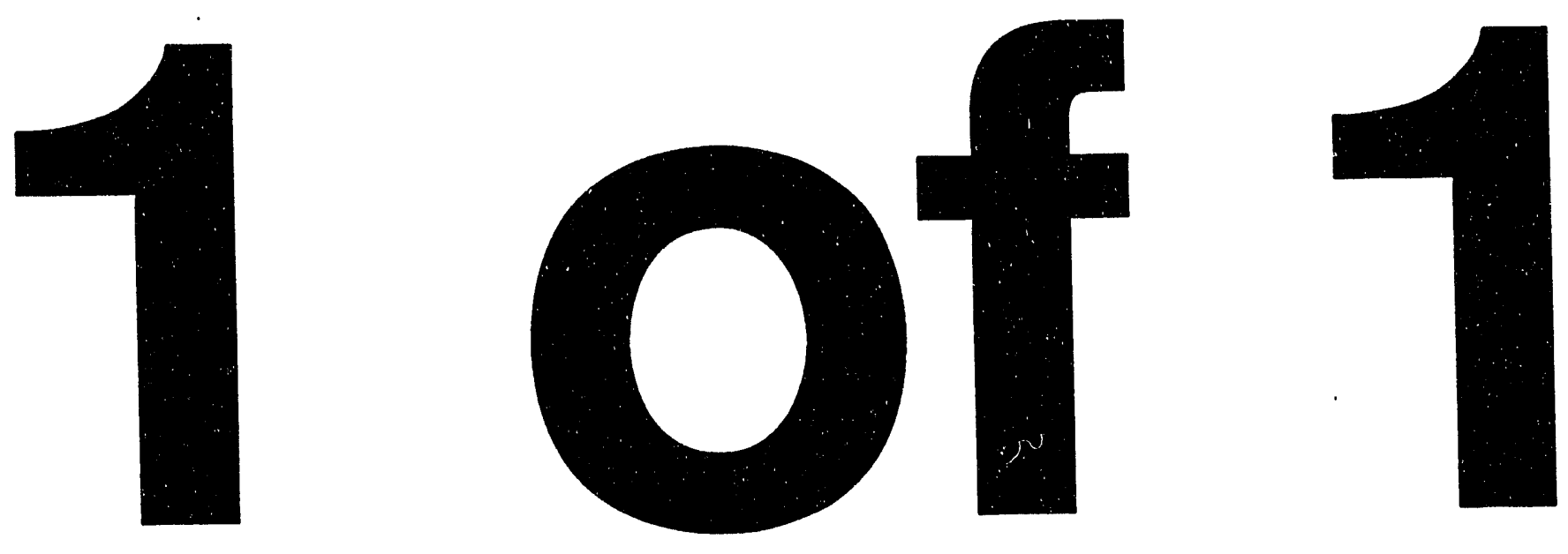
Energy Technology Division Energy Technology Division Energy Technology Division Energy Technology Division Energy Technology Division Energy Technology Division

\section{Experiment on Fluidelastic Instability of Loosely Supported Tube Arrays in Crossflow} by S. S. Chen, S. Zhu, and Y. Cai 
Argonne National Laboratory, with facilities in the states of Illinois and Idaho, is owned by the United States government, and operated by The University of Chicago under the provisions of a contract with the Department of Energy.

\section{DISCLAIMER}

This report was prepared as an account of work sponsored by an agency of the United States Government. Neither the United States Government nor any agency there of, nor any of their employees, makes any warranty, express or implied, or assumes any legal liability or responsibility for the accuracy, completeness, or usefulness of any information, apparatus, product, or process disclosed, or represents that its use would not infringe privately owned rights. Reference herein to any specific commercial product, process, or service by trade name, trademark, manufacturer, or otherwise, does not necessarily constitute or imply its endorsement, recommendation, or favoring by the United States Government or any agency thereof. The views and opinions of authors expressed herein do not necessarily state or reflect those of the United States Government or any agency thereof.

Reproduced from the best available copy.

Available to DOE and DOE contractors from the

Office of Scientific and Technical Information

$$
\text { P.O. Box } 62
$$

Oak Ridge, TN 37831

Prices available from (615) 576-8401

Available to the public from the National Technical Information Service

U.S. Department of Commerce 528.5 Port Royal Road Springfield, VA 22161 
by

S. S. Chen, S. Zhu, and Y. Cai

Energy Technology Division

June 1993

Work supported by

U.S. DEPARTMENT OF ENERGY

Office of Basic Energy Sciences 


\section{Contents}

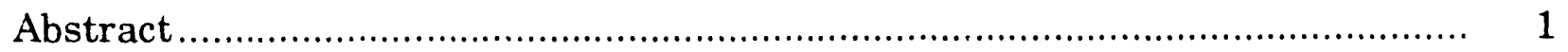

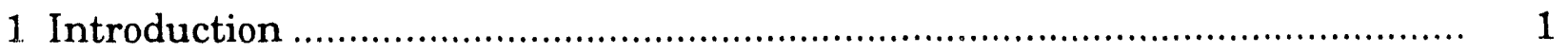

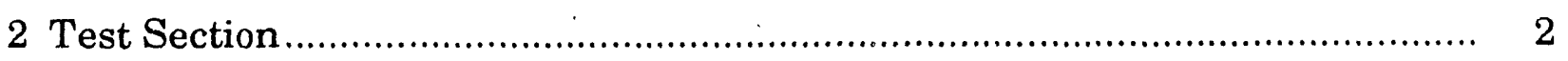

3 Test Procedure and Data Analysis ............................................................ 3

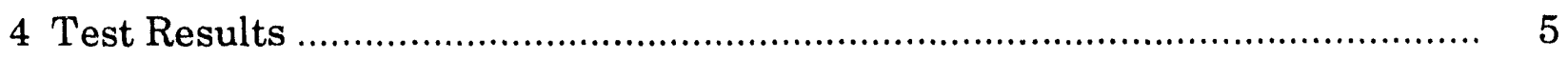

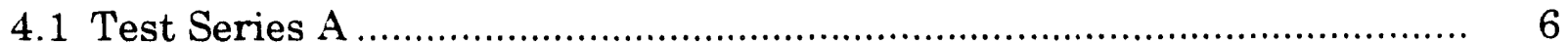

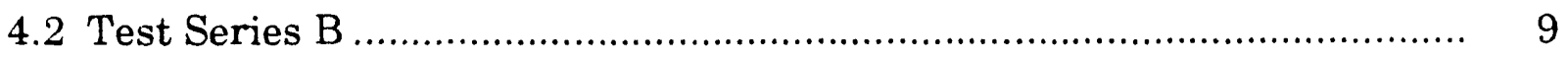

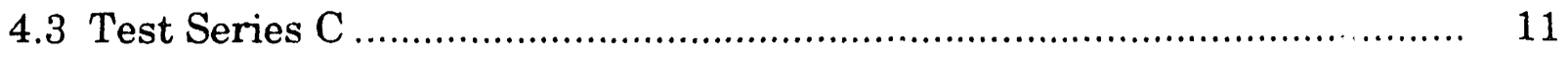

5 Comparison with Analytical Model ........................................................... 13

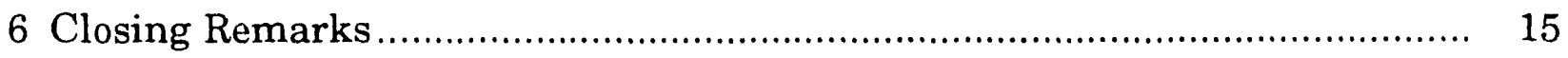

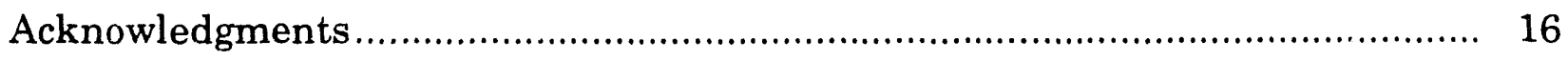

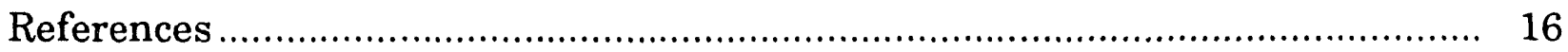

Figures

1 A row of tubes in crossflow; tube/support interaction ......................... 19

2 RMS tube displacement as a function of flow velocity, Test A.1 .......... 20

$3 \quad$ Frequency spectra for several flow velocities, Test A.1 ......................... 20

4 RMS tube displacement as a function of flow velocity, Test A.2 _.......... 21

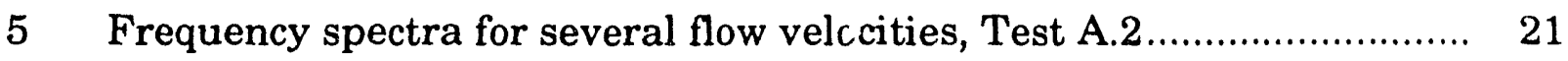

$6 \quad$ RMS tube displacement as a function of flow velocity, Test $A, 3 \ldots \ldots \ldots \ldots \quad 22$

$7 \quad$ Time histories of tube displacement, Test A.3 ................................... 22

$8 \quad$ RMS tube displacement as a function of flow velocity, Test A.4 …........ 23

9 Dominant response frequency as a function of flow velocity, Test A.4... 23 
10 Frequency spectra at several flow velocities, Test A.4 …..................... 24

11 RMS tube displacement as a function of flow velocity, Test A.5 ........... 25

12 Dominant response frequency as a function of flow velocity, Test A.5... 25

13 Frequency spectra for several flow velocities, Test A.5 ...................... 26

14 RMS tube displacement as a function of flow velocity, Test B.1 ........... 27

15 Dominant response frequency as a function of flow velocity, Test B.1... 27

16 Time histories of displacement transducer a at different flow velocities,

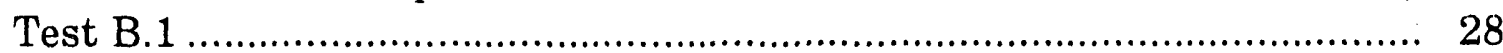

17 Time histories of displacement transducer $\mathrm{b}$ at different flow velocities, Test B.1 29

18 Power spectral densities of displacement transducer a, Test B.1.......... 30

19 Power spectral densities of displacement transducer b, Test B.1.......... 31

$20 \quad$ Phase planes of displacement transducer a, Test B.1 ......................... 32

$21 \quad$ Phase planes of displacement transducer b, Test B.1 ........................... 33

22 Poincaré maps for displacement transducer a, Test B.1 ...................... 34

23 Poincaré maps for displacement transducer b, Test B.1 ....................... 35

24 Lyapunov exponent as a function of flow velocity, Test B.1 ….............. 36

25 RMS tube displacement as a function of flow velocity, Test B.2 …........ 37

26 Dominant response frequency as a function of flow velocity, Test B.2... 37

27 Time histories of displacement transducer a at different flow velocities, Test B.2

28 Time histories of displacement transducer $b$ at different flow velocities, Test B.2

29 Power spectral densities of displacement transducer a, Test B.2........... 
30 Power spectral densities of displacement transducer b, Test B.2............

$31 \quad$ Phase planes of displacement transducer a, Test B.2 …..................... 42

32 Phase planes of displacement transducer b, Test B.2 .......................... 43

33 Poincaré maps for displacement transducer a, Test B.2 ..................... 44

$34 \quad$ Poincaré maps for displacement transducer b, Test B.2 ...................... 45

35 Lyapunov exponent as a function of flow velocity, Test B.2 …............ 46

$36 \quad$ RMS tube displacement as a function of flow velocity, Test C.1 ........... 47

37 Dominant response frequency as a function of flow velocity, Test C.1...

38 Time histories of tube displacement at different flow velocities,

Test C.1

39 Time histories of tube displecement at different flow velocities,

Test C.1

40 Power spectral densities of tube displacement, Test C.1 50

41 Power spectral densities of tube displacement, Test C.1

42 Phase planes of tube motion, Test C.1

43 Phase planes of tube motion, Test C.1 53

44 Poincaré maps, Test C.1

Poincaré maps, Test C.1

Lyapunov exponent as a function of flow velocity, Test C.1 56

47 RMS tube displacement as a function of flow velocity, Test C.2

Dominant response frequency as a function of flow velocity, Test C.2...

49 RMS tube displacement as a function of flow velocity, Test C.3 58

50 Dominant response frequency as a function of flow velocity, Test C.3... 
$51 \quad$ Time histories of tube displacement, Test C.3 …................................. 60

$52 \quad$ Time histories of tube displacement, Test C.3 …................................ 61

$53 \quad$ Power spectral densities of tube displacement, Test C.3 …................. 62

54 Power spectral densities of tube displacement, Test C.3 ….................. 63

$55 \quad$ Phase planes of tube motion, Test C.3 …........................................... 64

$56 \quad$ Phase planes of tube motion, Test C.3 …........................................... 65

$57 \quad$ Poincaré maps, Test C.3

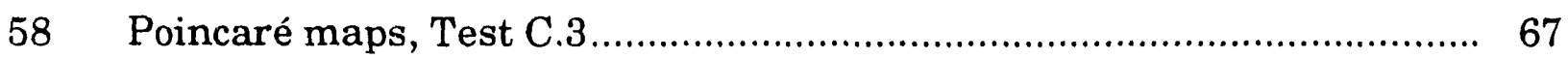

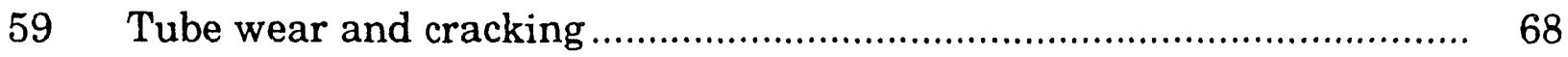

60 Comparison of theoretical results and exponent data of RMS tube displacements, Test B.1 ................................................................... 69

61 Time history, power spectral density, phase plane, and Lyapunov exponent at $2.063 \mathrm{~m} / \mathrm{s}$, Test B.1................................................... 70

62 Time history, power spectral density, phase plane, and Lyapunov exponent at $2.287 \mathrm{~m} / \mathrm{s}$, Test B.1....

63 Time history, power spectral density, phase plane, and Lyapunov exponent at $3.39 \mathrm{~m} / \mathrm{s}$, Test B.1....

64 Time history, power spectral density, phase plane, and Lyapunov exponent at $3.802 \mathrm{~m} / \mathrm{s}$, Test B.1.

\section{Tables}

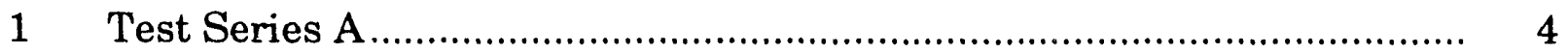

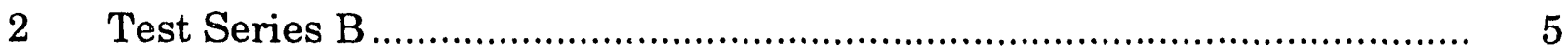

$3 \quad$ Test Series C 


\section{Experiment on Fluidelastic Instability of Loosely Supported Tube Arrays in Crossflow}

by

S. S. Chen, S. Zhu, and Y. Cai

Abstract

A tube array supported by baffle plates in crossflow may be subjected to fluidelastic instability in the tube-support-plate-inactive mode. An experimental study is presented to characterize the tube motion. Three series of tests were performed to measure tube displacements as a function of flow velocity for different clearances. The motion was examined by root-mean-square values of tube displacements, power spectral densities, phase planes, Poincaré maps, and Lyapunov exponents. The experimental data agree reasonably well with the analytical model, based on the unsteady flow theory.

\section{Introduction}

Tube arrays in heat exchangers, steam generators, condensers, boilers, etc., are frequently restrained by tube support plates, antivibration bars, and other types of supports. To facilitate manufacture and to allow for thermal expansion of the tubes, small clearances are used between tubes and tube supports. When the tubes oscillate due to subcritical vibration or fluidelastic instability caused by flowing fluid, tube failure can occur through fretting wear, fatigue, and impacting associated with dynamic tube/support interaction. Such failures have resulted in numerous plant shutdowns, which are often very costly.

In the last decade, extensive studies to improve the understanding of dynamic tube/support interaction and to prevent tube failure have been published. A recent review of this subject is available (Chen 1991). Several aspects of the problem have been studied extensively: (1) the dynamics of tubes with loose supports, in order to understand the response to harmonic excitation; (2) the effect of the fluid in the clearance between the tube and support plates; (3) the wear rate and the effect of other system pindmeters on wear characteristics; and (4) the response of tube arrays in flow.

Because a loosely supported tube in crossflow is a nonlinear dynamic system with many interesting nonlinear characteristics, a series of analytical investigations have been reported recently (Axisa et al. 1988; Fricker 1992; de Langre et al. 1992; 
Paidoussis and Li 1992; Vento et al. 1992; Eisinger et al. 1991; Cai and Chen 1991, 1992). Most of the analyses are based on the quasistatic or quasisteady flow theories, which are applicable in some specific parameter range only. Several analyses are based on the unsteady flow theory (Eisinger et al. 1991; Cai and Chen 1991, 1992; Chen and Chen 1993), which is expected to provide more aicurate prediction.

Since the publication of a systematic experiment of tube arrays in crossflow with loose supports (Chen, Jendrzejczyk, and Wambsganss 1985), many tests have been performed to understand this interesting and important problem. Some experiments were directed to the general tube response to a specific excitation and characterization of the tube/support interaction and wear (Haslinger et al. 1987, 1989; Fisher and Ingham 1988; Ko and Magel 1989; Fisher et al. 1988; Goyder 1985). Several studies are directed to the chaotic characteristics. Antunes et al. $(1988,1990,1992)$ used a single tube with a velocity feedback loop to simulate fluidelastic instability; they studied tube/support interaction for both symmetric and asymmetric gaps. The same approach was also used to investigate the planar motion of a tube inside a baffle plate with circular clearance (Vento et al. 1992). Paidoussis et al. (1992) tested flexibly mounted rigid tube arrays with a rotated triangular array having a pitch-to-diameter ratio of 1.375 in a water channel, using different annular gaps and materials for the support. In another study, steam generator tubes in the U-bend area were supported by antivibration bars; tests were performed to understand vibration characteristics (Gay and Granger 1992).

In the present study, a tube row with pitch ratio of 1.35 is tested, because this is the only tube array arrangement whose fluid-force coefficients are available at this time. The purpose of this experiment is to verify the theoretical model on the basis of the unsteady flow theory and to characterize the fluidelastic instability associated with tube-support-plate (TSP)-inactive modes. The experimental data agree reasonably well with analytical results.

\section{Test Section}

The experiments are performed in a rectangular flow channel that is $10.7 \mathrm{~cm}$ (4.2 in.) wide and $25.9 \mathrm{~cm}$ (10.2 in.) high and is situated in a test chamber connected to a water loop with a maximum flow rate of $0.052 \mathrm{~m}^{3} / \mathrm{s}(700 \mathrm{gpm})$. The rectangular flow channel is formed by four internal walls that separate the internal flow from the almost stagnant water contained in the surrounding external $30-\mathrm{cm}$-diameter (12 in.) pressure shell. A section of this shell is fitted with two vertical pipe branches that accommodate a test assembly. The details of the test chamber are the same as those in earlier experiments for tube arrays in crossflow (Chen, Jendrzejczyk, and Wambsganss 1985). 
The arrangement of the tuhe row is shown in Fig. 1a. Each tube element is suspended as a simply supported beam on two $O$-rings mounted $91.4 \mathrm{~cm}$ (36 in.) apart ( $A$ to $D)$. The O-rings are seated in compression plates. The tube is submerged in fluid between the two O-ring supports (A to D) but is subjected to flow only in its middle portion $\mathrm{B}$ to $\mathrm{C}$ (measuring $25.9 \mathrm{~cm}$ [10.2 in.]). Two types of tubes are used:

- Tube 3 is a brass tube with $1.59 \mathrm{~cm}$ (5/8 in.) OD, $1.59 \mathrm{~mm}(1 / 16 \mathrm{in}$. wall thickness, and $126.37 \mathrm{~cm}$ (49.75 in.) length.

- Tubes $1,2,4$, and 5 are stainless steel tubes with $1.59 \mathrm{~cm}(5 / 8 \mathrm{in}$.) OD, $0.32 \mathrm{~cm}(1 / 8 \mathrm{in}$.$) wall thickness, and 99.06 \mathrm{~cm}$ (39.0 in.) length.

The cverhung portion (the portion outside the tube supports A and D) for tubes 1, 2, 4 , and 5 is $3.81 \mathrm{~cm}$ ( 1.5 in.), and for tube 3 is $3.18 \mathrm{~cm}$ (1.25 in.) at one end and 31.75 $\mathrm{cm}$ (12.5 in.) at the other end. The overhung portion of the tubes between $D$ and $G$ is in air. To raise their natural frequencies in the lift (i.e., perpendicular-to-flow) direction, tube's 2-3 and 4-5 are welded together outside the flow region.

Tube 3 is also "supported" by a brass baffle plate (TSP), shown in Fig. 1a at Location G; its thickness is $0.64 \mathrm{~cm}(0.25$ in.) for test series A ('1able 1) or $1.27 \mathrm{~cm}$ ( $1 / 2$ in.) for test series $B$ and $C$ (Tables 2 and 3 ). The diametral clearance (gap) between the tube and the TSP is set at different values to study the effect of clearance on tube response: $1.27 \mathrm{~mm}$ (50 mil), $1.905 \mathrm{~mm}$ (75 $\mathrm{mil}$ ), and $2.54 \mathrm{~mm}$ (100 $\mathrm{mil}$ ).

Two sets of displacement transducers are located at $a$ and $b$ to measure the displacement of tube 3; two transducers at $b$ are close to the TSP and the other two transducers at a are at approximately the midspan of the overhung portion. The transducers measure the displacements in the lift and drag directions.

\section{Test Procedure and Data Analysis}

The test section is installed vertically in the water loop with the overhung portion pointing upward. The span DG is in air.

Tube damping depends on water temperature; this is attributed to the O-rings, whose characteristics are a function of temperature. Therefore, tube damping car be controlled by controlling water temperature in the loop. In each test, the tube damping value was measured at the operating temperature. 
The objectives are to measure the response characteristics of tube 3 for different support conditions. Because tubes 1,2, 4, and 5 are much stiffer than tube 3 , they can be considered as rigid tubes. Three series of tests are performed:

A. The TSP is $0.64 \mathrm{~cm}(0.25 \mathrm{in}$.) thick and is placed at the free end. Tube displacement is measured at $b$, which is $6.35 \mathrm{~cm}(2.5 \mathrm{in}$.) from the free end. The natural frequencies for the first and second modes in air and in water are as follows:

- Natural frequencies in air: $\quad 29.67 \mathrm{~Hz}$ (1st mode) $69.67 \mathrm{~Hz}$ (2nd mode).

- Natural frequencies in water: $26.50 \mathrm{~Hz}$ (1st mode) $66.00 \mathrm{~Hz}$ (2nd mode).

- Damping ratio in air: $\quad 1.2 \%$.

Different clearances between the tube and TSP, as well as different water temperatures, are tested. The five tests performed for this series are listed in Table 1.

In this series, the tube displacements were analyzed on-line. The results are time histories, root-mean-square (RMS) tube displacements, power spectral densities, and dominant response frequencies.

B. The tube-support-plate is $1.27 \mathrm{~cm}(0.5 \mathrm{in}$.$) thick and placed 1.27 \mathrm{~cm}$ ( $0.5 \mathrm{in}$.) from the free end. Two displacement transducers are placed at a, which is $10.8 \mathrm{~cm}$ (4.25 in.) from $\mathrm{D}$, and $\mathrm{b}$, which is $4.13 \mathrm{~cm}$ (1.625 in.) from the free end. The natural frequencies for the first and second modes in air and in water are the same as in series A. The two tests performed for this series are shown in Table 2. Tube displacements and flow rate are recorded on tape for detailed analysis.

Table 1. Test Series A

\begin{tabular}{cclcc}
\hline Test & $\begin{array}{c}\text { Support } \\
\text { Condition at } \mathrm{G}\end{array}$ & \multicolumn{1}{c}{$\begin{array}{c}\text { Gaps } \\
\mathrm{g}_{1} \text { and } \mathrm{g}_{2}(\mathrm{~mm})\end{array}$} & $\begin{array}{c}\text { Water } \\
\text { Temperature }\left({ }^{\circ} \mathrm{F}\right)\end{array}$ & $\begin{array}{c}\text { Damping } \\
\text { Value }(\%)\end{array}$ \\
\hline A.1 & None & & 70 & 2.6 \\
A.2 & TSP & $\mathrm{g}_{1}=\mathrm{g}_{2}=2.54$ & 70 & 2.7 \\
A.3 & TSP & $\mathrm{g}_{1}=\mathrm{g}_{2}=2.54$ & 60 & 4.4 \\
A.4 & TSP & $\mathrm{g}_{1}=2.54$ & 72 & 2.4 \\
& & $\mathrm{~g}_{2}=$ infi..iie & & \\
& & (Baffle plate on & & \\
A.5 & one side only) & & 4.4 \\
\hline
\end{tabular}


Table 2. Test Series B

\begin{tabular}{ccccc}
\hline Test & $\begin{array}{c}\text { Support } \\
\text { Condition at } \mathrm{G}\end{array}$ & $\begin{array}{c}\text { Gaps } \\
\mathrm{g}_{1}, \mathrm{~g}_{2}(\mathrm{~mm})\end{array}$ & $\begin{array}{c}\text { Water } \\
\text { Temperature }\left({ }^{\circ} \mathrm{F}\right)\end{array}$ & $\begin{array}{c}\text { Damping } \\
\text { Value }(\%)\end{array}$ \\
\hline B.1 & TSP & $\mathrm{g}_{1}=\mathrm{g}_{2}=2.54$ & 60 & 4.3 \\
B.2 & TSP & $\mathrm{g}_{1}=\mathrm{g}_{2}=1.27$ & 60 & 4.3 \\
\hline
\end{tabular}

C. The tube arrangement and support geometry are the same as in Series B. The three tests performed for this series are shown in Table 3. Tube displacements are recorded on tape for detailed analysis.

Table 3. Test Series $C$

\begin{tabular}{cclcc}
\hline Test & $\begin{array}{c}\text { Support } \\
\text { Condition at } \mathrm{G}\end{array}$ & \multicolumn{1}{c}{ Gap $(\mathrm{mm})$} & $\begin{array}{c}\text { Water } \\
\text { Temperature }\left({ }^{\circ} \mathrm{F}\right)\end{array}$ & $\begin{array}{c}\text { Damping } \\
\text { Value }(\%)\end{array}$ \\
\hline C. 1 & TSP & $\mathrm{g}_{1}=\mathrm{g}_{2}=1.91$ & 60 & 4.3 \\
C. 2 & TSP & $\mathrm{g}_{1}=\mathrm{g}_{2}=1.27$ & 60 & 4.3 \\
C. 3 & TSP & $\mathrm{g}_{1}=1.27$ & 60 & 4.3 \\
& & $\mathrm{~g}_{2}=$ infinite & & \\
& (Baffle plate on \\
& one side only) & & \\
\hline
\end{tabular}

\section{Test Results}

Because of the clearance at support G (the TSP), tube 3 can respond in different modes: the TSP-inactive mode, in which support $G$ is inactive (the tube does not contact the support), and the TSP-active mode, in which support G is active (the tube contacts the support). The natural frequencies of the TSP-active mode are higher than those of the TSP-inactive mode. In the three series of tests, the TSPinactive mode becomes unstable first. Therefore, the lowest critical flow velocity is associated with the fundamental TSP-inactive mode. 


\subsection{Test Series A}

In this series, the displacements are analyzed on line. It is expected that displacements in the drag direction are much smaller than those in the lift direction and that the lift displacement $a t b$ is larger than that at $a$. Only the tube displacement at $\mathrm{b}$ in the lift direction is analyzed.

\section{Test A.1}

Figure 2 shows RMS tube displacement as a function of flow velocity. Tube response follow different paths with increasing and decreasing flow velocity, as indicated by the arrows in Fig. 2. This is a typical hysteresis effect of fluidelastic instability. Similar behavior also appears in axial-flow-induced instability of pipes (Chen and Jendrzejczyk 1985). Two regions can be defined:

- Excited instability: In Fig. 2, this region corresponds to the flow velocity from about 1.44 to $1.53 \mathrm{~m} / \mathrm{s}$. If the tube is given proper excitation, it may become flutter in this exciced region. Without excitations, the tube is stable.

- Intrinsic instability: No mechanical excitation is needed in this region. Once the flow is increased to the stability limit for intrinsic instability, large tube motion occurs. In Fig. 2, this corresponds to the region where flow velocity is $>1.53 \mathrm{~m} / \mathrm{s}$.

Once the tube loses stability (in the linear sense) by either intrinsic or excited instability, with decreasing flow velocity, large-amplitude tube motion does not stop until flow velocity decreases to the lower limit of the excited instability region. The difference between excited and intrinsic instability can be significant; in this case, the excited and intrinsic flutter speeds are 1.44 and $1.53 \mathrm{~m} / \mathrm{s}$, respectively.

Figure 3 shows the power spectral densities of tube displacement for several flow velocities. When flow velocity is increasing, at $1.52 \mathrm{~m} / \mathrm{s}$ the tube is stable. The dominant mode is the fundamental TSP-inactive mode with some contributions of higher modes (Fig. 3a). At $1.54 \mathrm{~m} / \mathrm{s}$, the tube is unstable and oscillates with large amplitude. The frequency spectrum show a series of superharmonic frequencies associated with the tube impacting the two surrounding tubes between $B$ and $C$, (Fig. 3b). At $1.46 \mathrm{~m} / \mathrm{s}$ when the flow velocity is reduced, the impact becomes mure irregular (Fig. 3c). At $1.42 \mathrm{~m} / \mathrm{s}$ with decreasing flow velocity, the spectra (Fig. 3d) are similar to that of increasing flow velocity at $1.52 \mathrm{~m} / \mathrm{s}$.

This test demonstrates again that the hysteresis exists for a single tube in a rigid tube array. 


\section{Test A.2}

Figures 4 and 5 show RMS tube displacement and power spectral densities, respectively, as a function of flow velocity. Tube response characteristics can be divided into two regions:

- Low-amplitude oscillations: For flow velocity less than about $1.5 \mathrm{~m} / \mathrm{s}$, which is the lowest critical flow velocity of the fundamental TSPinactive mode, tube motion is small and the tube responds in the TSP-inactive mode. The dominant frequency is the fundamental mode of the TSP-inactive mode (Fig. 5a).

- Instability of the TSP-inactive mode: As flow velocity increases to $>1.5 \mathrm{~m} / \mathrm{s}$, the TSP-inactive mode becomes unstable. Once the tube loses stability, large-amplitude oscillations occur and the tube impacts against the TSP. Therefore, the maximum peak-to-peak displacement at the TSP is that of the clearance of $2.54 \mathrm{~mm}$. In this range of flow velocity, tube displacement at TSP is almost independent of flow velocity. The RMS displacement is between 1.4 $\mathrm{mm}$ and $1.55 \mathrm{~mm}$, which is less than the RMS value of a sine wave with its peak amplitude of $2.54 \mathrm{~mm}$. This is expected because the displacement is not a pure sine wave due to the impact at support $G$.

Figure 5 shows variation of the frequency spectra with flow velocity. Once the TSP mode becomes unstable, the tube impacts against the TSP. At $1.50 \mathrm{~m} / \mathrm{s}$ (Fig. $5 \mathrm{~b}$ ), the frequency spectra resemble narrow-band chaos in which the fundamental TSP-inactive mode is still dominant. At this flow velocity, impact at the TSP may not be regular. As flow velocity increases, such as at $1.57,1.71$, and $1.77 \mathrm{~m} / \mathrm{s}$ (Fig. $5 \mathrm{c}, 5 \mathrm{~d}$, and $5 \mathrm{e}$ ), the superharmonics become more pronounced. At those flow velocities, the tube impacts the TSP very regularly. At $1.86 \mathrm{~m} / \mathrm{s}$, both superharmonics and subharmonics appear; this may be due to the additional impacts between $\mathrm{B}$ and $\mathrm{C}$ with the two neighbor tubes or instability of TSP-active modes. The exact reason is unknown.

It can be summarized that once the tube becomes unstable, it begins to impact the TSP. The contact is intermittent and the motion appears to be narrow-band chaos. For example, at $1.5 \mathrm{~m} / \mathrm{s}$ the impact is irregular. As flow velocity increases, the impacts at TSP become more frequent and regular. For example, at $1.71 \mathrm{~m} / \mathrm{s}$, the impacts are very regular and the motion appears to be sinusoidal with superharmonics. 


\section{Test A.3}

Another test of the clearance with $2.54 \mathrm{~mm}$ (100 mils) on each side was performed at $60^{\circ} \mathrm{F}$. The damping ratio in water is $4.4 \%$, which is higher than that at $70^{\circ} \mathrm{F}$ in Test A.2. Figures 6 and 7 show tube displacement and time histories.

At higher damping values, the critical flow velocity is clearly defined. When the tube is in the stable region (because of high damping), the tube response excited by flow turbulence is small. Once it become unstable, large displacement occurs. At $1.95 \mathrm{~m} / \mathrm{s}$, the tube is stable; but at $1.98 \mathrm{~m} / \mathrm{s}$, the tuive becomes unstable. With only a minor difference in flow velocity $(0.03 \mathrm{~m} / \mathrm{s})$, the oscillations increase about 6.5 times. RMS tube displacements are about the same as those in Test A.2.

Figure 7 shows the time histories at two flow velocities corresponding to the stable and unstable regions. At $1.60 \mathrm{~m} / \mathrm{s}$, the tube is stable, oscillation amplitude is small, and the oscillations are not very steady. At $1.98 \mathrm{~m} / \mathrm{s}$, the motion is fairly steady and the tube impacts the TSP on both sides.

\section{Test A.4}

The TSP is on one side only. Water temperature is $72^{\circ} \mathrm{F}$ and the damping ratio for the TSP-inactive mode is $2.4 \%$. Figures 8.10 show the tube displacement, dominant frequency, and power spectral density. Some characteristics are noticed:

- The critical flow velocity is about $1.55 \mathrm{~m} / \mathrm{s}$, close to that in Test A.1 at $70^{\circ} \mathrm{F}$. When the tube is stable, its response frequency is about $26.38 \mathrm{~Hz}$. Once it become unstable, the dominant frequency and tube displacement increase with flow velocity.

- There is a plateau in tube displacement at flow velocities of about 1.55 to $1.67 \mathrm{~m} / \mathrm{s}$. However, the dominant frequency continues to increase with flow velocity. Several characteristics are noted:

- At $1.46 \mathrm{~m} / \mathrm{s}$, motion is stable with no impacts.

- At $1.58 \mathrm{~m} / \mathrm{s}$, motion is not very steady and impacts are not regular.

- At 1.62 and $1.86 \mathrm{~m} / \mathrm{s}$, superharmonics appear.

- At $1.95 \mathrm{~m} / \mathrm{s}$, response increases sharply.

\section{Test A.5}

The clearance is $1.27 \mathrm{~mm}$ (50 mils) on each side and the temperature is $60^{\circ} \mathrm{F}$. The modal damping is $4.4 \%$. Figures $11-13$ show RMS tube displacement, dominant response frequencies, and power spectral density. 
Two critical flow velocities are established. The lowest is about $1.96 \mathrm{~m} / \mathrm{s}$; this is the intrinsic instability critical flow velocity. As flow velocity is increased, the upper stability boundary is shown between 2.83 and $2.97 \mathrm{~m} / \mathrm{s}$; this is the excited instability limit of the upper boundary. Once the flow velocity reaches the upper stability limit, the response amplitude is reduced. A more detailed trend is presented in Test C.1.

The dominant response frequency is shown in Fig. 12. Once it is in the unstable region, it increases with flow velocity. In this region, tube response amplitude remains at a constant value; however, impact amplitude and number increase. Tube wear at the TSP will increase with flow velocity because of the increase in number and amplitude of the impacts. The increase of the dominant response frequency can be understood easily; it occurs because the dominant modes are the fundamental modes of the TSP-inactive and TSP-active modes. Once the tube becomes unstable in the TSP-inactive mode, the tube will impact the TSP, and the TSP-active mode will contribute a portion of the motion.

Figure 13 shows the power spectral densities for a series of flow velocities. The general trend is very similar to Fig. 5 at $2.54 \mathrm{~mm}$ clearance. At $1.98 \mathrm{~m} / \mathrm{s}$ (Fig. 13b), it resembles narrow-band chaos. As flow velocity increases (Fig. 13c, d, and e), the response frequency consists of the fundamental TSP-inactive mode $\mathrm{f}$ and $\mathrm{nf}(\mathrm{n}=1$, $2,3,4 \ldots)$; the important frequencies are associated with odd-numbered values of $n$. At $3.06 \mathrm{~m} / \mathrm{s}$, the motion is similar to that at $1.98 \mathrm{~m} / \mathrm{s}$.

\subsection{Test Series B}

In this series, tube displacements at $a$ and $b$ in the lift and drag directions are recorded on tape. The tube response can be observed at the overhung portion; in particular, interaction of the free end with the TSP can be seen when the flow velocity is changed.

The tube displacement components are analyzed in detail to provide an understanding of the response characteristics; these include RMS tube displacements, time histories, power spectral densities, dominant response frequencies, phase planes, Poincaré maps, and Lyapunov exponents.

Displacement components are measured, and the velocity components are obtained from the time series of the displacement components. Because the dominant motion is in the lift direction, all phase planes are presented for the lift direction motion. 
The system under consideration is autonomous. Because two displacement components in the lift direction at $a$ and $b$ are measured simultaneously, one of the components is used as the trigger signal. When the displacement at $b$ is passing through the equilibrium point with a positive velocity, the displacement and velocity components at a are saved to plot Poincare maps. The same technique is used for Poincaré maps at $b$.

The Lyapunov exponent is a quantitative measure used to identify chaotic characteristics. It is an average exponential rate of divergence or convergence of nearby orbits in phase space. In this analysis, the algorithms proposed by Wolf et al. (1985) are used to determine Lyapunov exponents from the time series of tube motion.

\section{Test B.1}

Figure 14 shows RMS tube displacement components at two locations as a function of flow velocity. Damping of the tube at $60^{\circ} \mathrm{F}$ is about $4.3 \%$. Because of this higher damping value, both the lower and upper critical flow velocities are clearly defined; the lower limit is about $2.0 \mathrm{~m} / \mathrm{s}$ and the upper limit is about $3.8 \mathrm{~m} / \mathrm{s}$. It should be noted that $2.0 \mathrm{~m} / \mathrm{s}$ is the lower limit for excited instability, while $3.8 \mathrm{~m} / \mathrm{s}$ is the upper limit for excited instability. Figure 14 shows that once the tube become unstable, the RMS displacements do not change significantly with flow velocity. However, the dominant response frequency continues to increase in the instability zone, as shown in Fig. 15.

Figures 16-23 show time histories, power spectral densities, phase planes, and Poincare maps for the displacement components at $a$ and $b$ for a series of flow velocities $(1.975,2.063,2.287,3.39,3.802$, and $3.95 \mathrm{~m} / \mathrm{s})$. Some general characteristics are noted:

- In the instability zone, tube response is fairly steady. At 2.063, $2.287,3.39$, and $3.802 \mathrm{~m} / \mathrm{s}$, peak amplitudes range from about $2.2 \mathrm{~mm}$ to $2.8 \mathrm{~mm}$ at $\mathrm{b}$, and from about $1.4 \mathrm{~mm}$ to $2.2 \mathrm{~mm}$ at $\mathrm{a}$. Because the transducer at $b$ is close to the TSP, maximum displacement is close to the gap of $2.54 \mathrm{~mm}$. Outside the instability zone, tube displacement is much smaller.

- In the instability zone, the dominant frequency $f$ is associated with the fundamental TSP-inactive and -active modes. A series of frequencies is noted; those frequencies are equal to about $\mathrm{nf}(\mathrm{n}=1,2$, $3,4 \ldots)$. However, the more significant frequencies are associated with $\mathrm{nf}$ when $\mathrm{n}$ is an odd number, as noted in Test A.5. 
- From the phase planes and Poincaré maps, the motion in the instability zone appears to be limited-band chaos.

Figure 24 shows the Lyapunov exponents for the displacements at a and $\mathrm{b}$ in the lift direction. Although the value of the exponent is small, its value is positive in the stability zone. This demonstrates that the motion is chaotic. The general trend of the Lyapunov exponent agrees with the power spectral density, phase plane, and Poincaré maps. It is also noted that the values of Lyapunov exponents near the lower and upper stability boundaries are larger than those in the middle region. This means that at the two ends, the motion is more irregular.

\section{Test B.2}

The same analyses as in Test B.1 are performed. Figures 25-35 show the corresponding figures for $1.27 \mathrm{~mm}$.

It is noted that the unstable zone of Test B.2 is much smaller than that of Test B.1; this is believed to be due to the difference of the stability limits. In Test B.1, both the lower and upper limits are excited instability, while in Test B.2, they are intrinsic instability. For a smaller gap, the motion does not reach steady-state oscillations.

Figure 26 shows the dominant response frequency as a function of flow velocity. In the unstable zone, the dominant frequency is higher than the stable regions. There is a jump of the dominant frequency at both stability limits. In comparison with Fig. 15, it is noted that the jump in the dominant response frequency is much more rapid than that in Fig. 15 at the lower stability limit.

Figures 27 and 28 show that in the instability region, the motions are fairly steady. Outside the intrinsic instability zone, the motion is much more unsteady.

The other general characteristics are very similar to those of $2.54 \mathrm{~mm}$.

\subsection{Test Series C}

The test method and analysis method are the same as in Series B. However, more detailed data are collected.

\section{Test C.1}

Figures 36-46 show the results for $1.91 \mathrm{~mm}$. In Fig. 36, the data were taken for increasing and decreasing flow velocity, as indicated by the arrows. By running 
through the lower and upper stability limits, both intrinsic and excited instability limits are obtained. It appears that these are the first experimental data on the establishment of the upper limits. The distance between excited instability and intrinsic instability limits in the lower and upper limits are about the same.

The dominant response frequencies for the increasing and decreasing flow velocity also show the hysteresis loops, as given in Fig. 37. In the instability zone, the dominant response frequency increases with flow velocity. The general trend is similar to that in Fig. 15 for a larger gap.

Figure 46 shows Lyapunov exponents for increasing and decreasing flow velocity. The values close to the intrinsic and excited instability limits are larger than those of other flow velocities.

The other response characteristics are very similar to those of $2.54 \mathrm{~mm}$ and $1.27 \mathrm{~mm}$.

\section{Test C.2}

Figures 47 and 48 show RMS tube displacements and dominant response frequency. Other response characteristics are very similar to those in Test C.1, and similar results were shown for Test B.2.

\section{Test C.3}

In this test, the TSP is on one side only. Figure 49 shows RMS tube displacements as a function of flow velocity. Tube displacement increases drastically when the flow velocity is much larger than the instability limit.

Figure 50 shows dominant response frequency as a function of flow velocity. In general, the dominant response frequency increases with flow velocity. When the response amplitude jumps to a high value, the corresponding dominant response frequency also has a jump. In this case, the dominant response continues to increase.

Figures 51-58 show time histories, power spectral densities, phase planes, and Poincaré maps for a series of flow velocities. Some interesting characteristics are noted:

- In each cycle of the dominant motion, there are several impacts on the TSP; the motion is fairly steady. 
- When the tube is oscillating with a large amplitude, the dominant frequency peaks are $\mathrm{nf}$, where $\mathrm{f}$ is the dominant response frequency, and $\mathrm{n}=1,2,3, \ldots$

- Motion in the instability zone appears to be limited-band chaos.

At the end of this test, water leakage was noticed. Tube 3 was removed for inspection. Cracks were found on both sides, as shown in Fig. 59. On one side, the crack begins at a, about $2 \mathrm{~cm}$ from the $\mathrm{O}$-ring support to $\mathrm{b}$, and $15 \mathrm{~cm}$ from the other support. On the other side, the crack starts at c, an O-ring support, and extends to $\mathrm{d}$, about $8 \mathrm{~cm}$ from the other O-ring support. On the plane about $90^{\circ}$ from the cracks, wear marks are seen at the middle of the span between the two supports; the wear marks are about $25 \mathrm{~cm}$ long and in the lift direction. This wear is due to the impact with the two surrounding tubes. The cracks are also due to continuous impact with neighboring tubes.

\section{Comparison with Analytical Model}

An analytical model based on the unsteady flow theory was developed (Cai and Chen 1991, 1992) and used to confirm the existence of chaos in the fluidelastic instability of tube arrays in crossflow and to understand the route to chaos. Measurement tools include power spectral densities, phase planes, Poincaré maps, Lyapunov exponents, and fractal dimensions. In this study the model was used to evaluate Test B.1. The detailed analysis method is given in earlier work (Cai and Chen 1991, 1992); only the numerical results are presented here.

Figure 60 shows the RMS displacement predicted from the mathematical model and derived from experimental data. The lower and upper limits of critical flow velocity are in good agreement. Predicted tube displacement at transducer $b$, which is close to the TSP, agrees well with the experimental data. The predicted response at transducer $b$ is slightly lower than that in the experimental data.

Figures 61-64 show the time histories, power spectral densities, phase planes, and Lyapunov exponents at four flow velocities. Those figures can be compared with the experimental data given in Figs. 16-21.

- At $2.063 \mathrm{~m} / \mathrm{s}$, the predicted time histories agree reasonably well with the measurement data. Power spectral density and phase planes are also in agreement. The Lyapunov exponent is positive; this indicates that the motion is chaotic. 
- At $2.287 \mathrm{~m} / \mathrm{s}$, the time histories agree well. In the power spectral density, both analytical and experimental results show the frequencies at odd multiples of the dominant response frequency. In the analytical model, the Lyapunov exponent is negative and the motion is periodic with superharmonics. However, the Lyapunov exponent from the experiment is positive, as shown in Fig. 24. This may be due to the minor difference between the analytical model and experiment setup. For example, the TSP gaps may not be perfectly symmetrical.

- At $3.39 \mathrm{~m} / \mathrm{s}$, the general characteristics are similar to those at $2.287 \mathrm{~m} / \mathrm{s}$.

- At $3.82 \mathrm{~m} / \mathrm{s}$, the analytical rnodel predicts quasiperiodic motion, while the experimental data show limited-band chaos. Again, this is believed to be due to the minor difference between the experimental setup and the analytical model.

In comparison, the analytical model predicts the general characteristics of tube response reasonably well. Specifically, the following statements can be made:

- Both the analytical model and the experimental data show chaos in the tube row subject to fluidelastic instability of the TSP-inactive mode.

- When the flow velocity is close to the lower and upper limits of the critical flow velocities, tube motion is chaotic. Between the two limits, the motion is much more regular, with the tube impacting the TSP regularly.

- Within the two stability limits, the motions include periodic, quasiperiodic, and chaotic, if the system is well defined. In experiments, minor variations can change the system characteristics drastically; this is a classical chaotic characteristic. The chaotic motion is of the limited-band type.

- The fractal dimension for this system is fairly low; based on the analytical model, it is between 1 and 2 . 


\section{Closing Remarks}

Three series of tests were performed for a loosely supported tube among a rigid tube row in crossflow. The objective of the tests was to understand the vibration characteristics when the tube becomes unstable and to validate the mathematical models for tube/support interaction. Tube displacements are analyzed to characterize the tube behavior by RMS values, power spectral densities, phase planes, Poincaré maps, and Lyapunov exponents.

The hysteresis of fluidelastic instability was demonstrated for both the lower and upper stability limits. This test appears to be the first to demonstrate the upper limit.

The tube motion consists of random vibration due to fluid turbulence and chaotic motion associated with fluidelastic instability of TSP inactive modes. In the instability zone, the dominant motion is limited-band chaos. In most cases, the motion is fairly steady and the impact with TSP is fairly regular.

The tube response for different TSP clearances appears to be very similar. However, for asymmetric TSP, the characteristics are much different.

The general characteristics predicted from the mathematical model based on the unsteady flow theory agree reasonably well with experimental data. These include time histories, phase planes, Poincaré maps, power spectral densities, and Lyapunov exponents. Because such a system is very sensitive to parameter variations, some predicted characteristics are not in complete agreement with measurements. This is probably due to minor differences between the experimental setup and the analytical model. In any case, it is believed that only the unsteady flow theory will provide reliable results when modeling chaotic behavior.

In the analytical model, the random forces due to turbulence in both lift and drag directions and steady drag force were not considered. In the experiment, those forces were operative and contributed to the wear process.

Based on this study, it can be emphasized that motion-dependent fluid forces on tube arrays should be studied. Without detailed data on such fluid forces, it will continue to be difficult to predict tube response in the instability region. 


\section{Acknowledgments}

This work was sponsored by the U.S. Department of Energy, Office of Basic Energy Sciences, Division of Engineering and Geosciences, under Contract W-31109-Eng-38.

The authors are grateful to Dr. T. M. Mulcahy for his help in setting up the test section.

\section{References}

Antunes, J., Axisa, F., Beaufils, B., and Guilbaud, D., 1988, Coulomb Friction Modelling in Numerical Simulations of Vibration and Wear Work Rate of Multispan Tube Bundles, Int. Symp. on Flow-Induced Vibration and Noise, Chicago, Vol. 5, pp. 157-176.

Antunes, J., Axisa, F., and Vento, M. A., 1990, Experiments on Vibro-Impact Dynamics Under Fluidelastic Instability, ASME Pressure Vessels and Piping Conf., Nashville, TN, PVP Vol. 189, pp. 127-138.

Antunes, J., de Langre, E., Vento, M. A., and Axisa, F., 1992, A Theoretical Model for the Vibro-Impact Motions of Tubes Bundles Under Fluidelastic Instability, presented at ASME Winter Annual Meeting, Nov. 9-13, 1992, Anaheim, CA; in ASME Publication PVP-Vol. 242, pp. 135-150.

Axisa, F., Antunes, J., and Villard, B., 1988, Overview of Numerical Methods for Predicting Flow-Induced Vibration, Trans. ASME, J. Pressure Vessel Technology, Vol. 110, pp. 6-14.

Cai, Y., and Chen, S. S., 1992, Chaotic Vibrations of Nonlinearly Supported Tubes in Crossflow, presented at ASME Winter Annual Meeting, Nov. 9-13, 1992, Anaheim, CA; in ASME Publication PVP-Vol. 242, pp. 223-241.

Cai, Y., and Chen, S. S., 1991, Chaotic Dynamics of Loosely Supported Tubes in Crossflow, Argonne National Laboratory Report ANL-91/30; also to appear in J. Sound and Vibration.

Chen, S. H., and Chen, S. S., 1993, Chaotic Vibration in Fluidelastic Instability of a Tube Row in Crossflow, Presented at 1993 ASME Pressure Vessels and Piping Conf., July 25-29, 1993, Denver, CO. 
Chen, S. S., 1991, A Review of Dynamic Tube-Support Interaction in Heat Exchanger Tubes, Proc. Institution of Mechanical Engineers, Flow Induced Vibrations, pp. 111-120, publ. by Mechanical Engineering Publishers Limited, May 1991.

Chen, S. S., and Jendrzejczyk, J. A., 1985, General Characteristics, Transition, and Control of Instability of Tubes Conveying Fluid, J. Acoustical Society of America, Vol. 77(3), pp. 887-895.

Chen, S. S., Jendrzejczyk, J. A., and Wambsganss, M. W., 1985, Dynamics of Tubes in Fluid with Tube-Baffle Interaction, J. Pressure Vessel Technology, Vol. 107, pp. 7-17.

Eisinger, F. L., Rao, M. S. M., and Steininger, D. A., 1991, Numerical Simulation of Fluidelastic Vibration and Comparison with Experimental Results, in FlowInduced Vibration and Wear, eds. M. K. Au-Yang and F. Hara, PVP Vol. 26, pp. 101-111.

Fisher, N. J., and Ingham, B., 1988, Measurement of Tube-to-Support Dynamic Forces in Fretting-Wear Rigs, Int. Symp. on Flow-Induced Vibration and Noise, Chicago, Vol. 5, pp. 137-156.

Fisher, N. J., Olesen, M. J., Rogers, R. J., and Ko, P. L., 1988. Simulation of Tube-to-Support Dynamic Interaction in Heat Exchange Equipment, Int. Symp. on Flow-Induced Vibration and Noise, Chicago, Vol. 5, pp. 121-136.

Fricker, A. J., 1992, Numerical Analysis of the Fluidelastic Vibration of a Steam Generator Tube with Loose Supports, J. Fluids and Structures, Vol. 6, pp. 85-107.

Gay, N., and Granger, S., 1992, Flow-Induced Decentering and Tube-Support Interaction for Steam Generator Tubes: Part 1: Experiment, ASME Publication PVP Vol. 24.2, pp. 207-222.

Goyder, H. G. D., 1985, Vibration of Loosely Supported Steam Generator Tubes, ASME Winter Annual Meeting, Miami Beach, Nov. 1985, pp. 35-42.

Haslinger, K. H., Martin, M. L., and Steininger, D. A., 1987, Pressurized Water Reactor Steam Generator Tube Wear Prediction Utilizing Experimental Technıyues, Int. Conf. on Flow Induced Vibrations, Bowness-on-Windermere, England, May 12-14, Paper K2, pp. 437-448. 
Haslinger, K. H., Martin, M. L., and Steininger, D. A., 1989, Experimental Characterization of Fluid and Squeeze Film Effects in Heat Exchanger Tube Supports, in Flow-Induced Vibration - 1989, ASME Publication, PVP Vol. 154, pp. 31-41.

Ko, P. L., and Magel, E., 1989, Impact and Sliding Wear in Steam Generators and Heat Exchangers: New Experimental Test Rig and Wear Model, in Flow-Induced Vibration - 1989, ASME Publication, PVP Vol. 154, pp. 63-69.

de Langre, E., Hadj-Sadok, C., and Beaufils, B., 1992, Non-Linear Vibrations Induced by Fluidelastic Forces in Tube Bundles, presented at the ASME Winter Annual Meeting, Nov. 9-13, 1992, Anaheim, CA; in ASME Publication PVP-Vol. 242, pp. 107-134.

aidoussis, M. P., and Li, G. X., 1992, Cross-Flow-Induced Chaotic Vibrations of Heat-Exchanger Tubes Impacting on Loose Supports, J. Sound and Vibration, Vol. 152(2), pp. 305-326.

Paidoussis, M. P., Price, S. J., and Mureithi, N. W., 1992, The Post-FluidelasticInstability Response of a Loosely Supported Tube in an Array Subjected to Water Cross-Flow, in Cross-Flow Induced Vibration of Cylinder Arrays, ASME Publication PVP-Vol. 242, pp. 243-263.

Vento, M. A., Antunes, J., and Axisa, F., 1992, Tube/Support Interaction under Simulated Fluidelastic Instability: Two-Dimensional Experiments and Computations of the Nonlinear Response of a Straight Tube, presented at ASME Winter Annual Meeting, Nov. 9-13, 1992, Anaheim, CA; in ASME Publication PVPVol. 242, pp. 151-166.

Wolf, A., Swift, J. B., Swinney, H. L., and Vastano, J. A., 1985, Determining Lyapunov Exponents from a Time Series, Physics, Vol. 16D, pp. 285-317. 

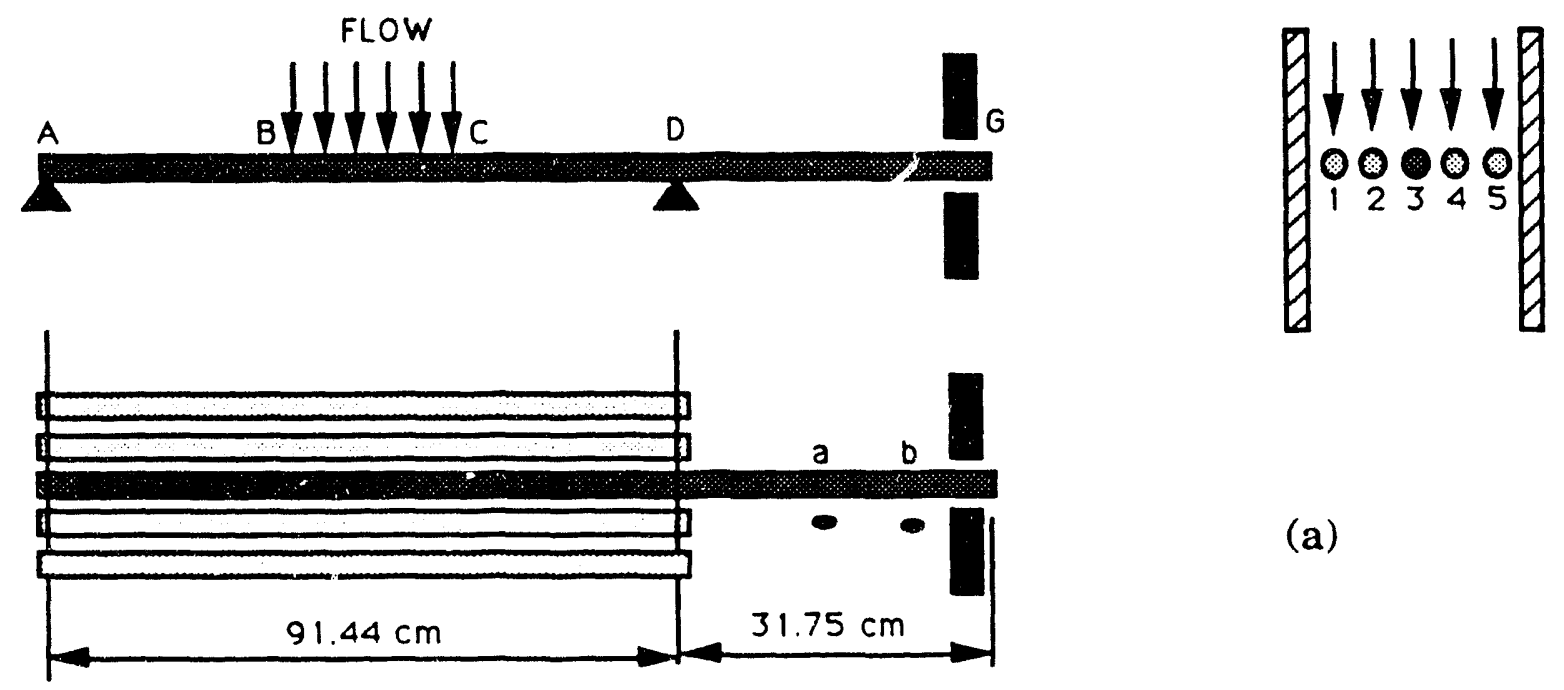

(a)

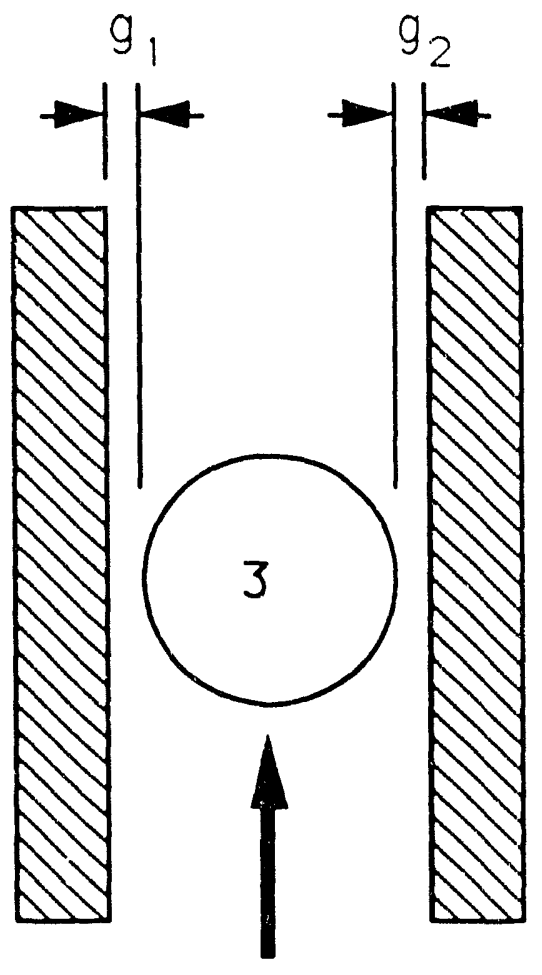

(b)

FLOW

Fig. 1. (a) A row of tubes in crossflow; (b) tube/support interaction 


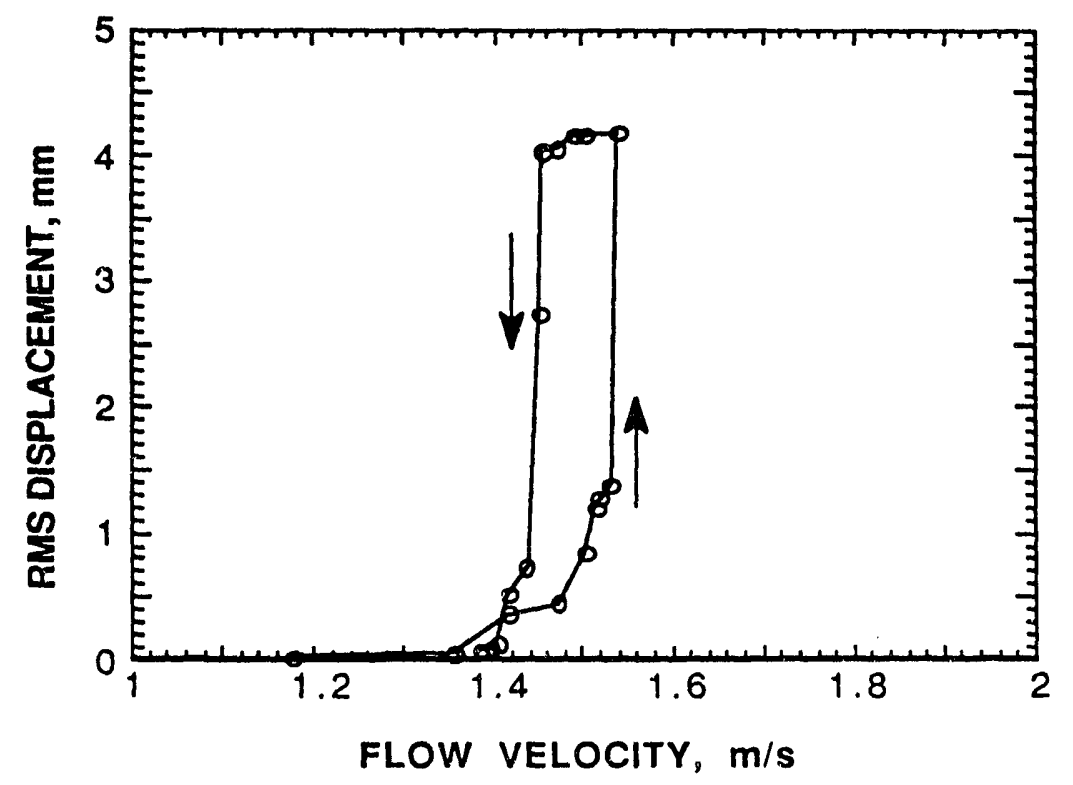

Fig. 2. RMS tube displacement as a function of flow velocity, Test A.1
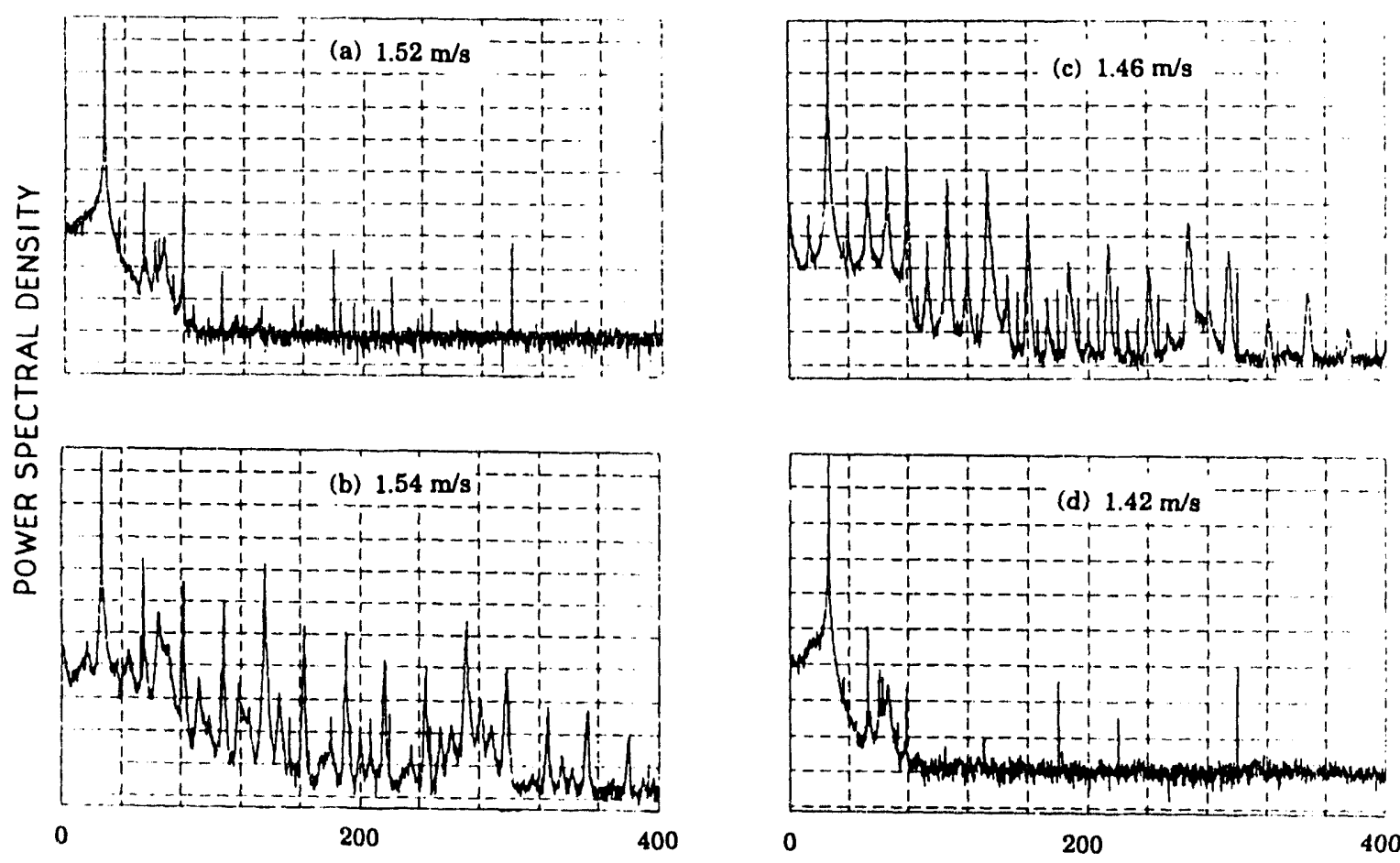

FREQUENCY, $\mathrm{HZ}$

Fig. 3. Frequency spectra for several flow velocities, Test A.1 


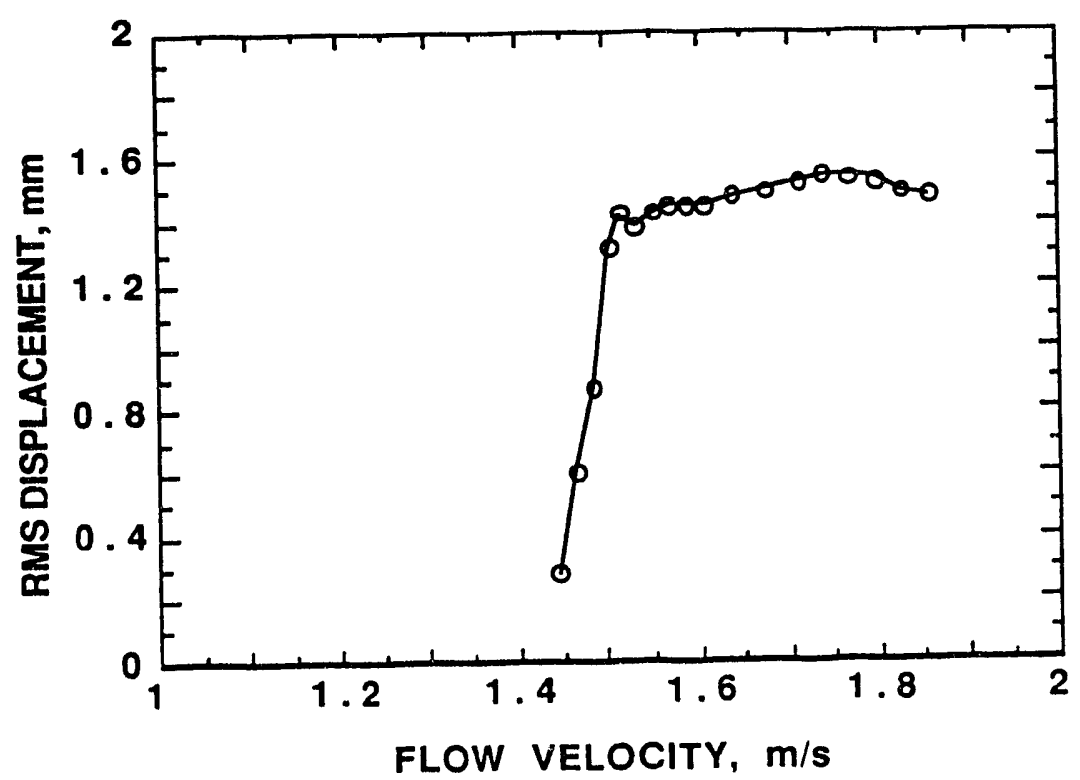

Fig. 4. RMS tube displacement as a function of flow velocity, Test A.2

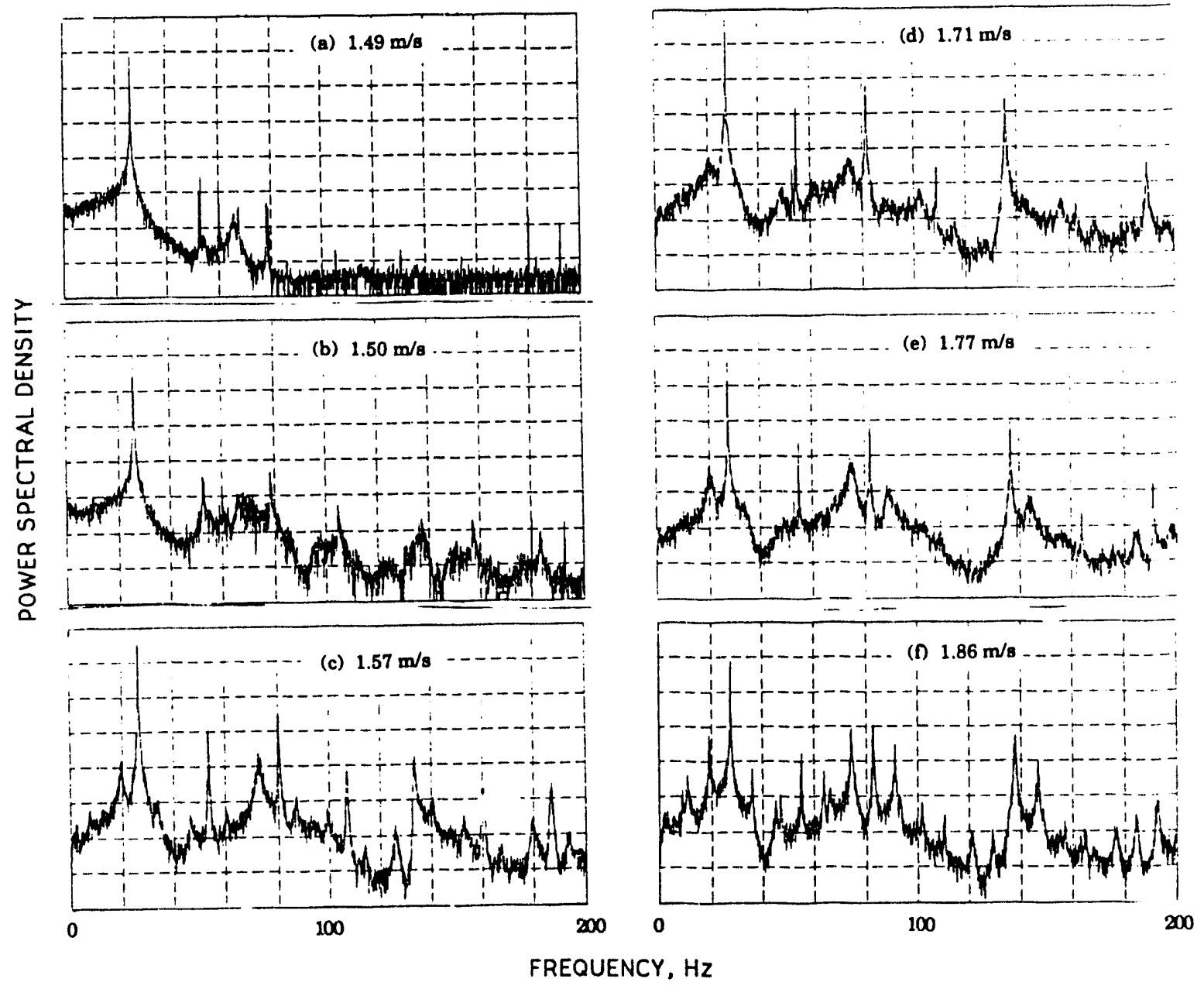

Fig. 5. Frequency spectra for several flow velocities, Test A.2 


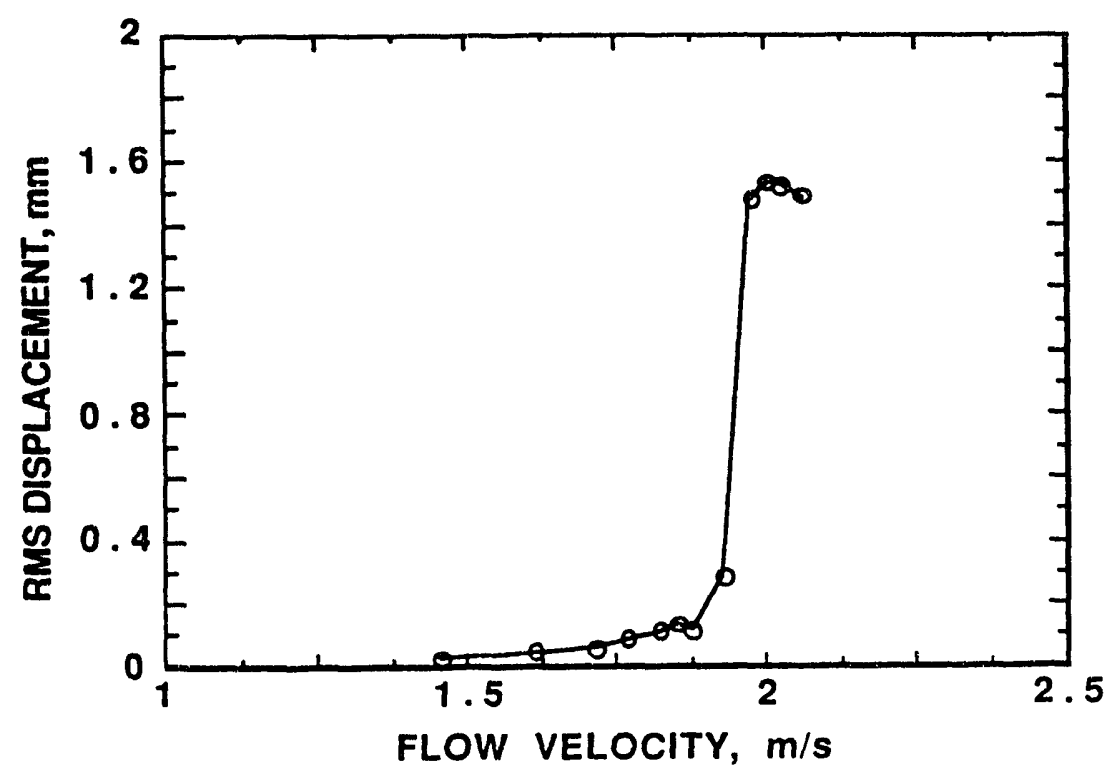

Fig. 6. RMS tube displacement as a function of flow velocity, Test A.3

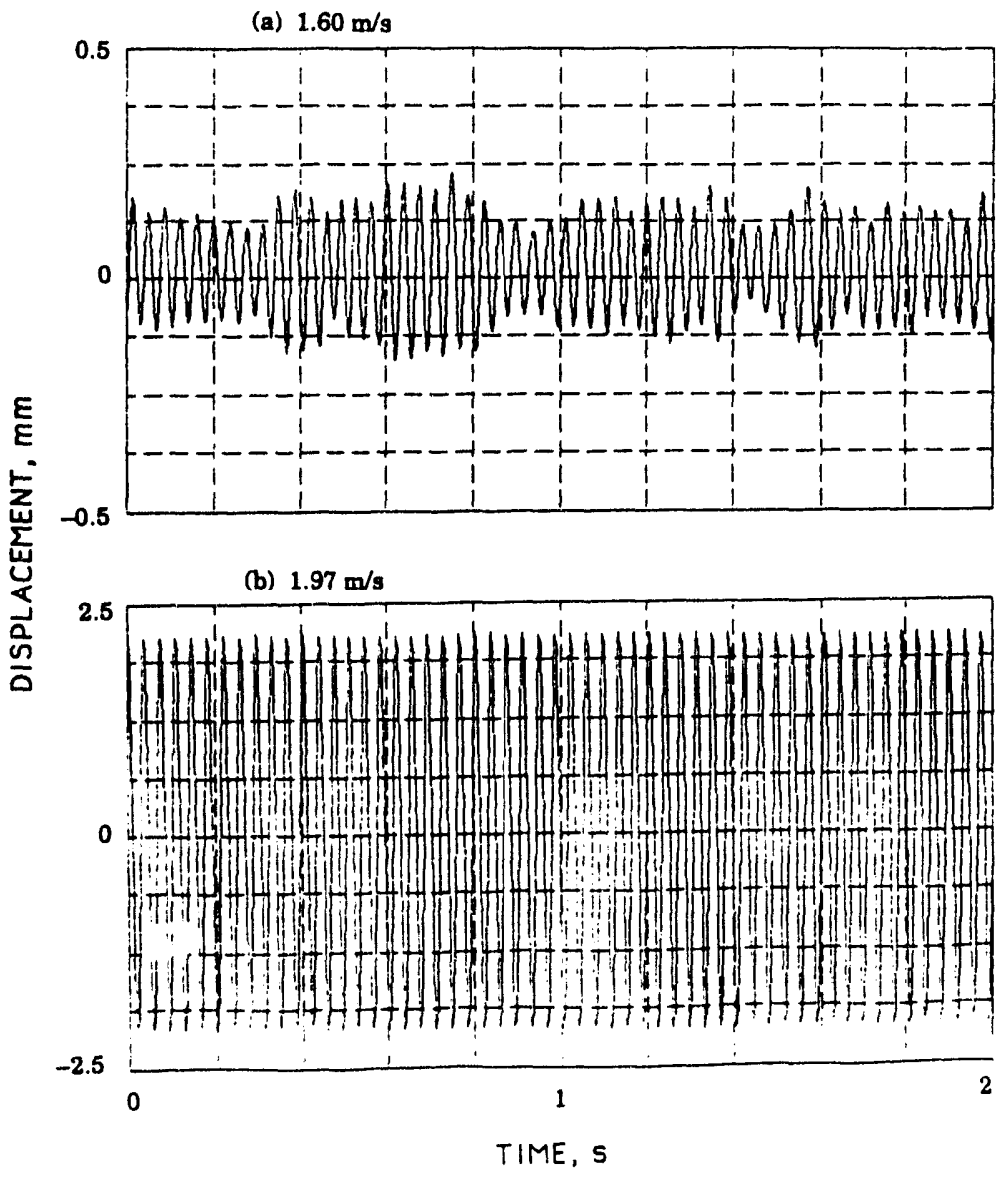

Fig. 7. Time histories of tube displacement, Test A.3 


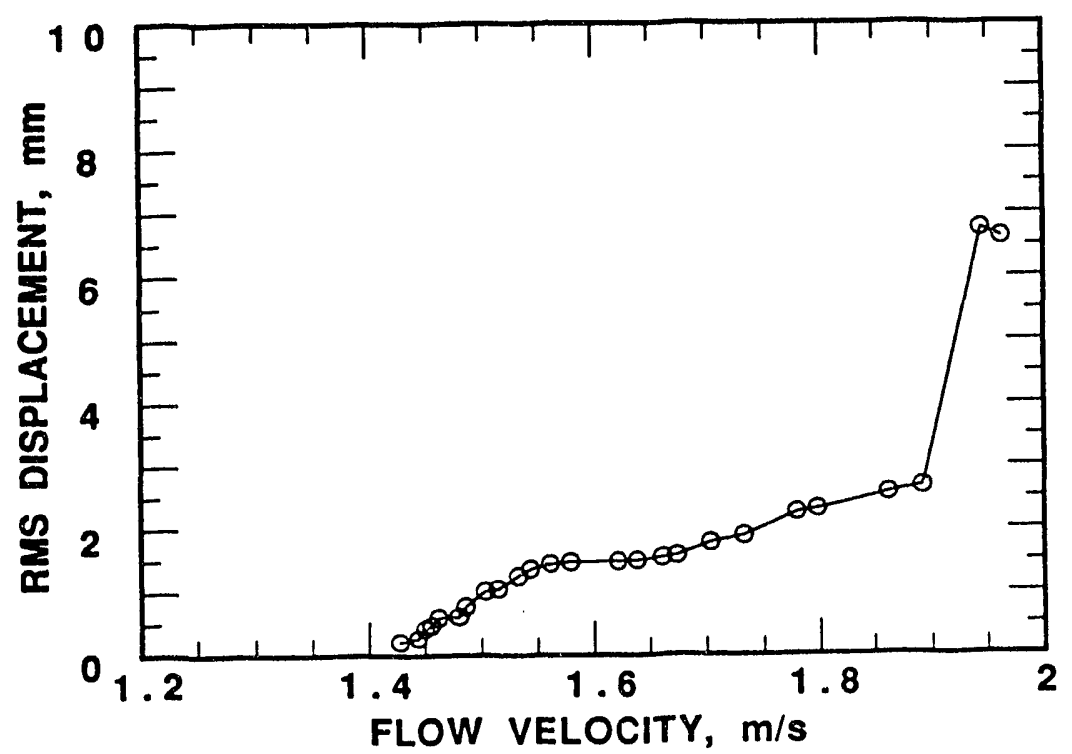

Fig. 8. RMS tube displacement as a function of flow velocity, Test A.4

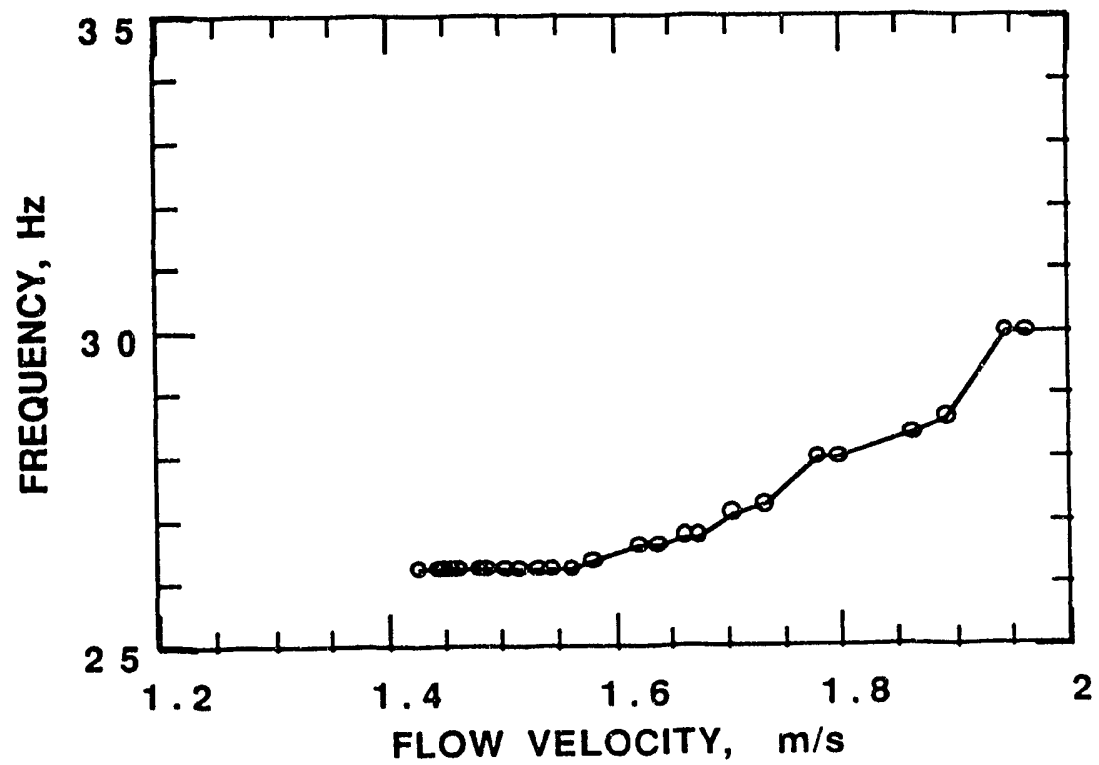

Fig. 9. Dominant response frequency as a function of flow velocity, Test A.4 

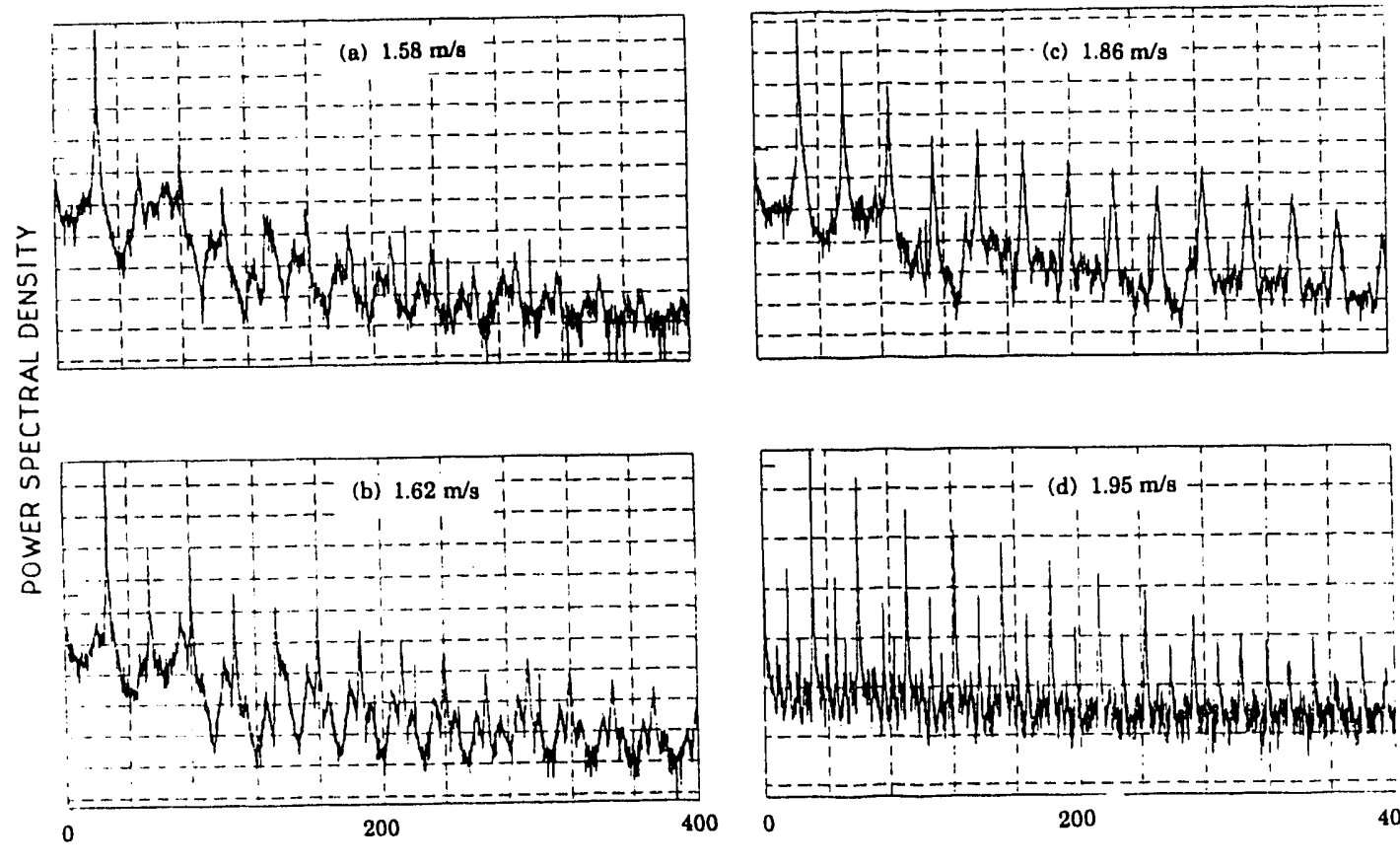

FREQUENCY, HZ

Fig. 10. Frequency spectra at several flow velocities, Test A.4 


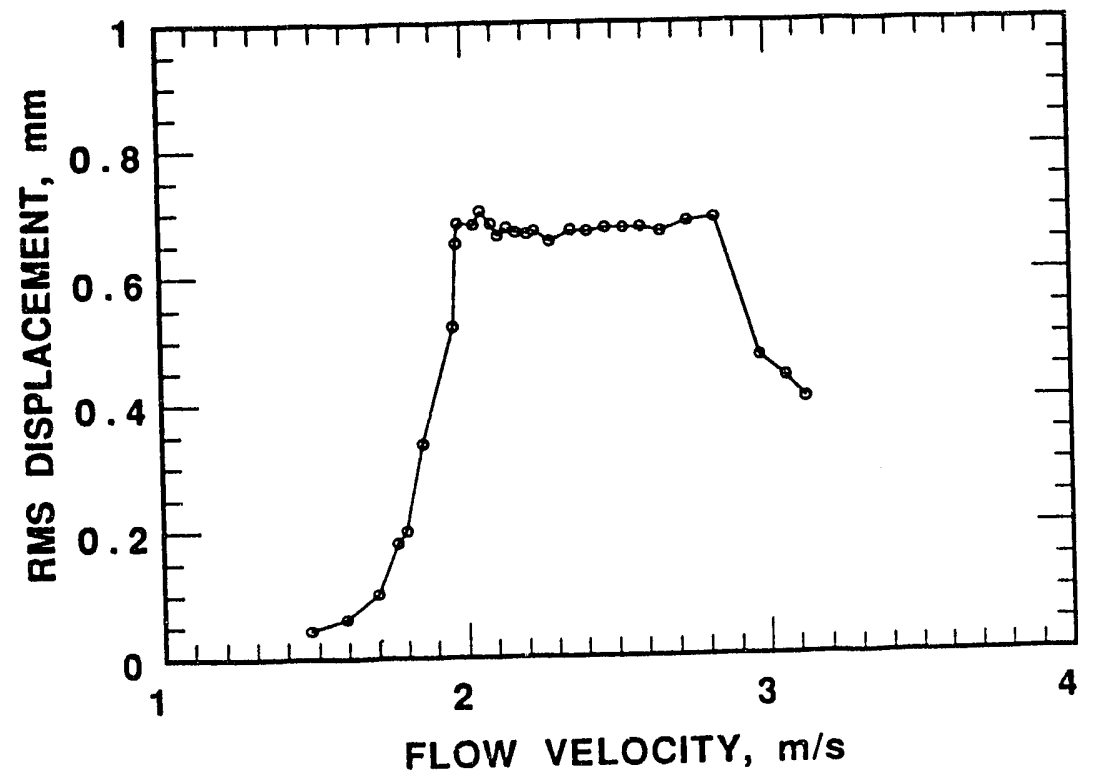

Fig. 11. RMS tube displacement as a function of flow velocity, Test A.5

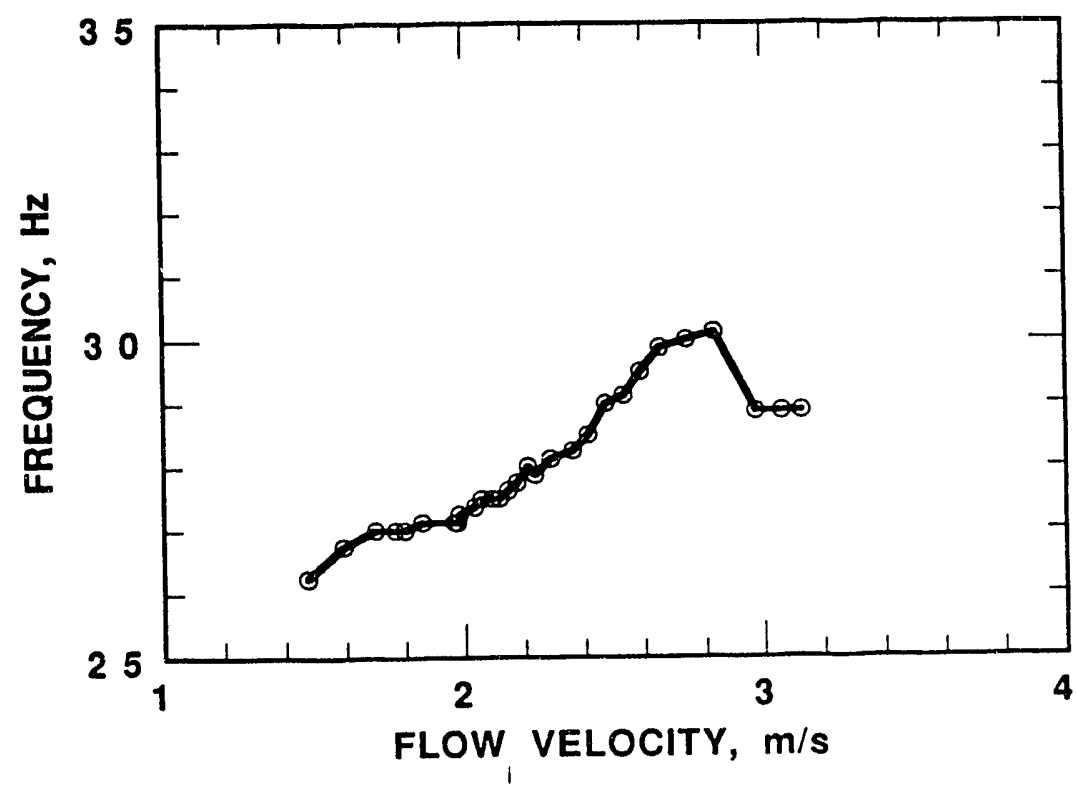

Fig. 12. Dominant response frequency as a function of flow velocity, Test A.5 

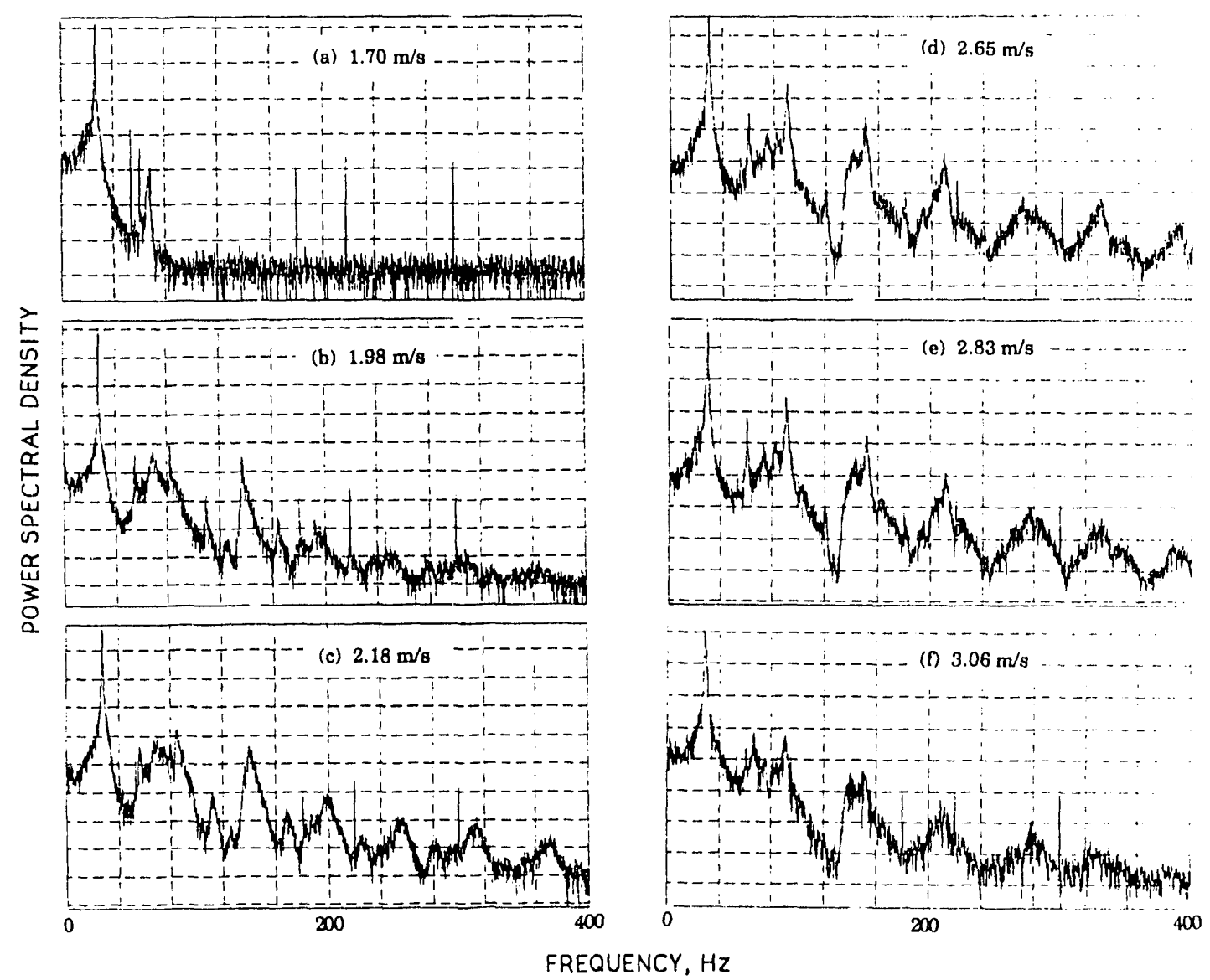

Fig. 13. Frequency spectra for several flow velocities, Test A.5 


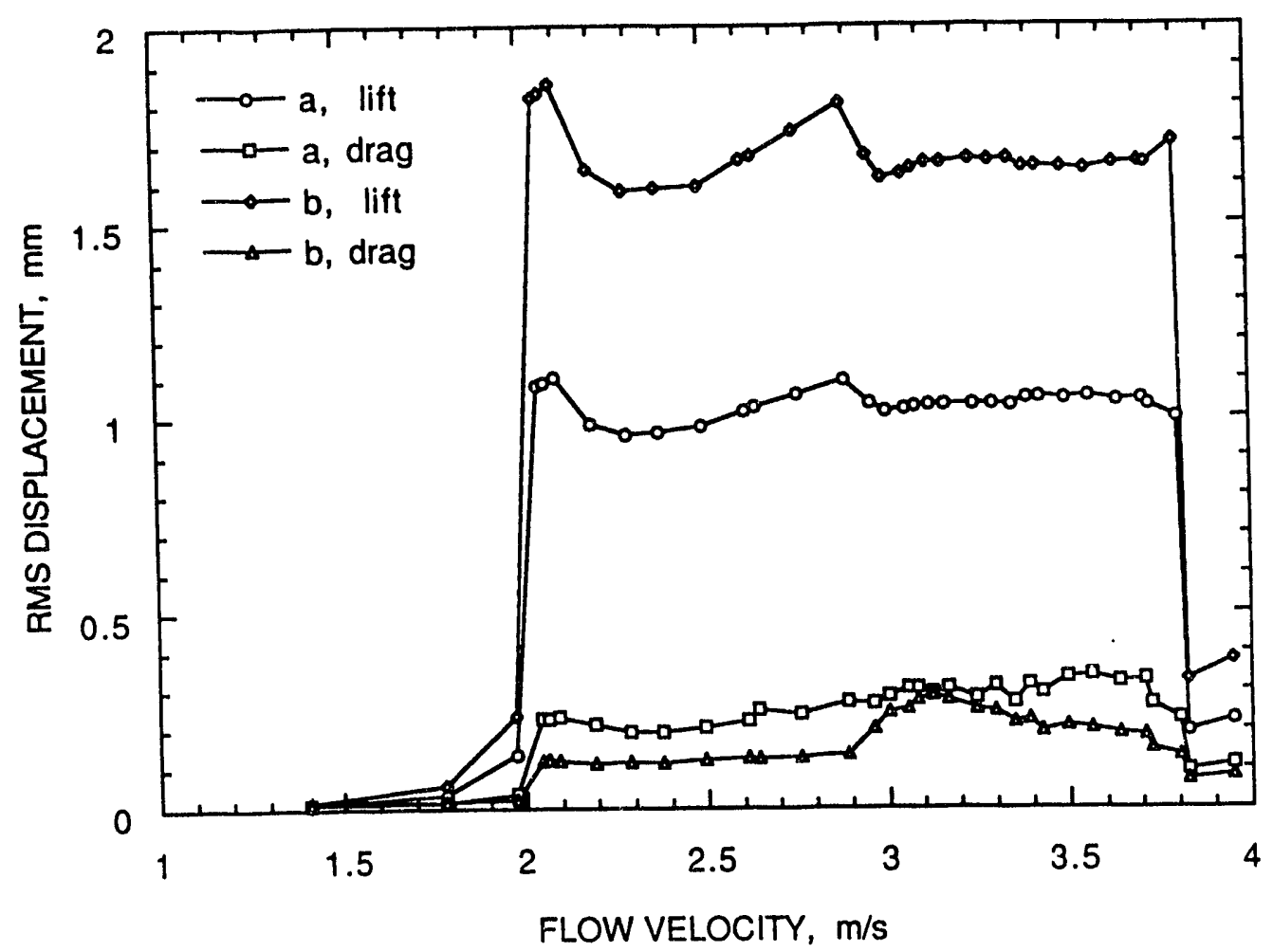

Fig. 14. RMS tube displacement as a function of flow velocity, Test B.1

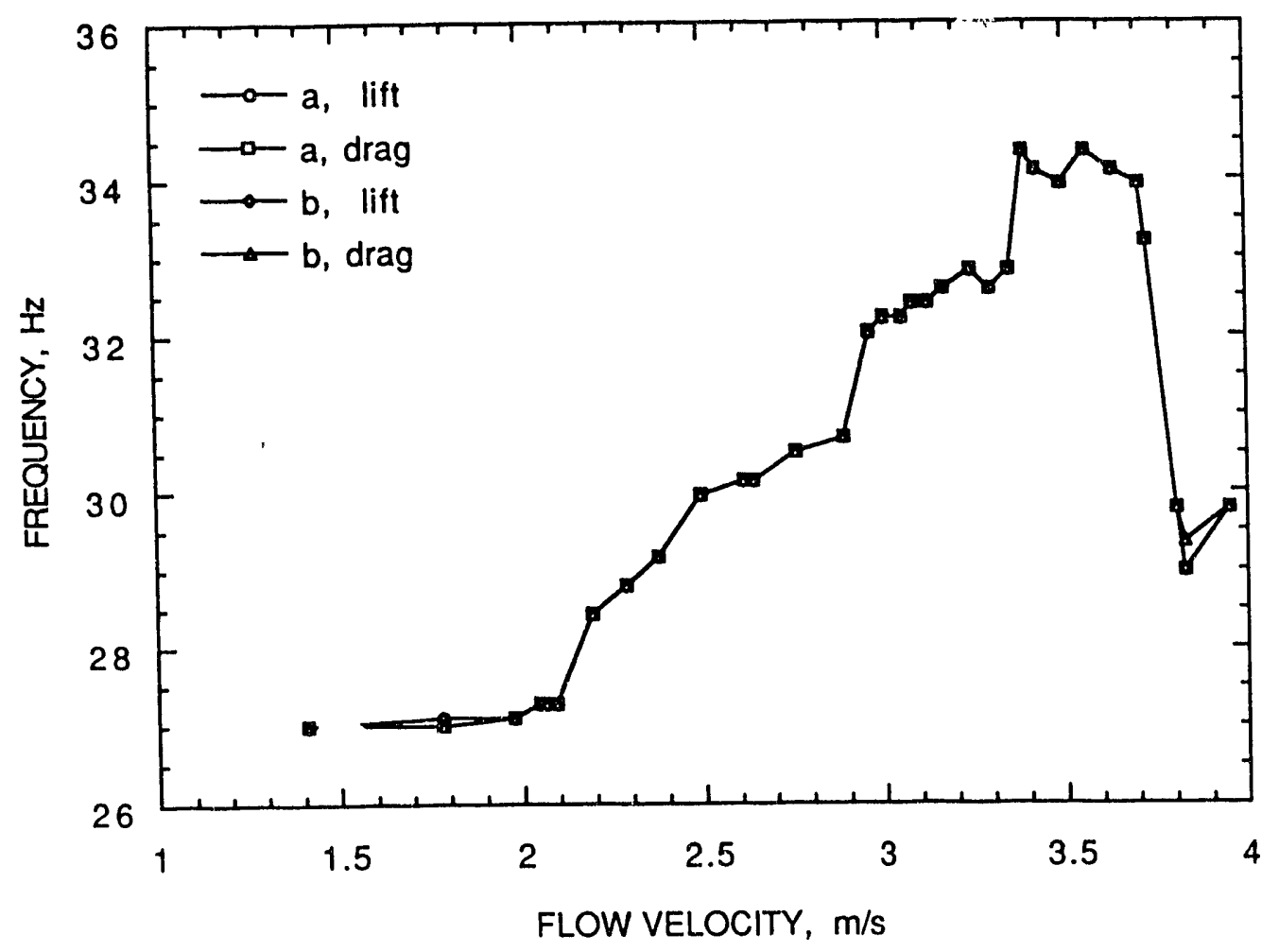

Fig. 15. Dominant response frequency as a function of flow velocity, Test B.1 

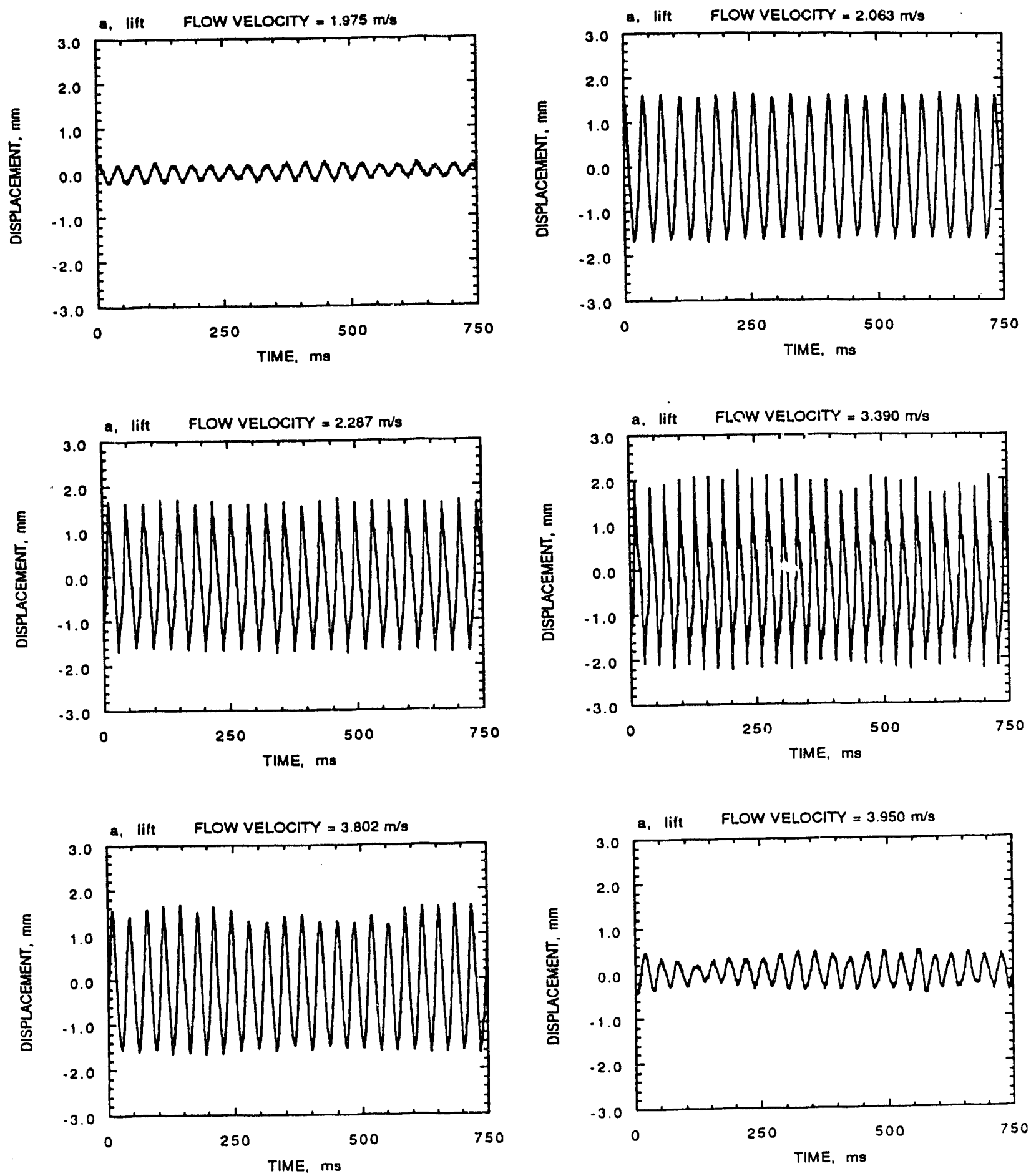

Fig. 16. Time histories of displacement transducer a at different flow velocities, Test B. 1 

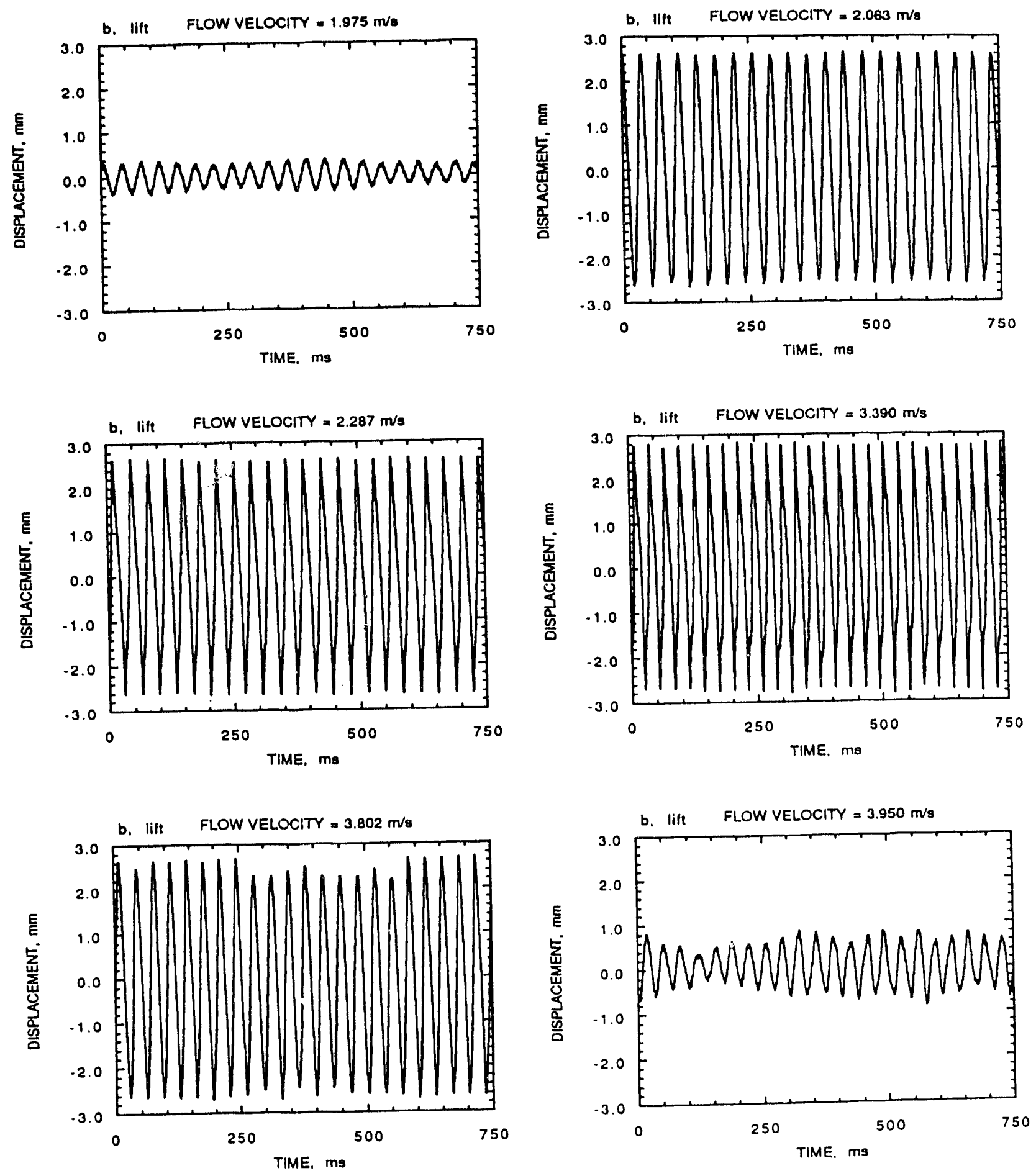

Fig. 17. Time histories of displacement transducer b at different flow velocities, Test B.1 

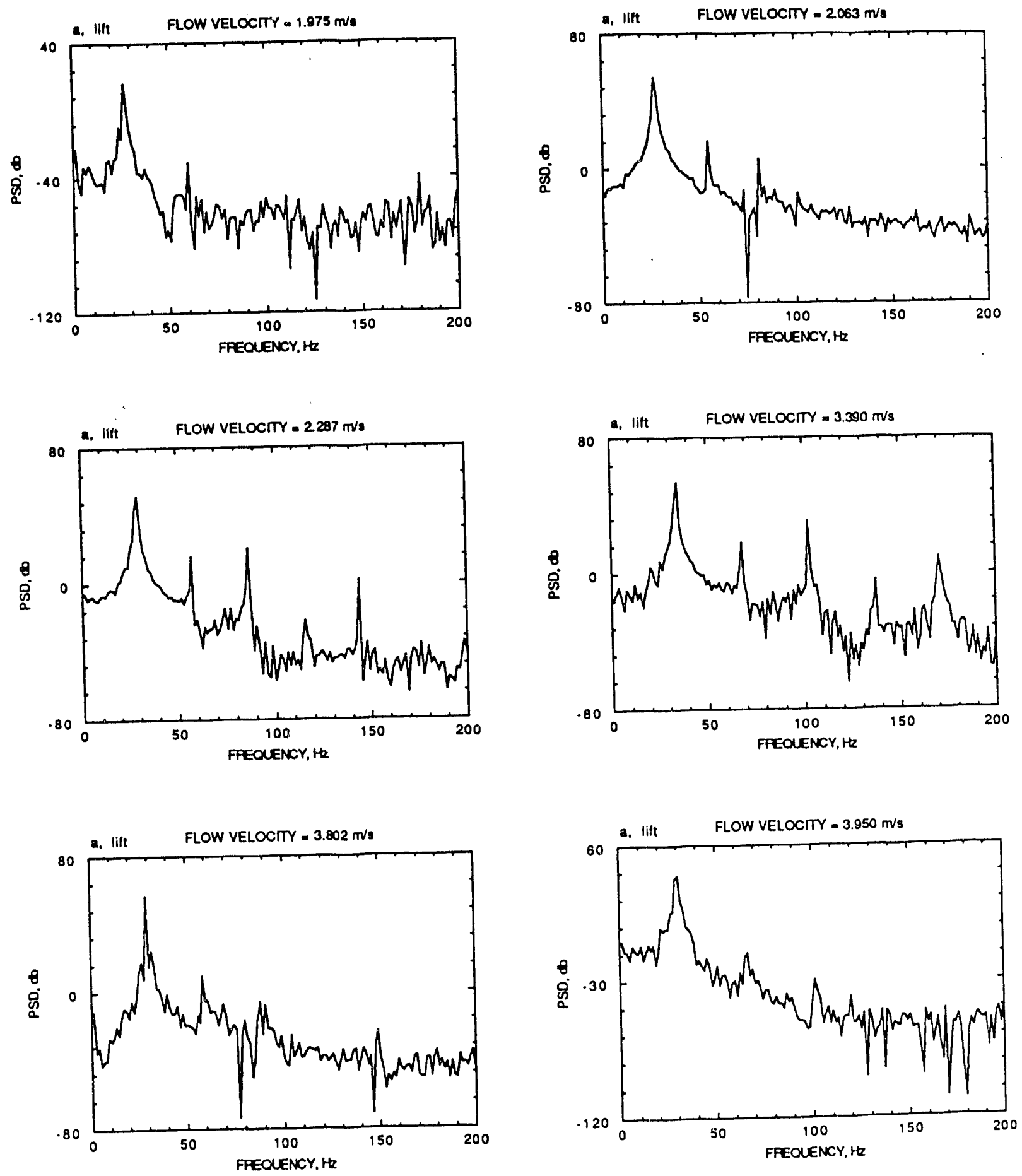

Fig. 18. Power spectral densities of displacement transducer a, Test B.1 

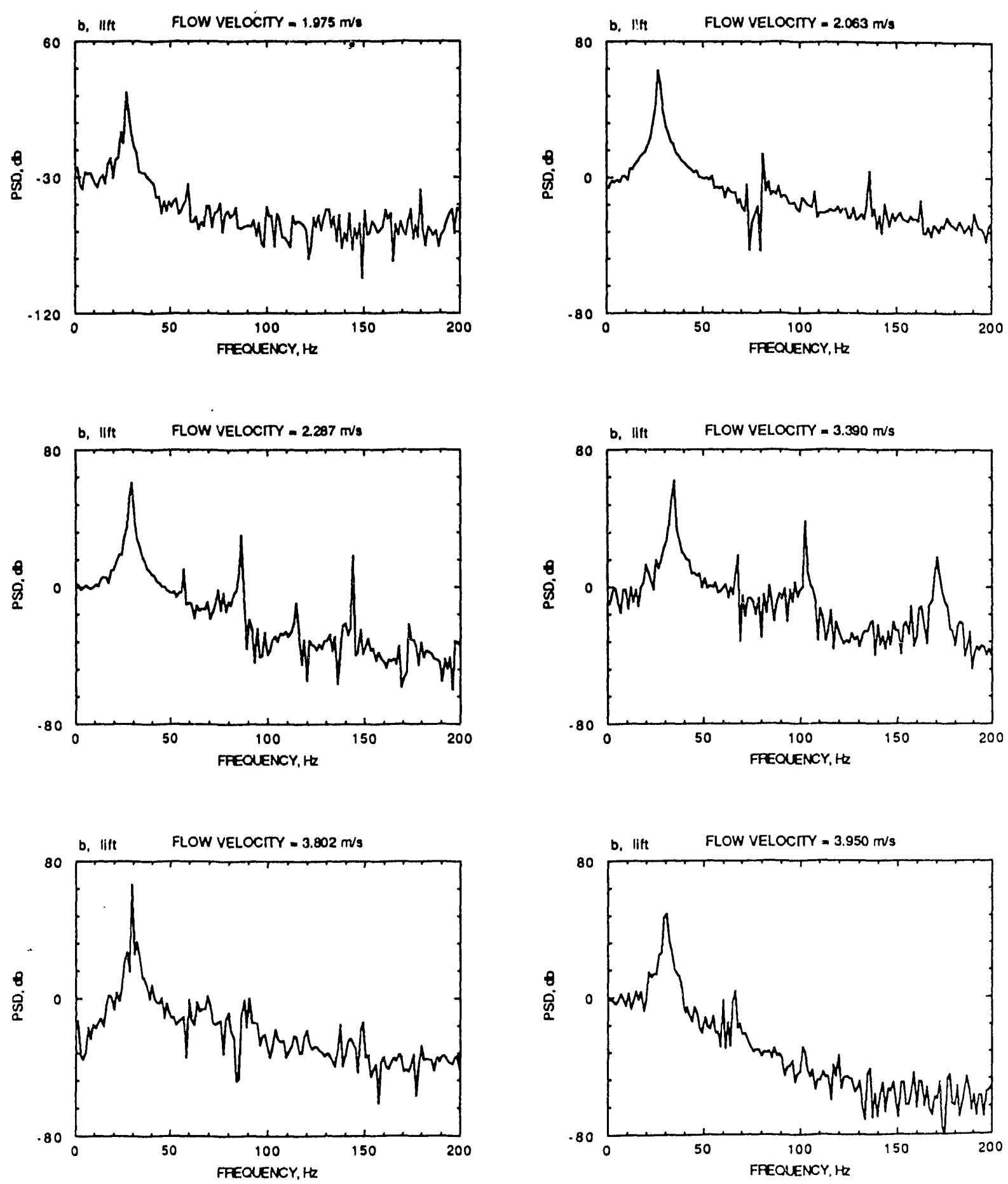

Fig. 19. Power spectral densities of displacement transducer b, Test B.1 

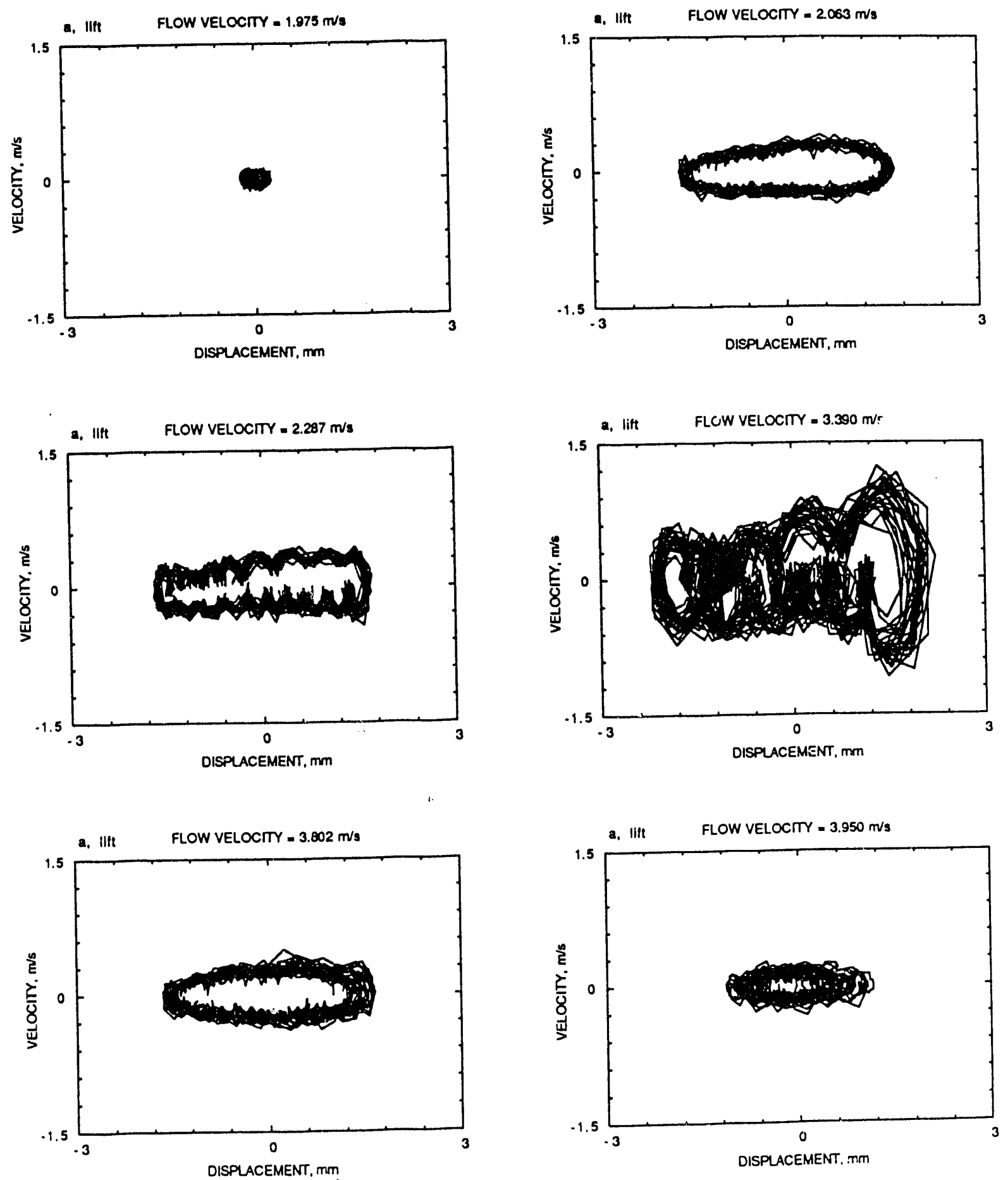

Fig. 20. Phase planes of displacement transducer a, Test B.1 

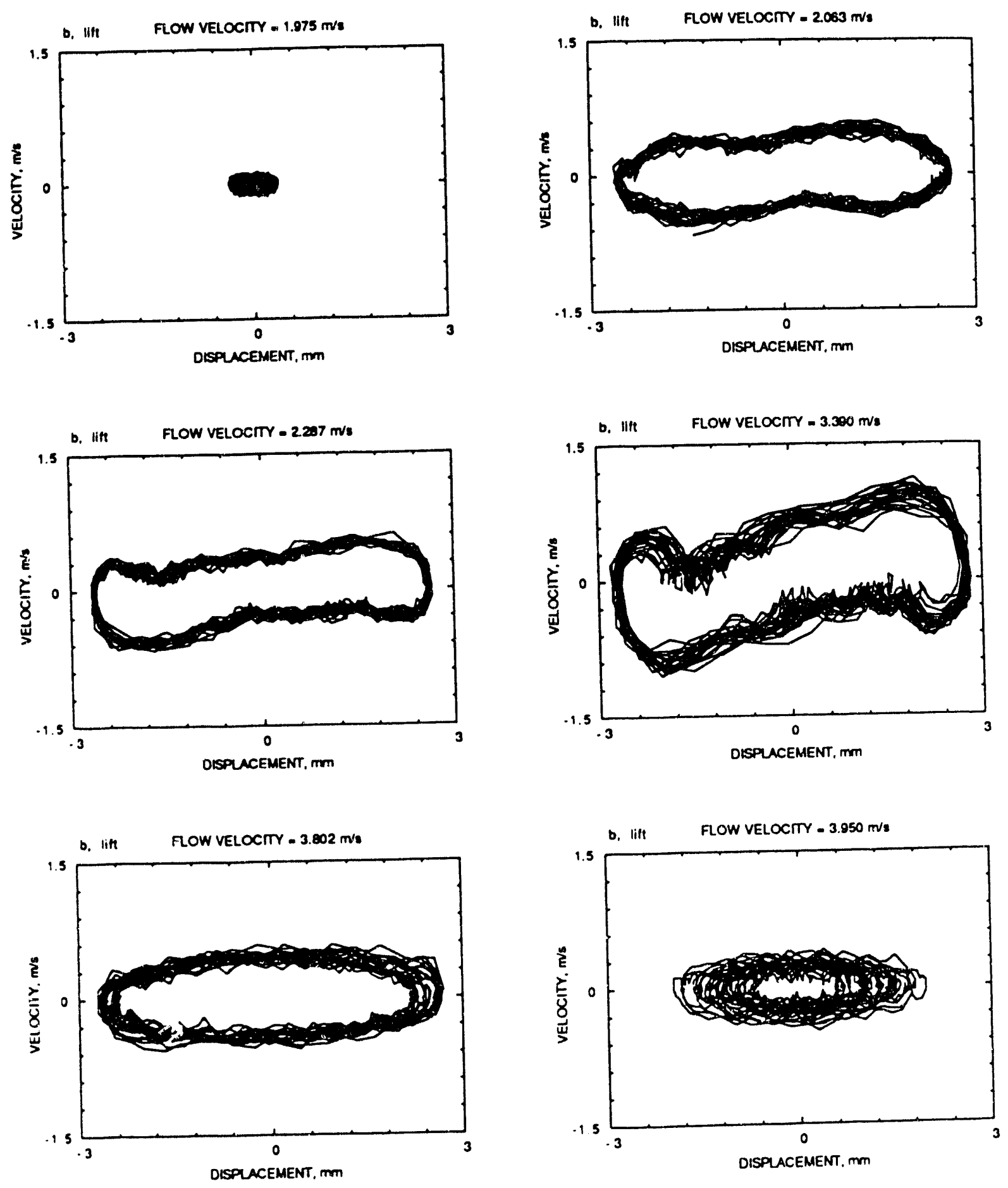

Fig. 21. Phase planes of displacement transducer b, Test B.I 

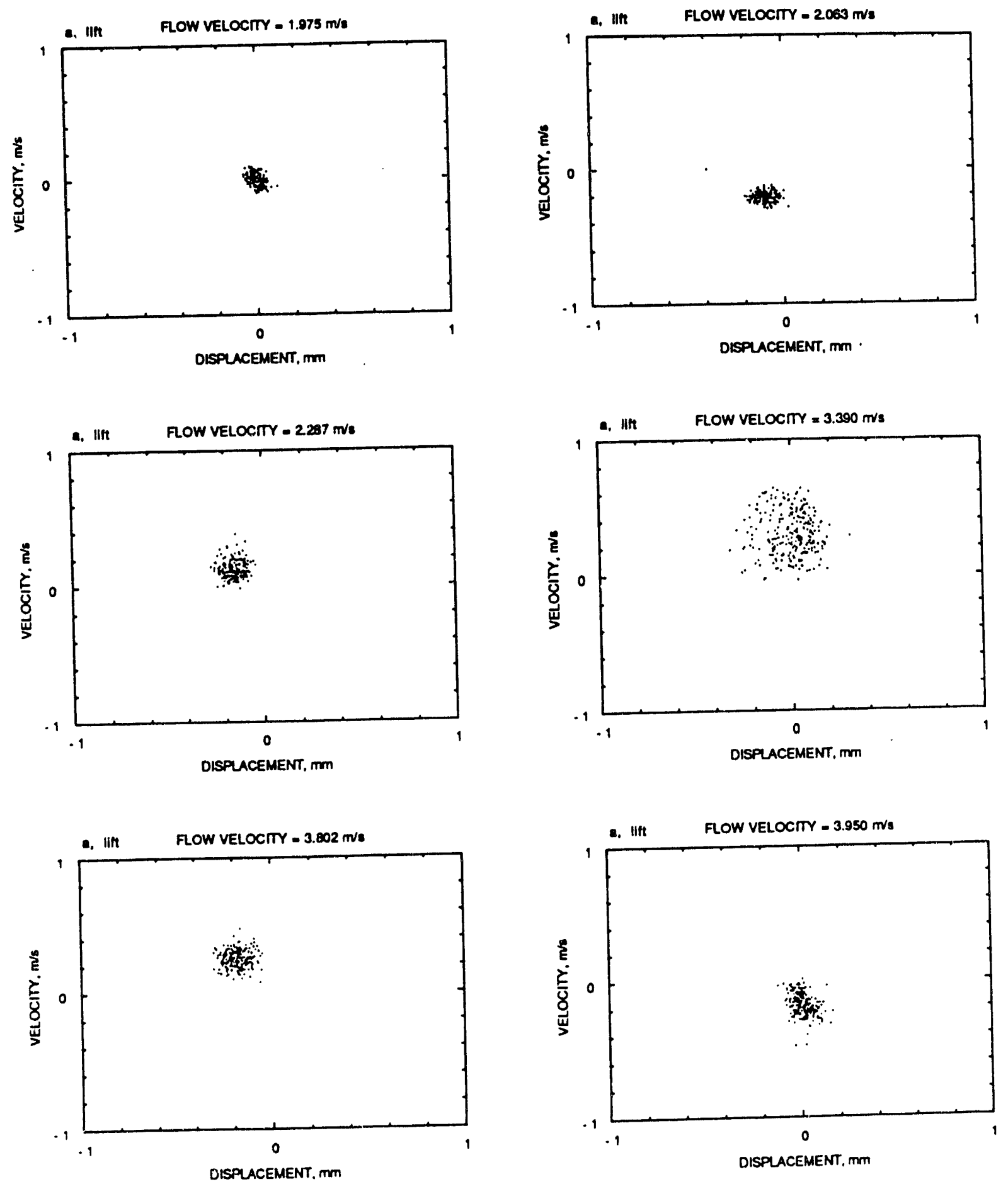

Fig. 22. Poincaré maps for displaceme 't transducer a, Test B.1 

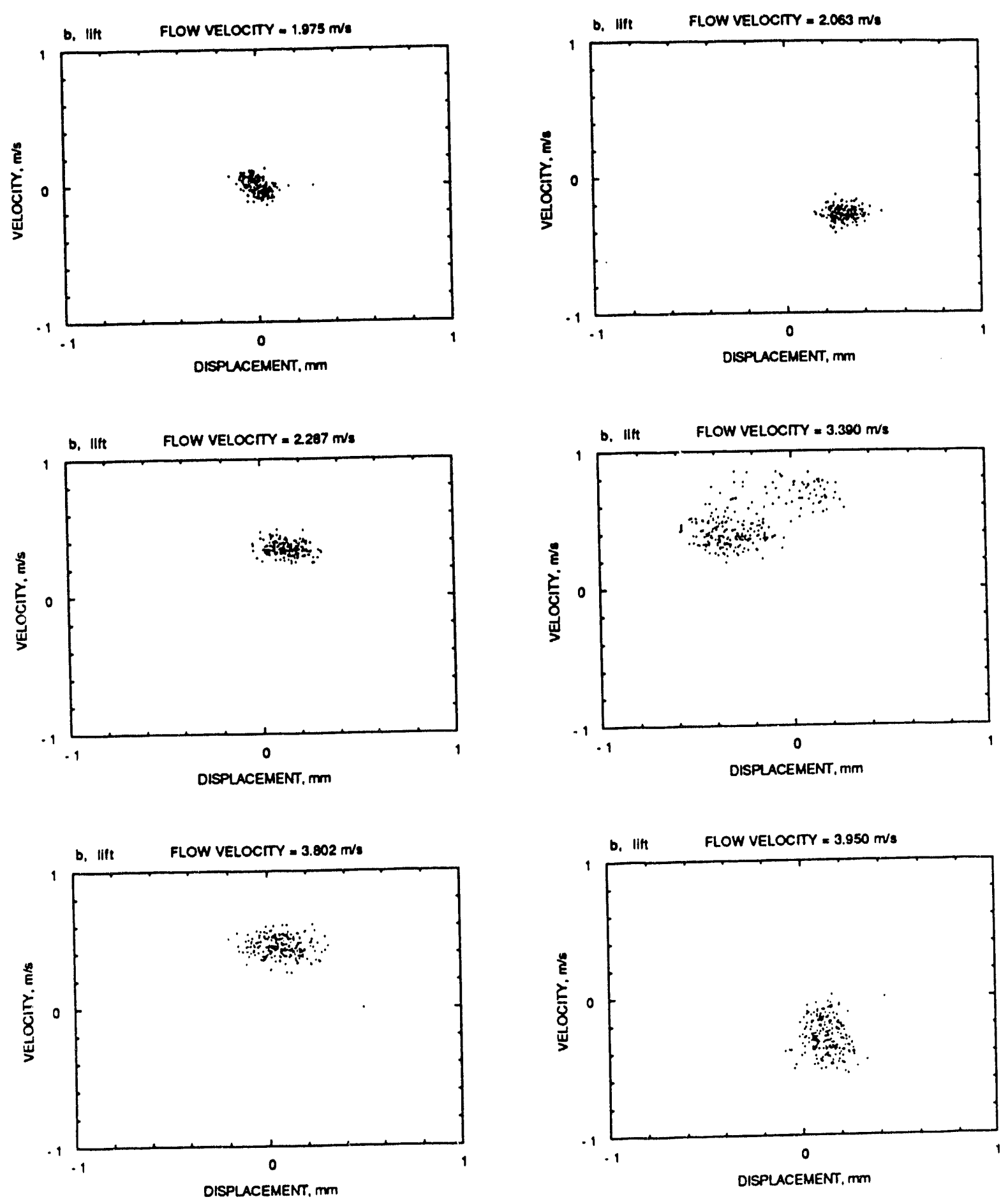

Fig. 23. Poincaré maps for displacement transducer b, Test B.1 


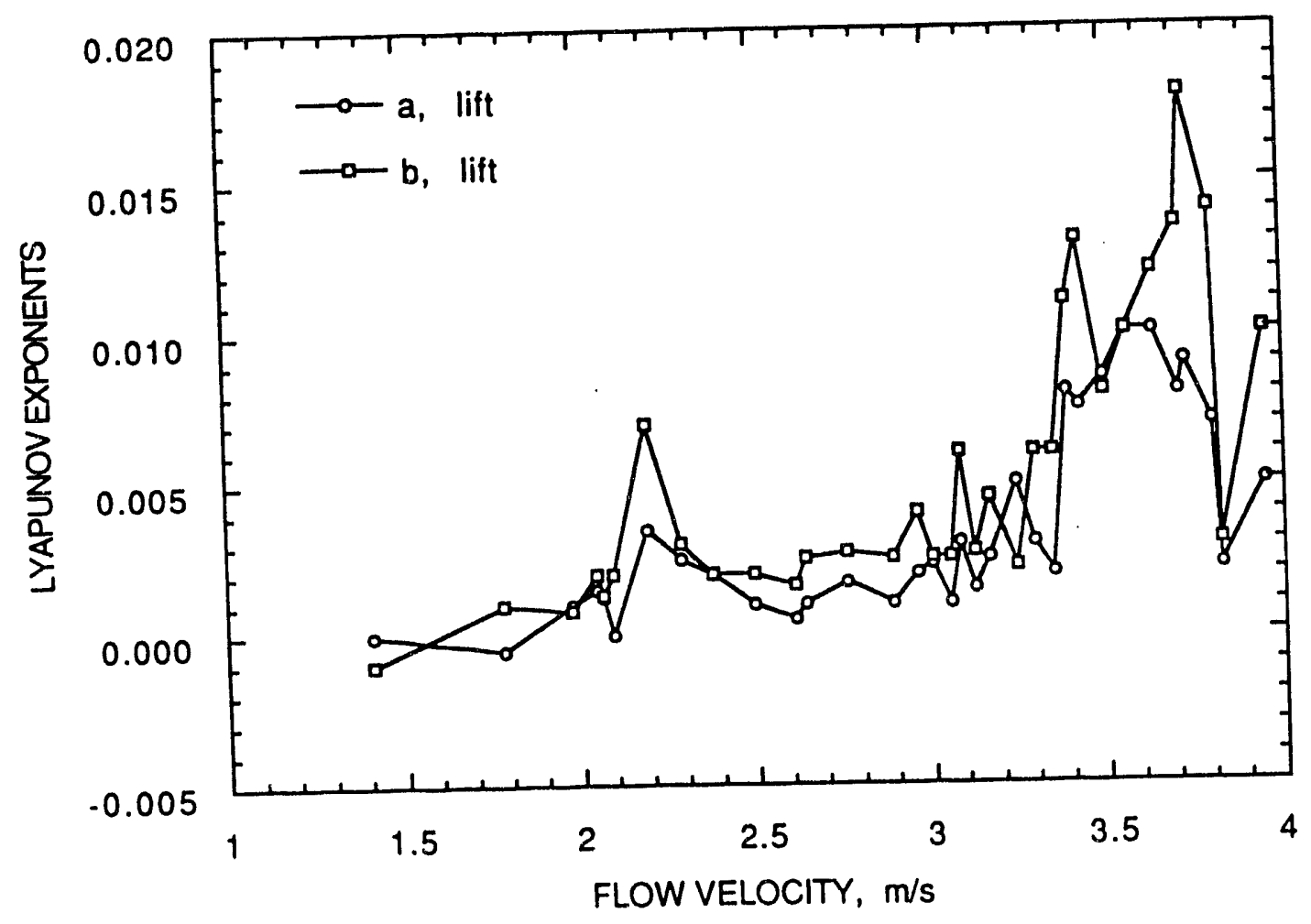

Fig. 24. Lyapunov exponent as a function of flow velocity, Test B.1 


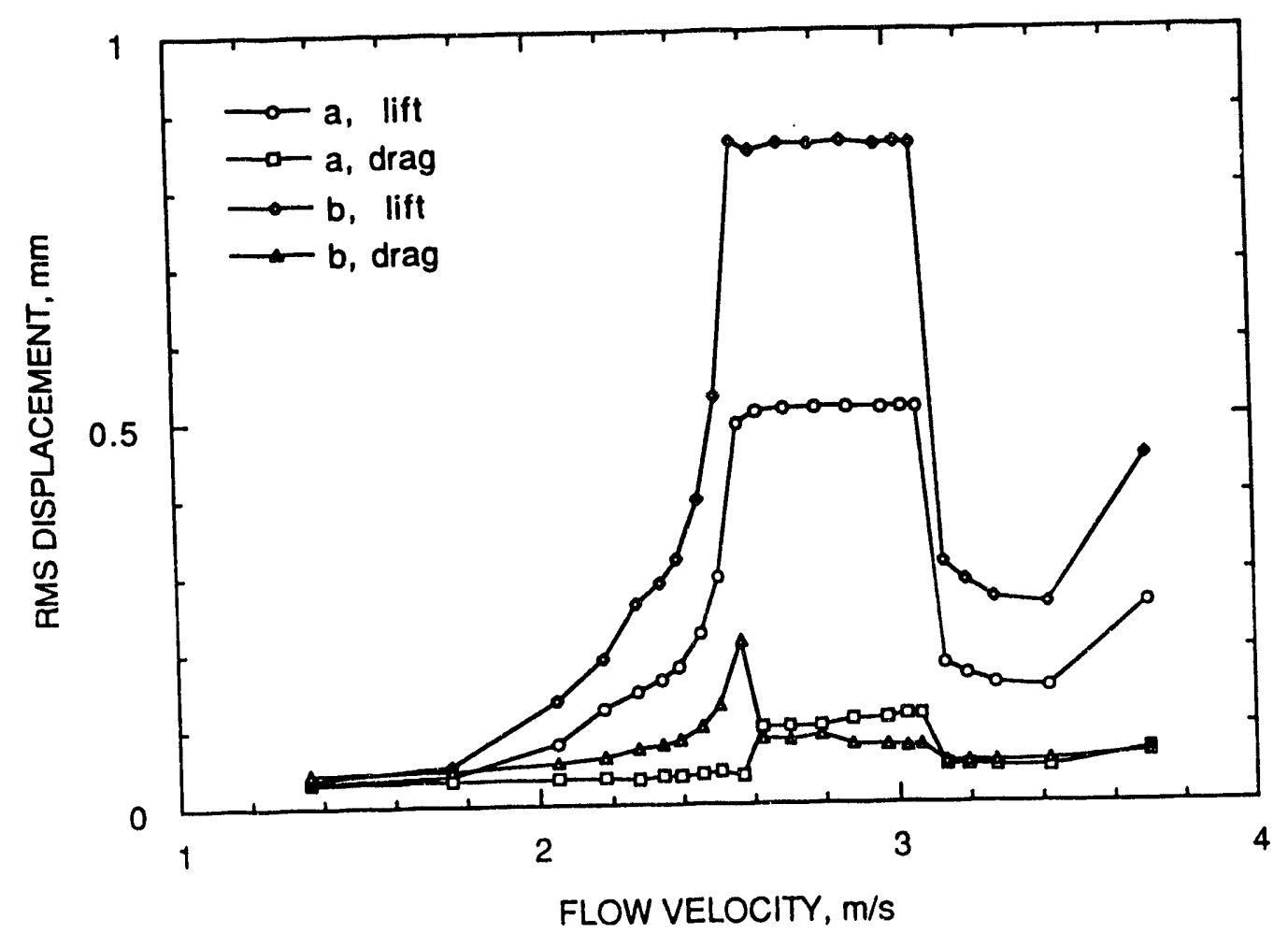

Fig. 25. RMS tube displacement as a function of flow velocity, Test B.2

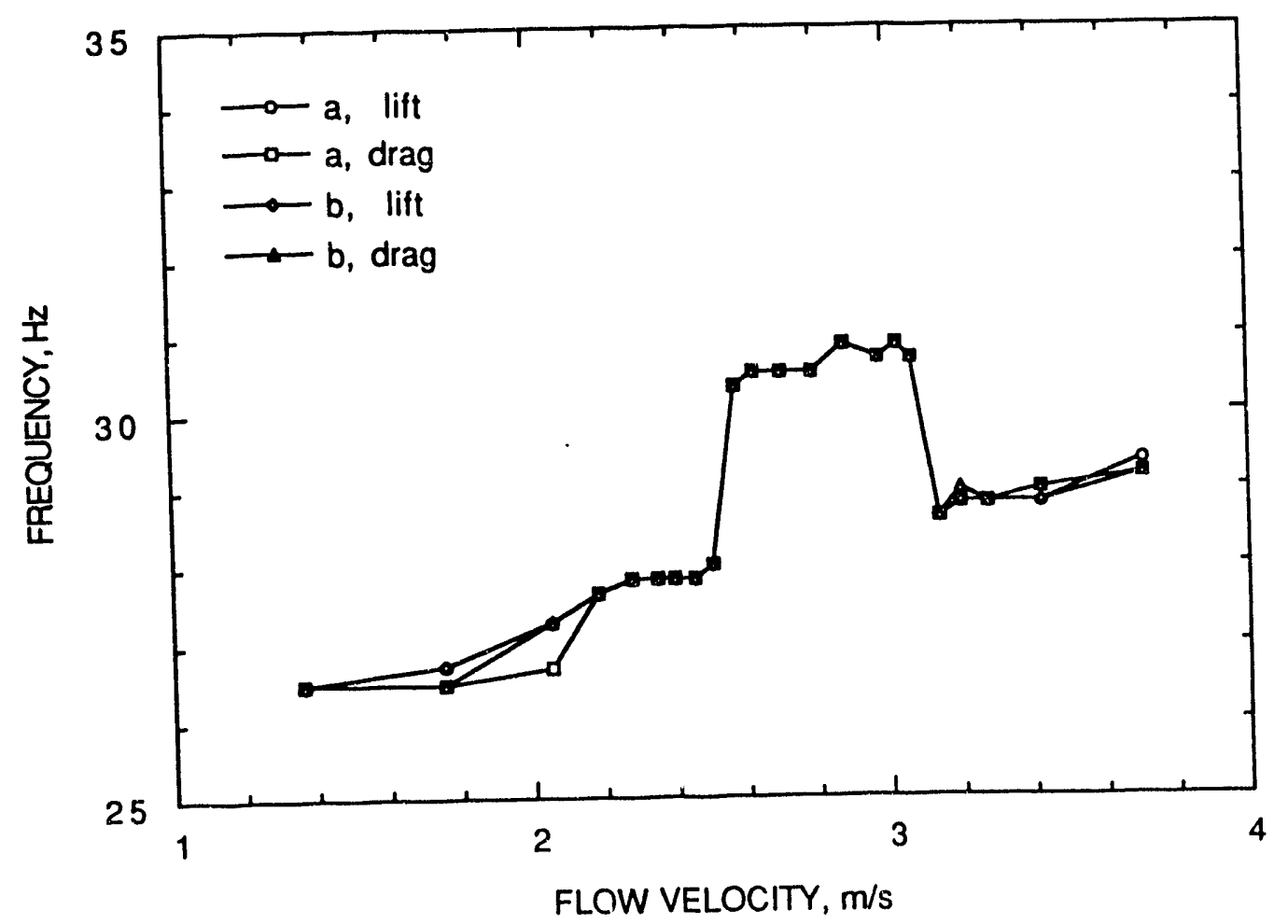

Fig. 26. Dominant response frequency as a function of flow velocity, Test B.2 

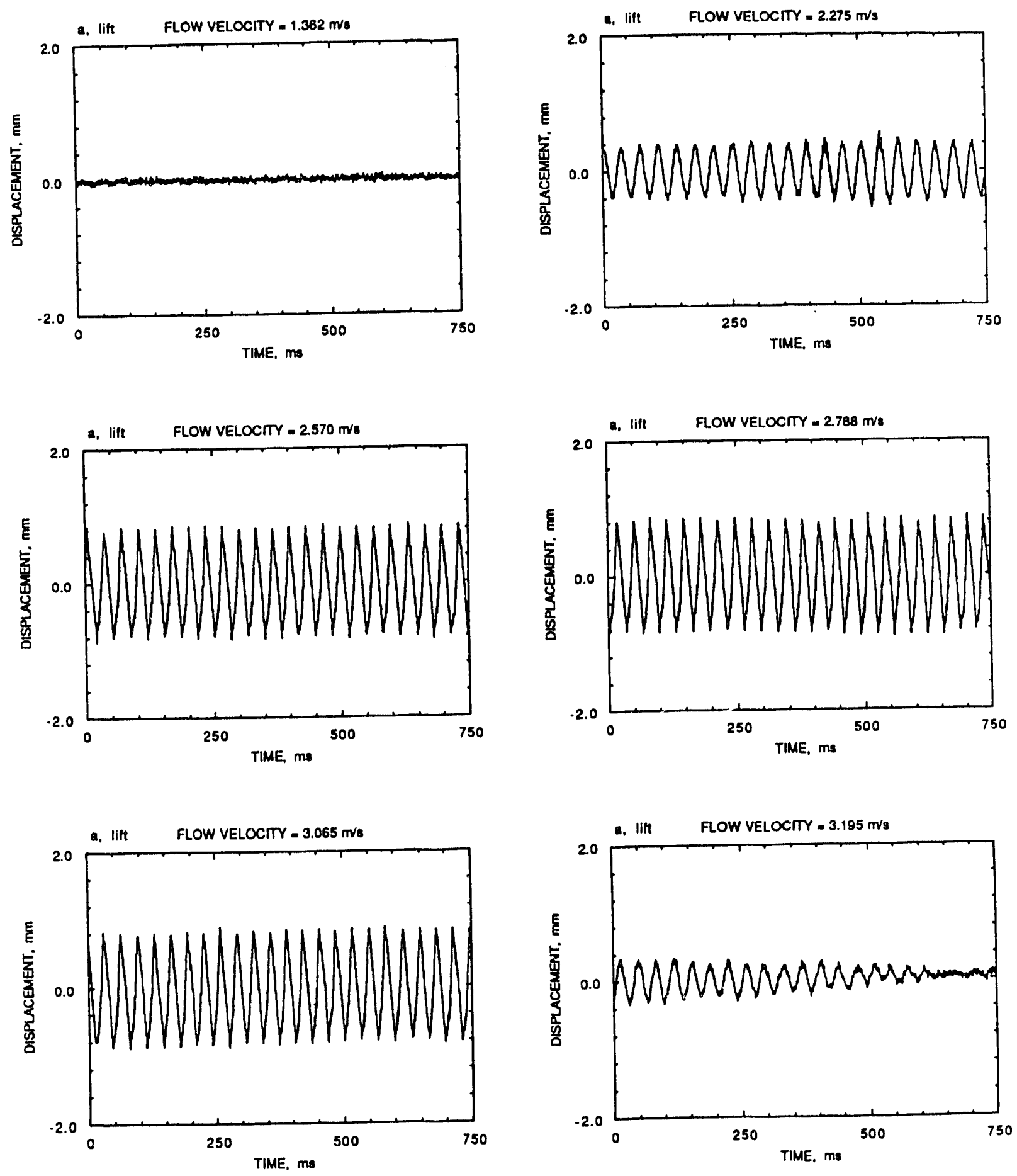

Fig. 27. Time histories of displacement transduce , at different flow velocities, Test B.2 

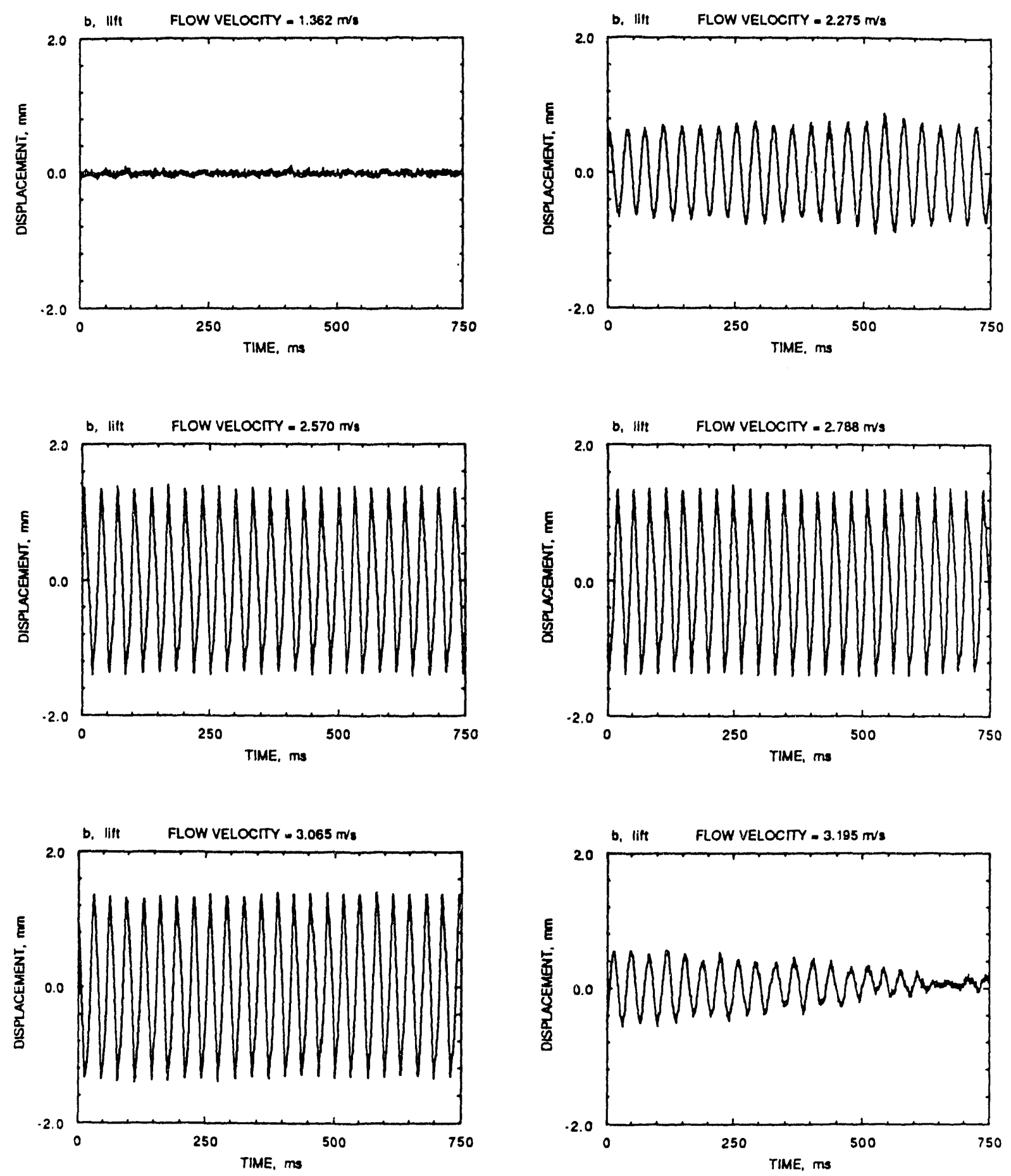

Fig. 28. Time histories of displacement transducer $b$ at different flow velocities, Test B.2 

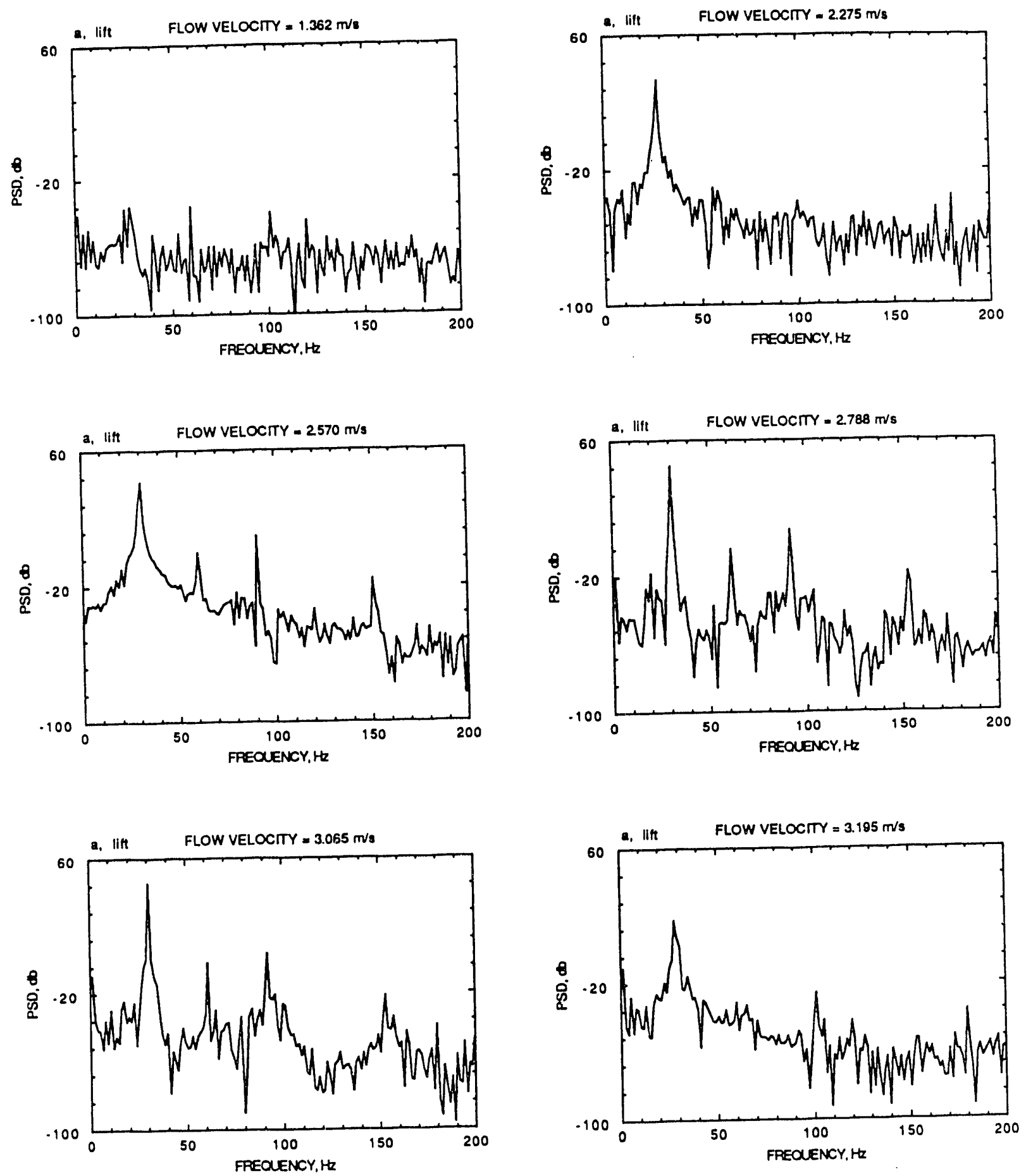

Fig. 29. Power spectral densitie of displacement transducer a, Test B.2 

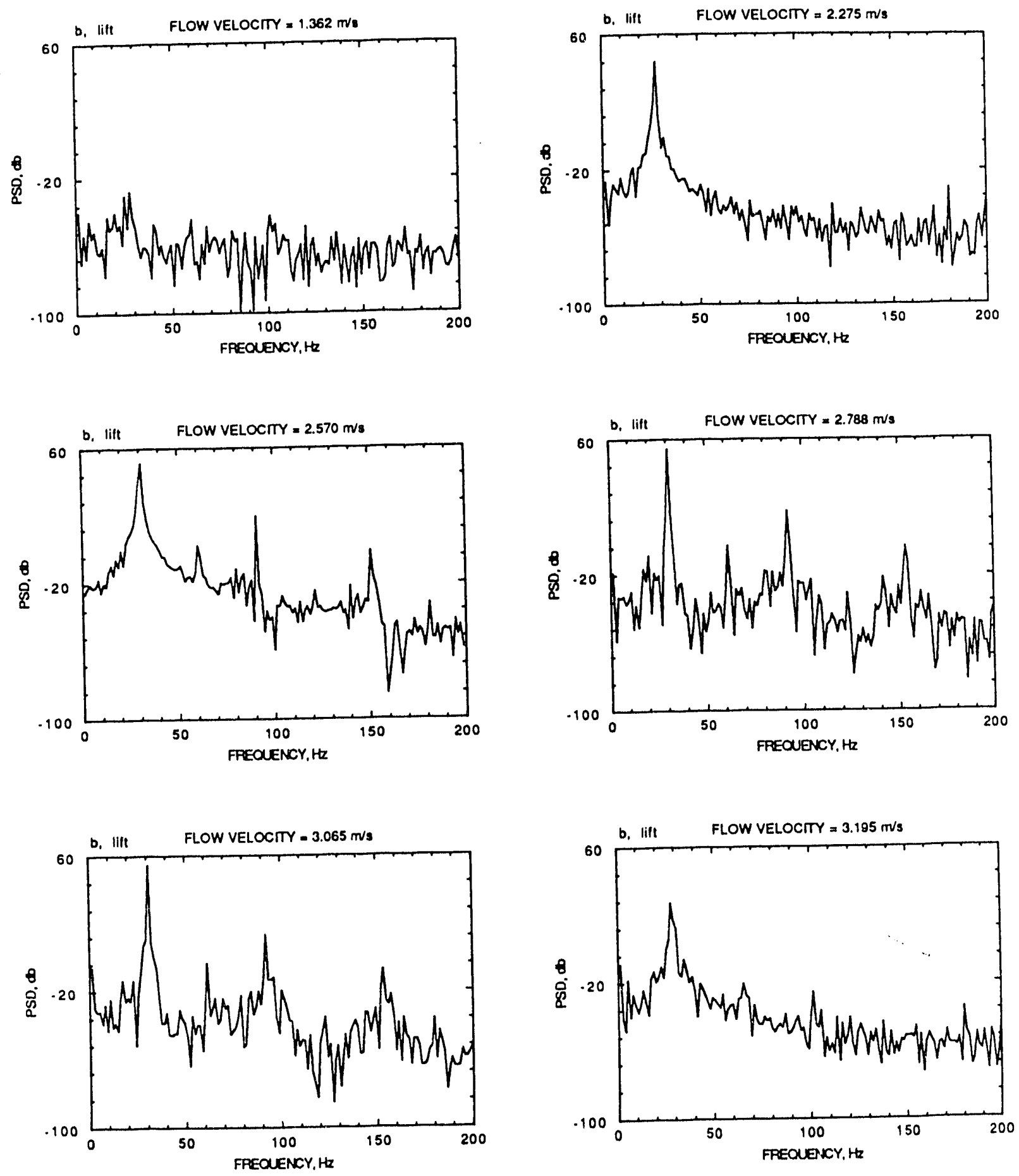

Fig. 30. Pou r spectral densities of displacement transducer b, Test B.2 

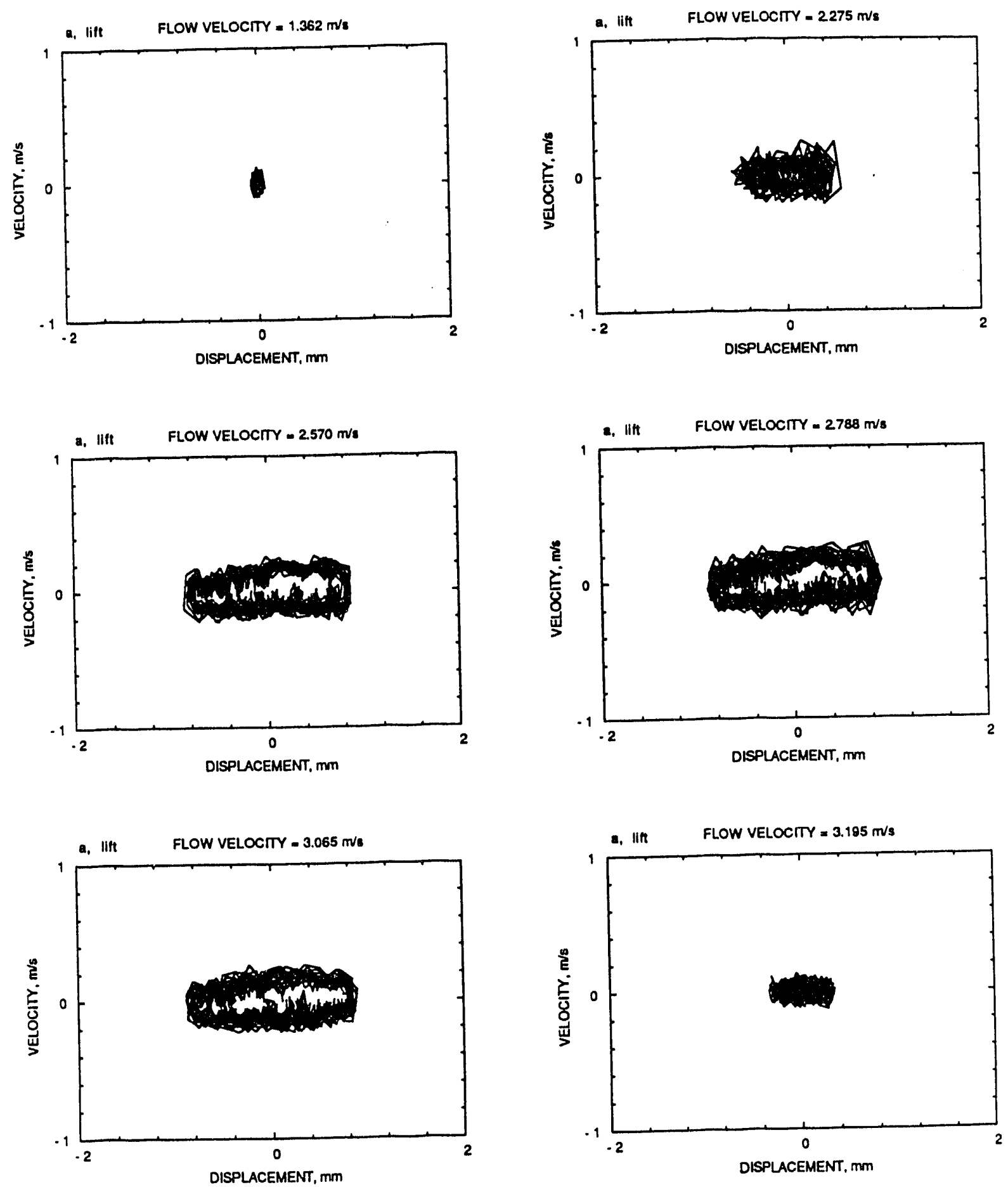

Fig. 31. Phase planes of displacement transducer a, Test B.2 

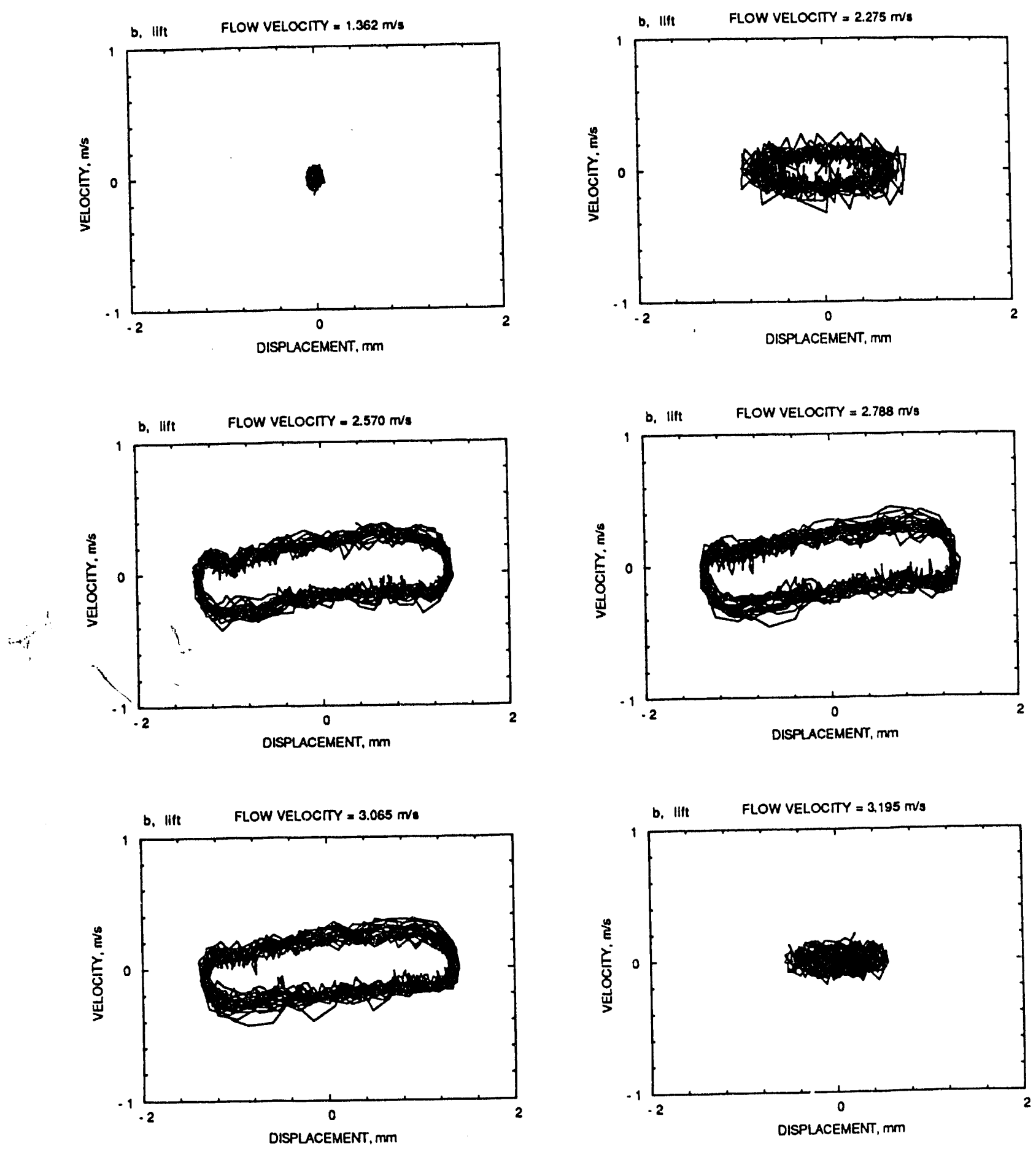

Fig. 32. Phase planes of displacement transducer b, Test B.2 

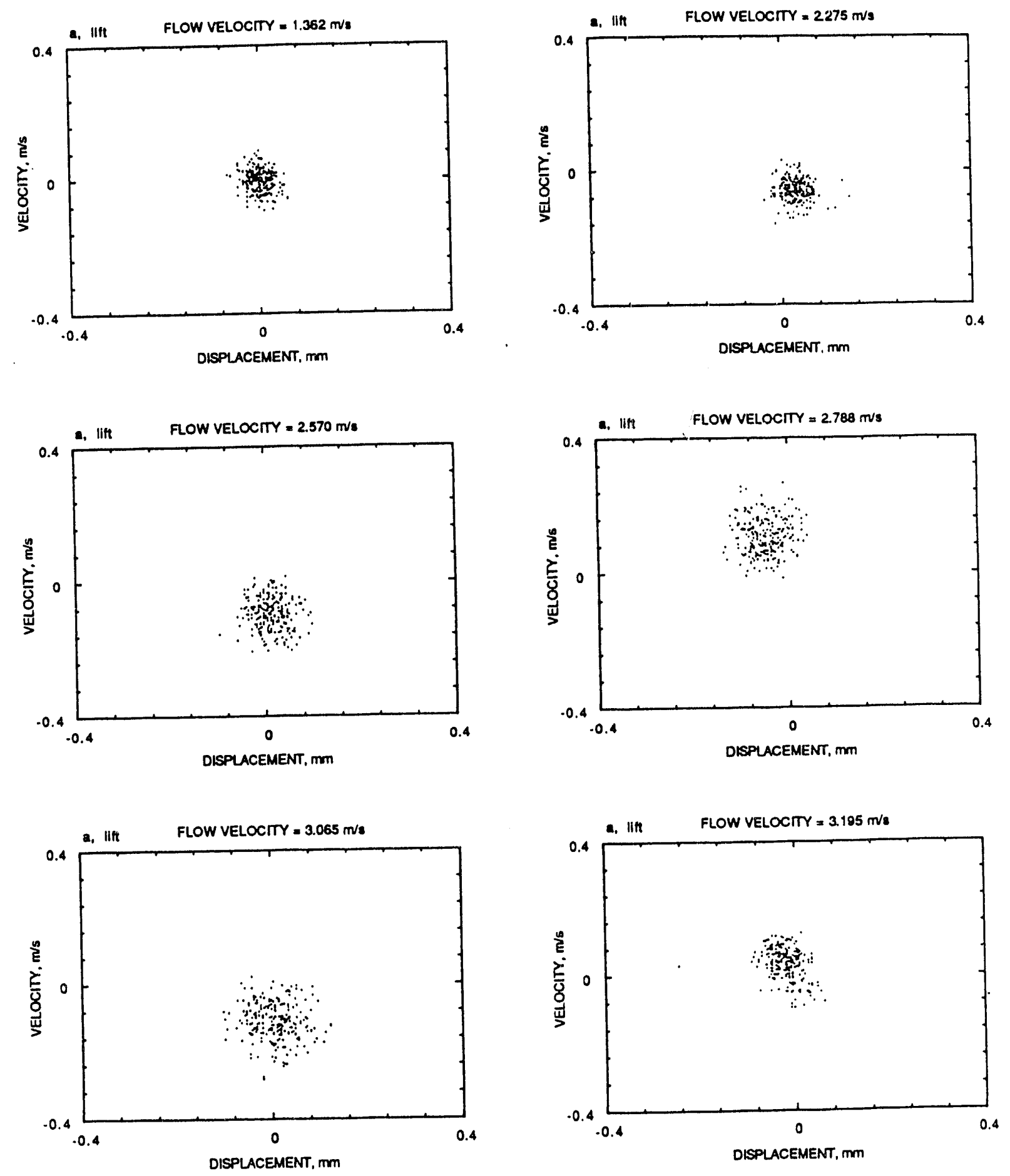

Fig. 33. Poincaré maps for displacement transducer a, Test B.2 

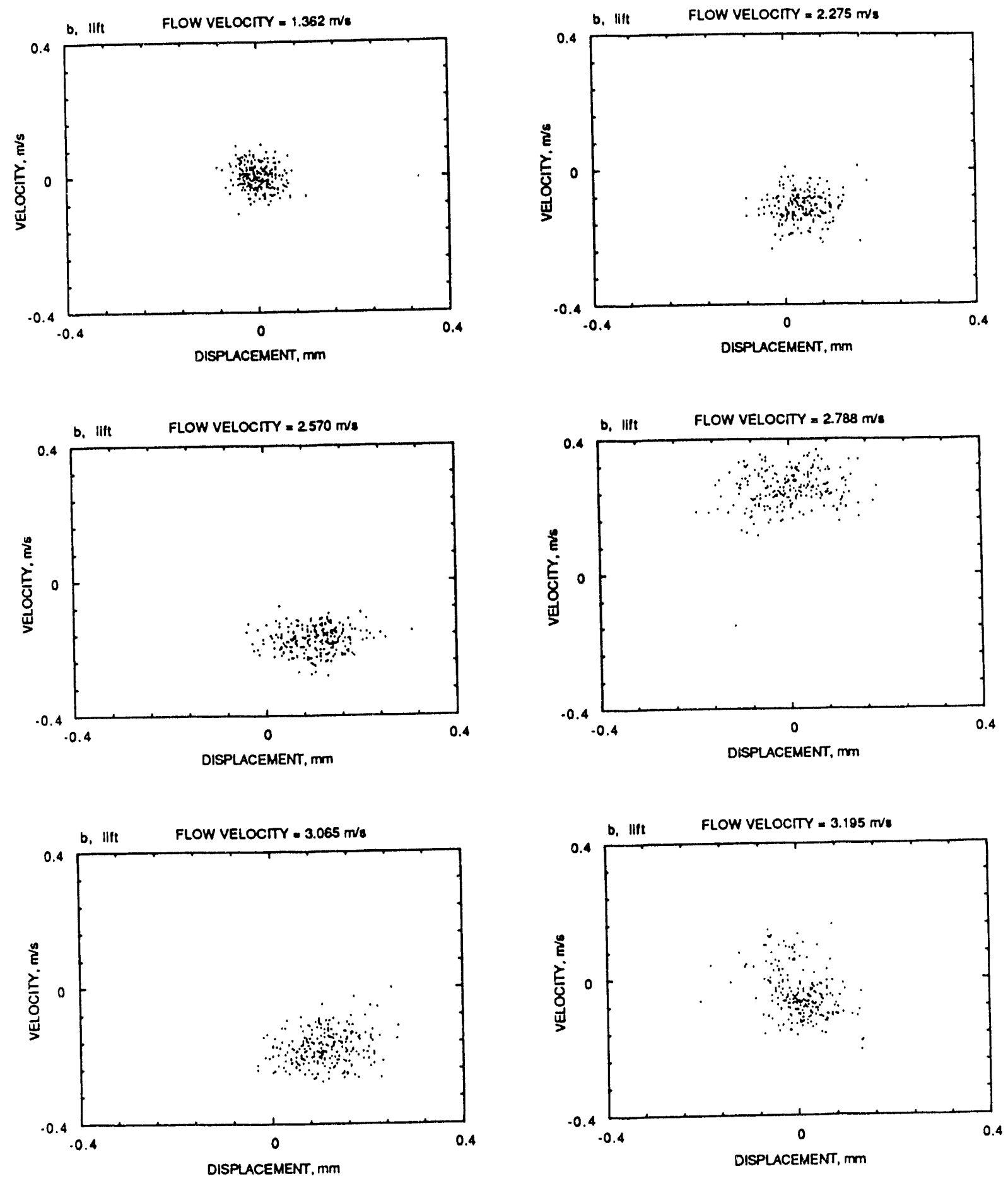

Fig. 34. Poincaré maps for displacement transducer b, Test B.2 


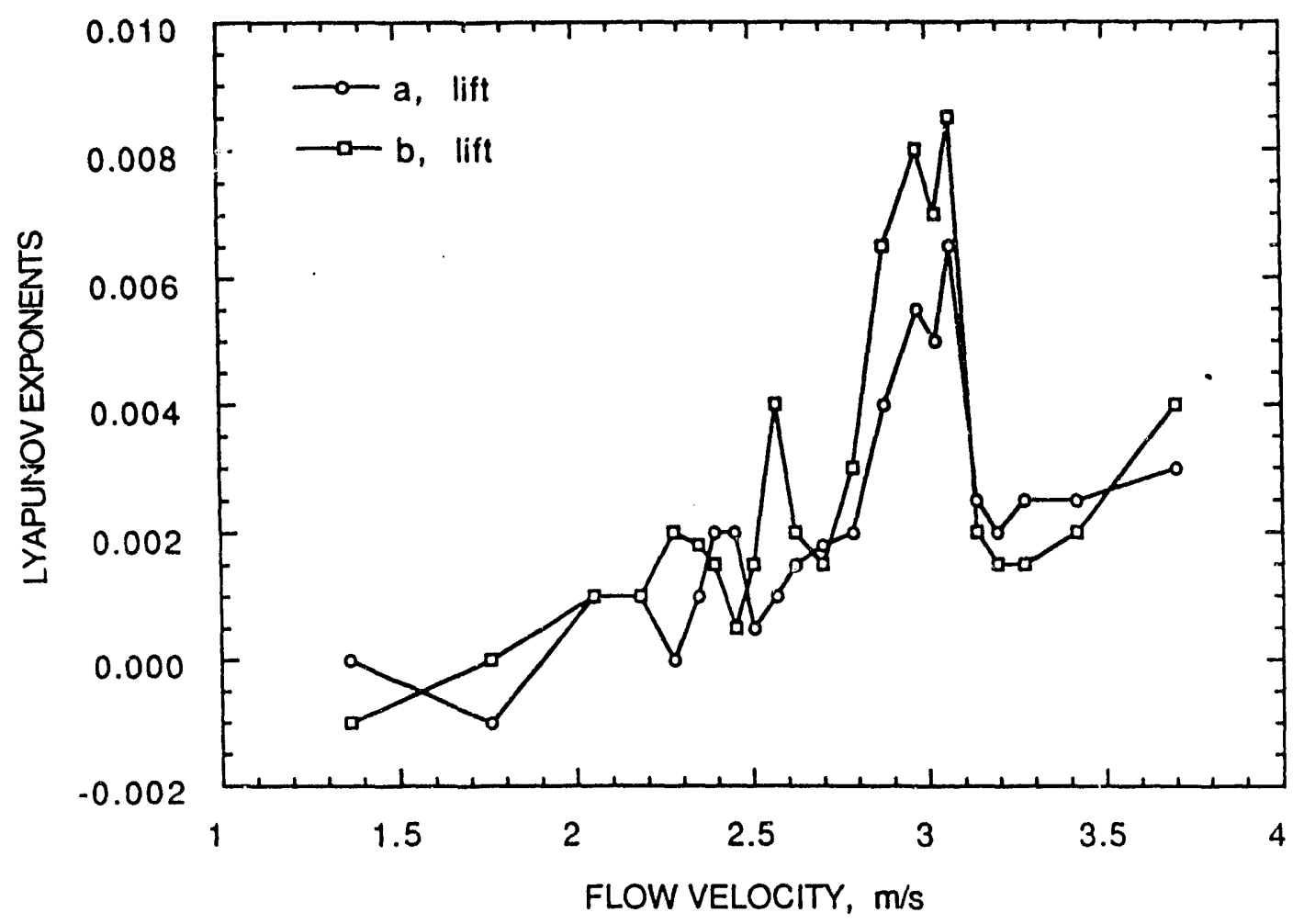

Fig. 35. Lyapunov exponent as a function of flow velocity, Test B.2 


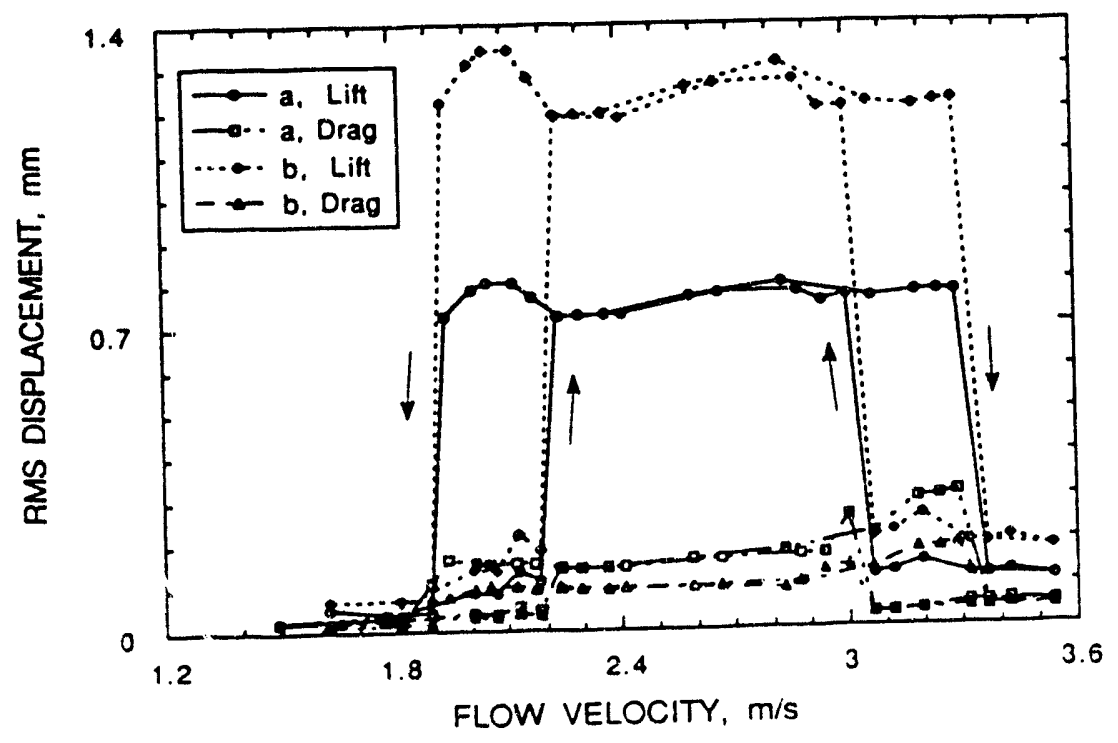

Fig. 36. RMS tube displacement as a function of flc'w velocity, Test C.1

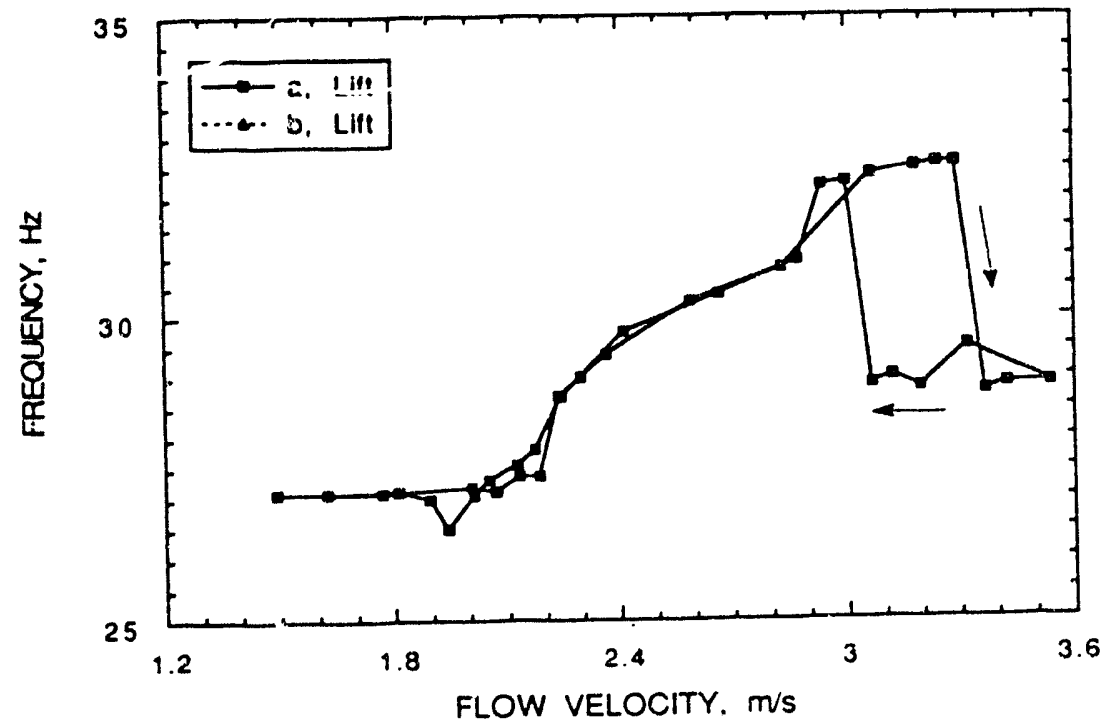

Fig. 37. Dominant response frequency as a function of flow velocity, Test C.1 

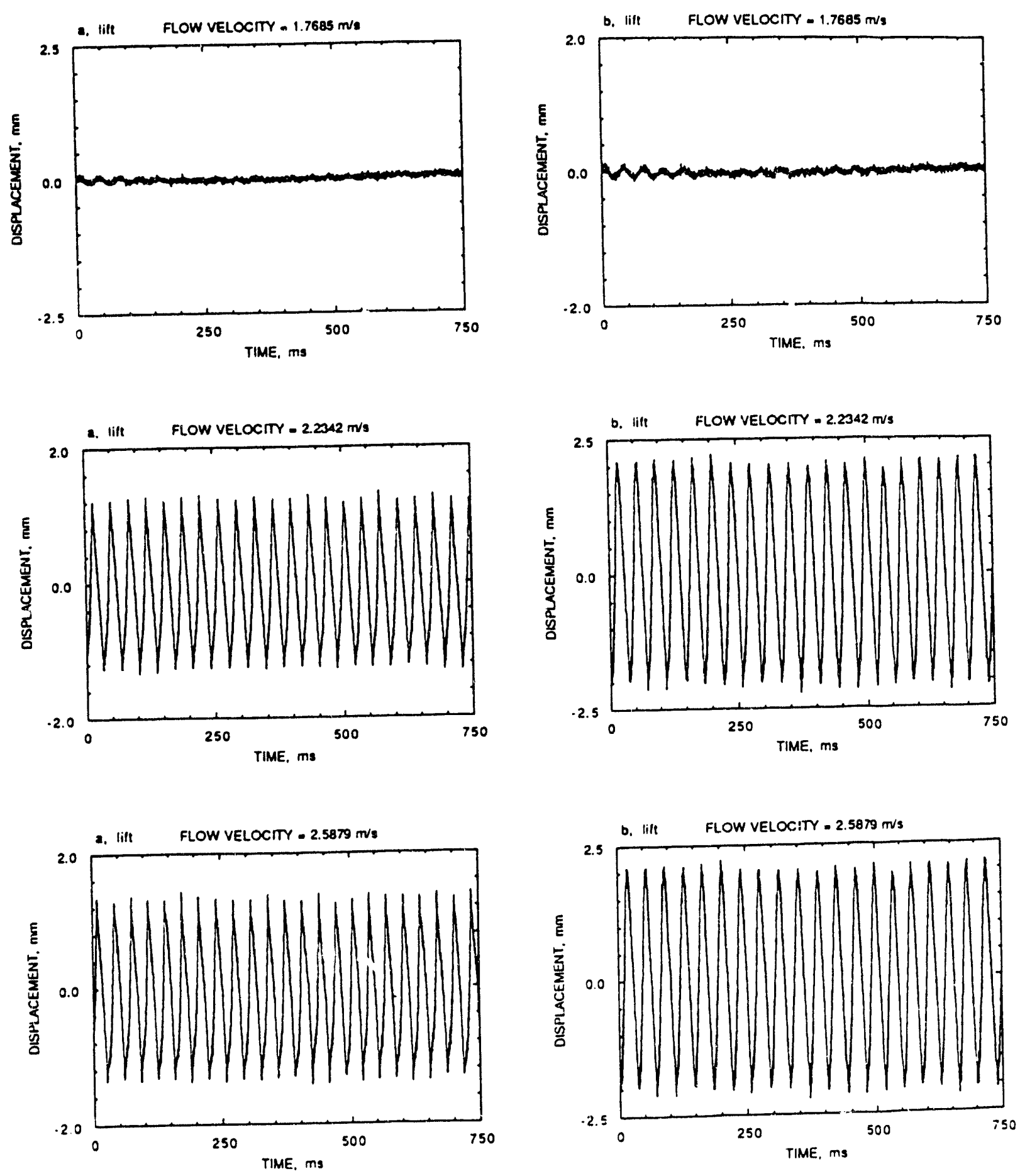

Fig. 38. Time histories of tube displacement at different flow velocitles, Test C.1 

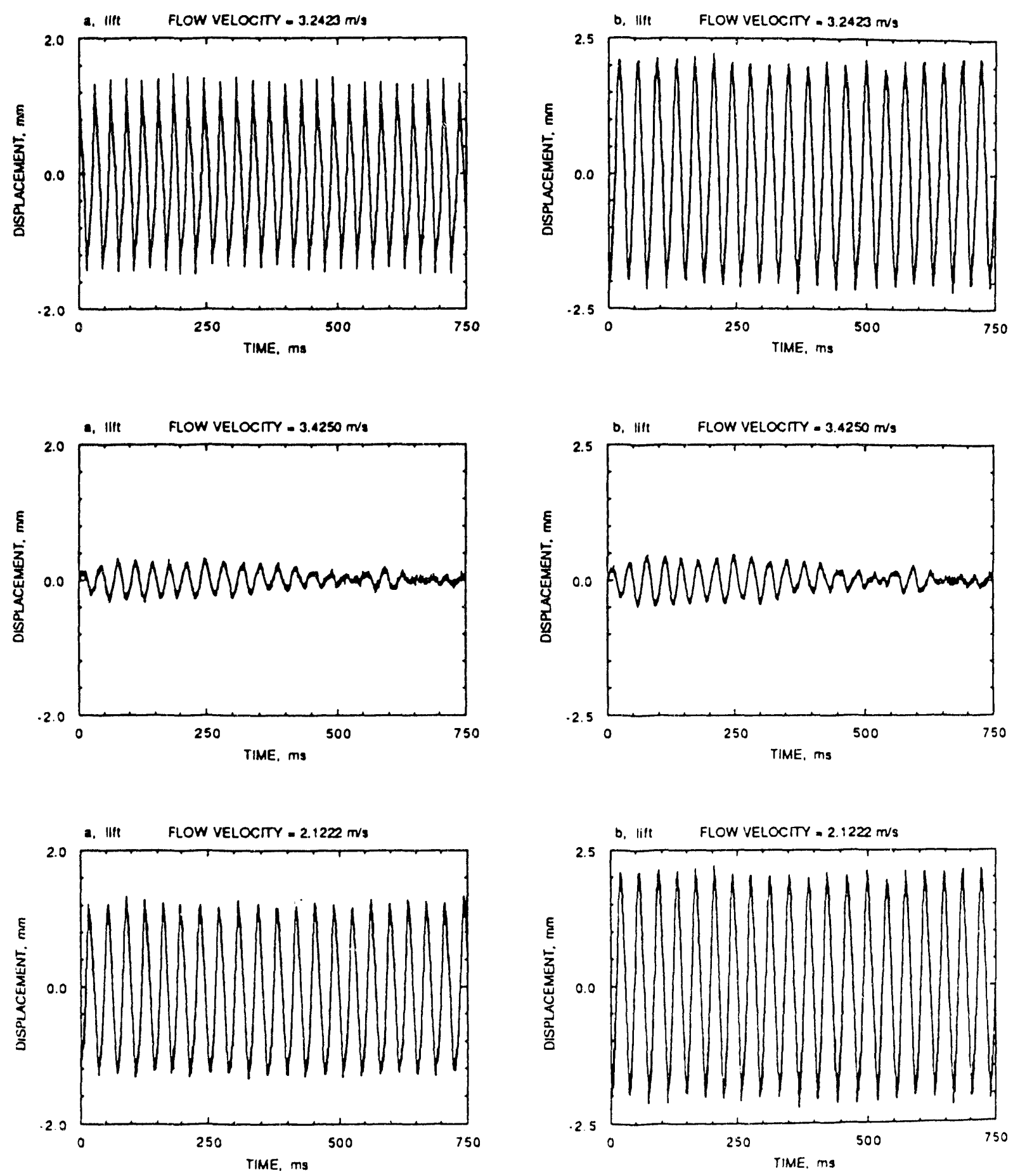

Fig. 39. Time histories of tube displacement at uifferent flow velocities, Test C.1 

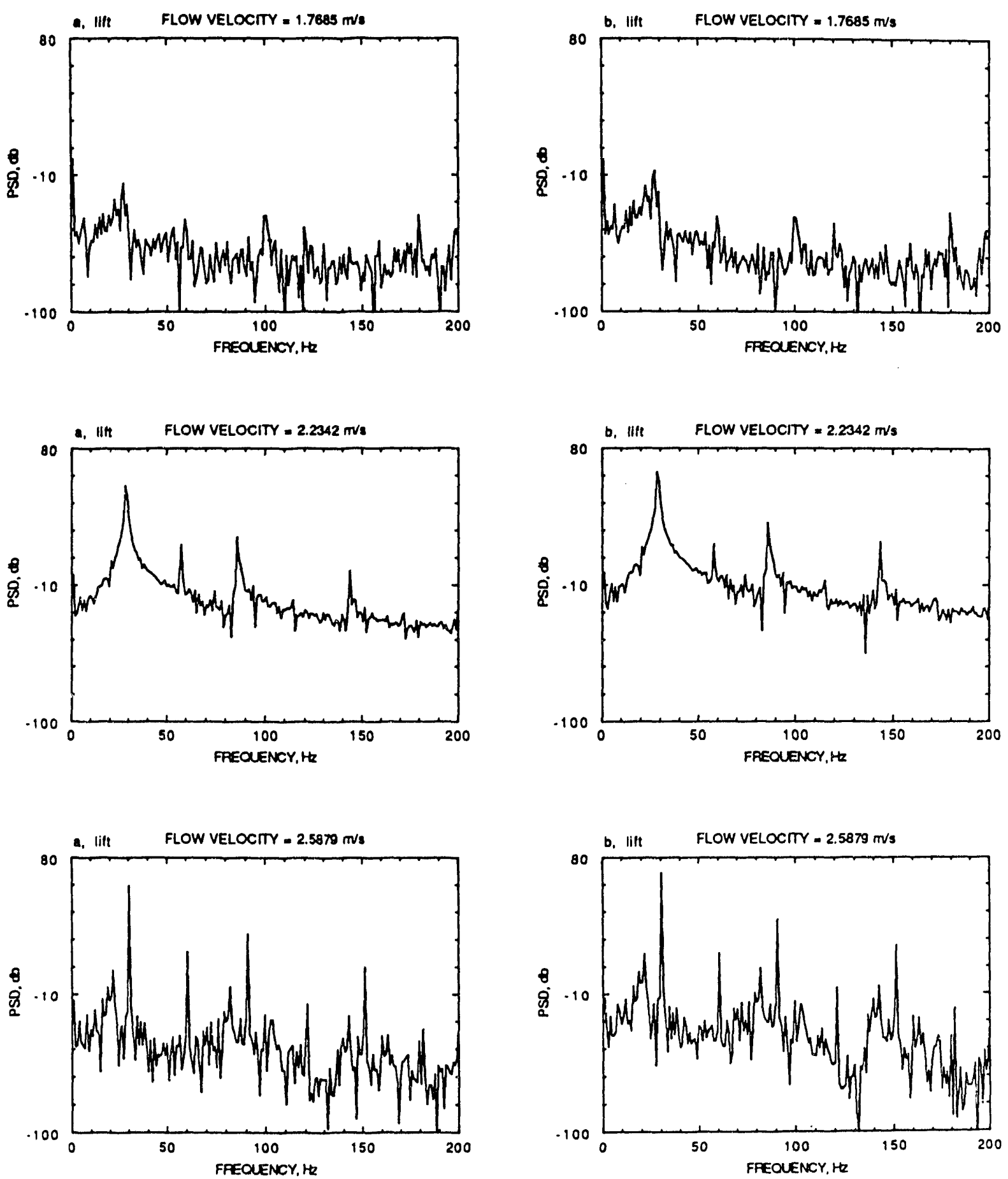

Fig. 40. Power spectral densuiues of tube displacement, Test C.1 

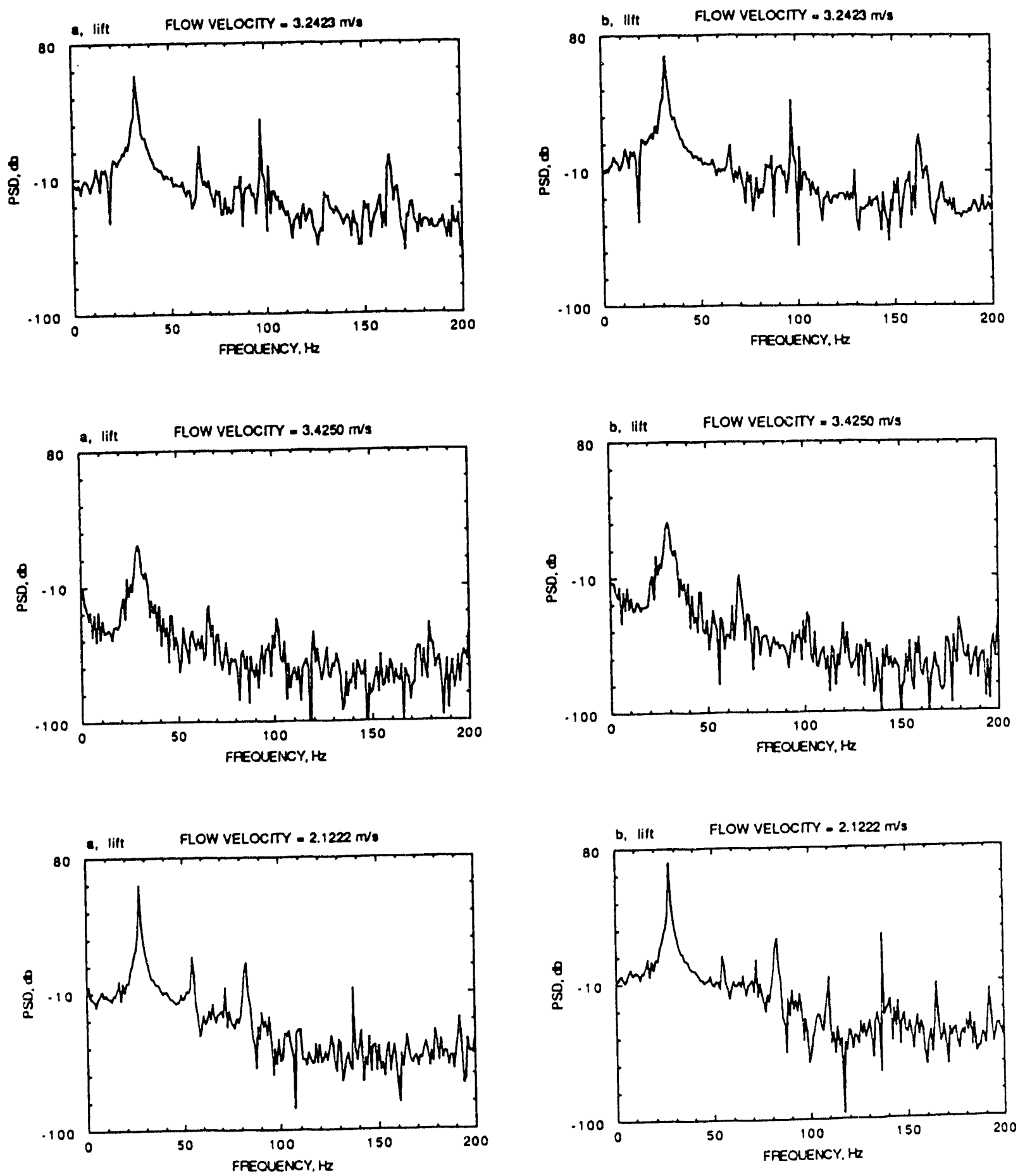

Fig. 41. Power spectral ciensities of tube displacement, Test C.1 

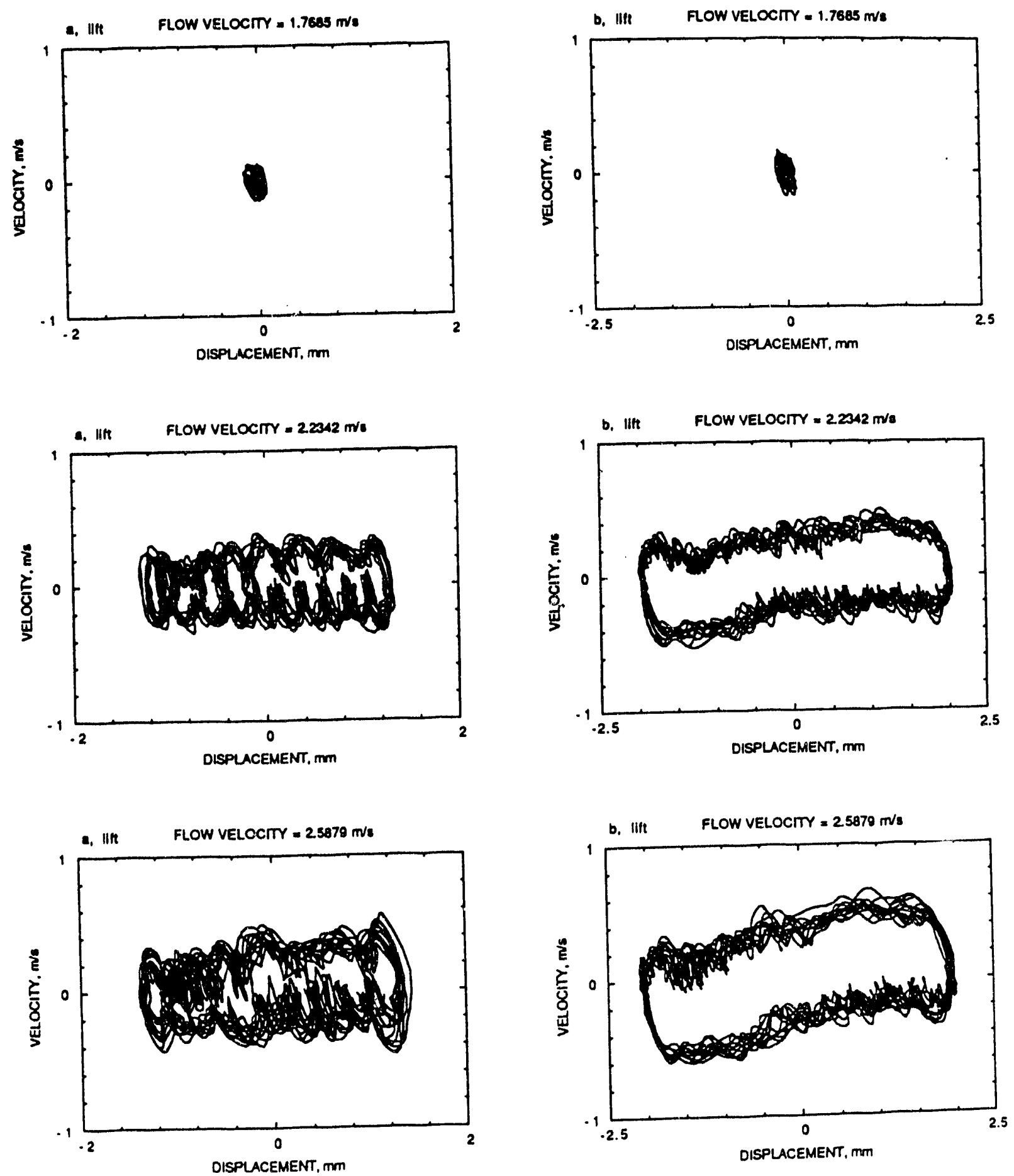

Fig. 42. Phase planes of tube motion, Test C.1 

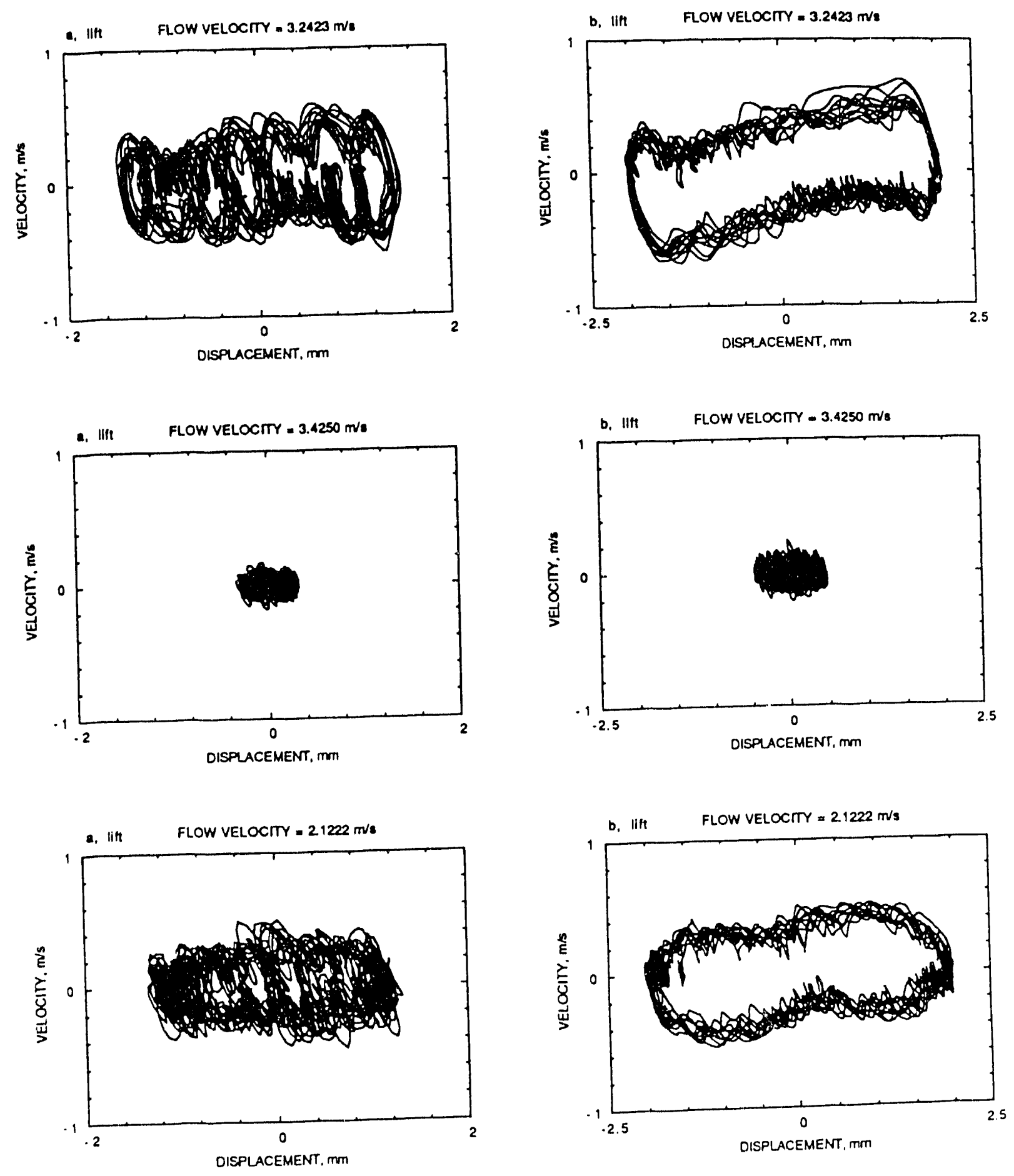

Fig. 43. Phase planes of tube motion, Test C.1 

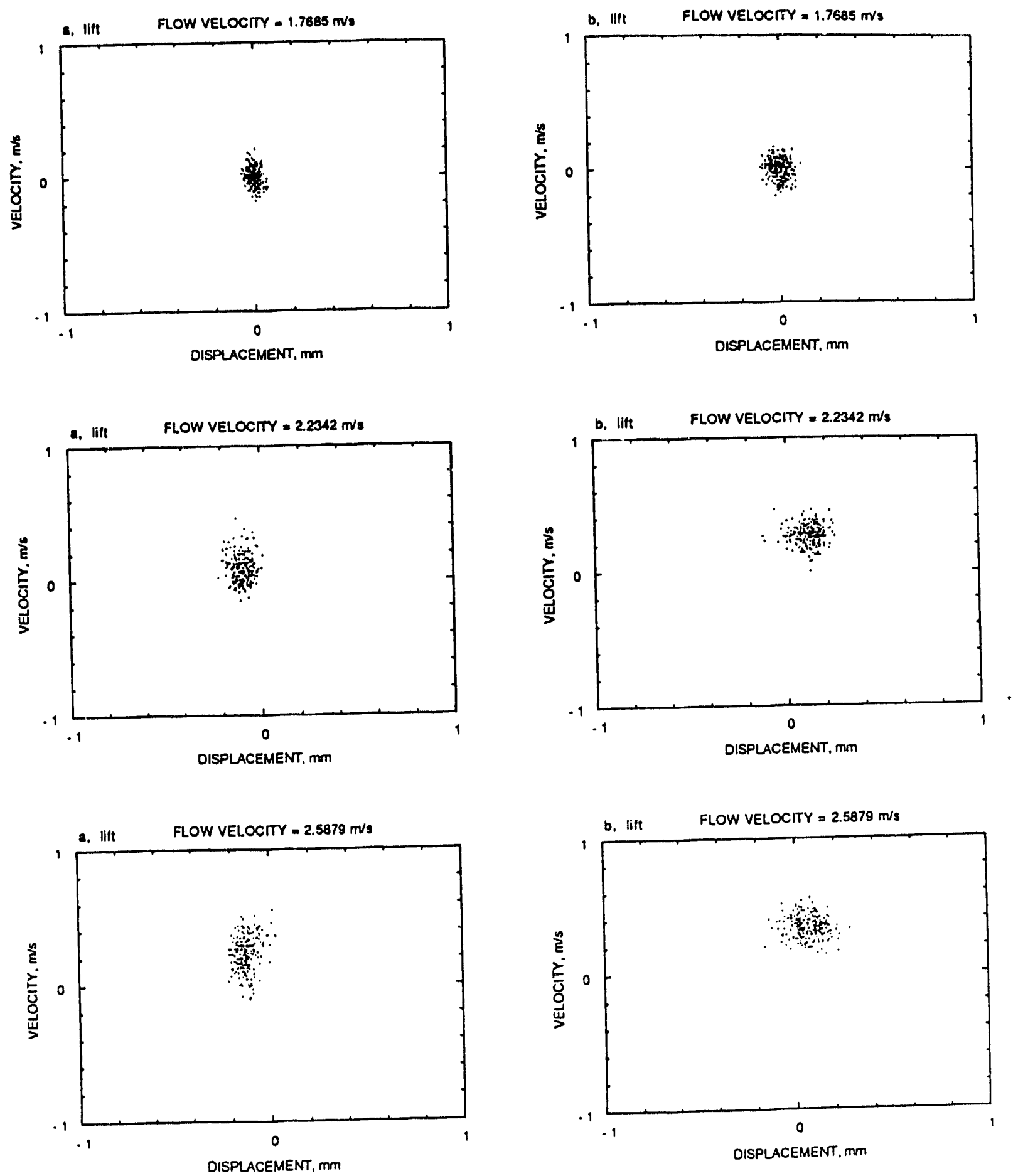

Fig. 44. Poincaré maps, Test C.1 

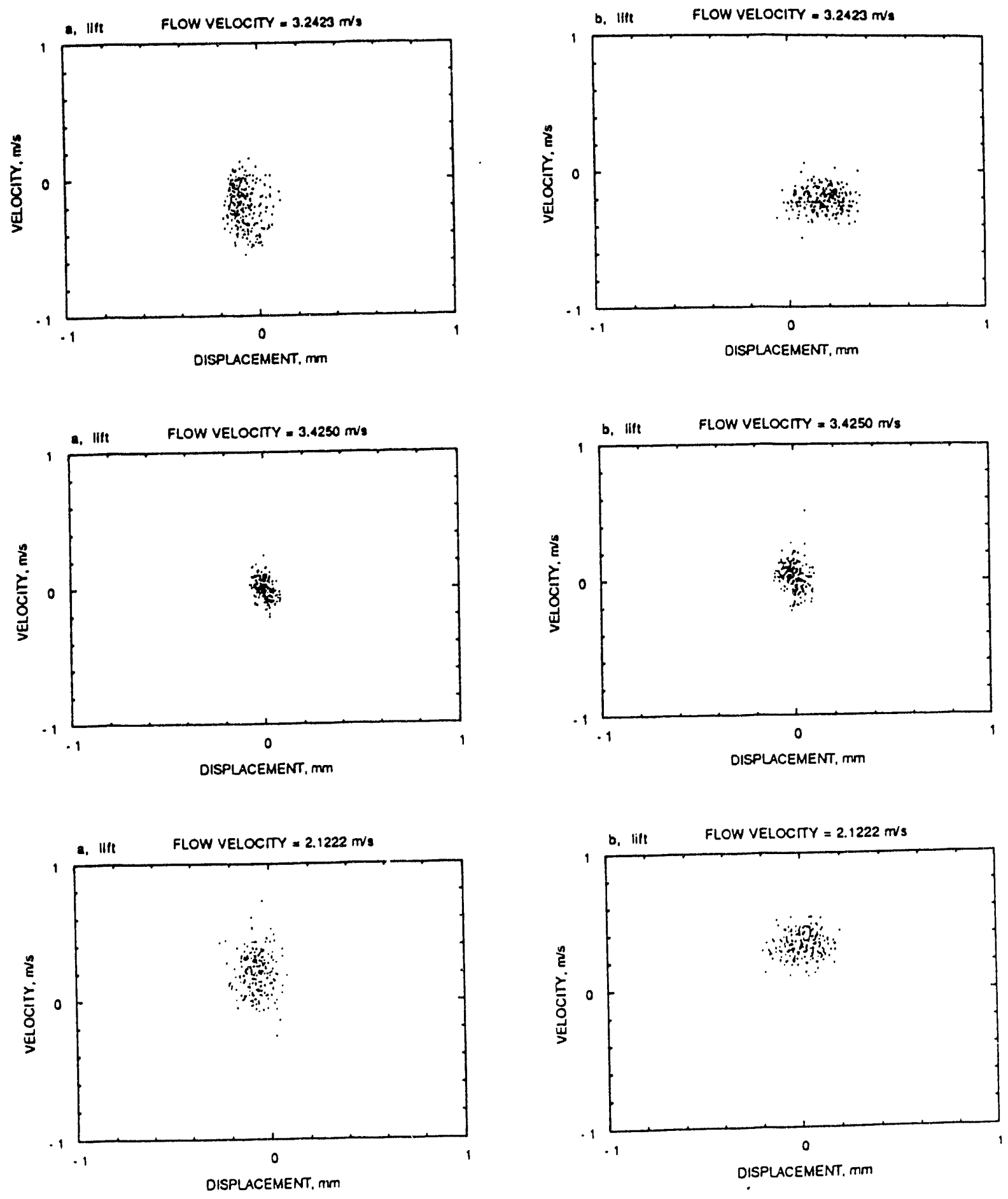

Fig. 45. Poincaré maps, Test C.1 


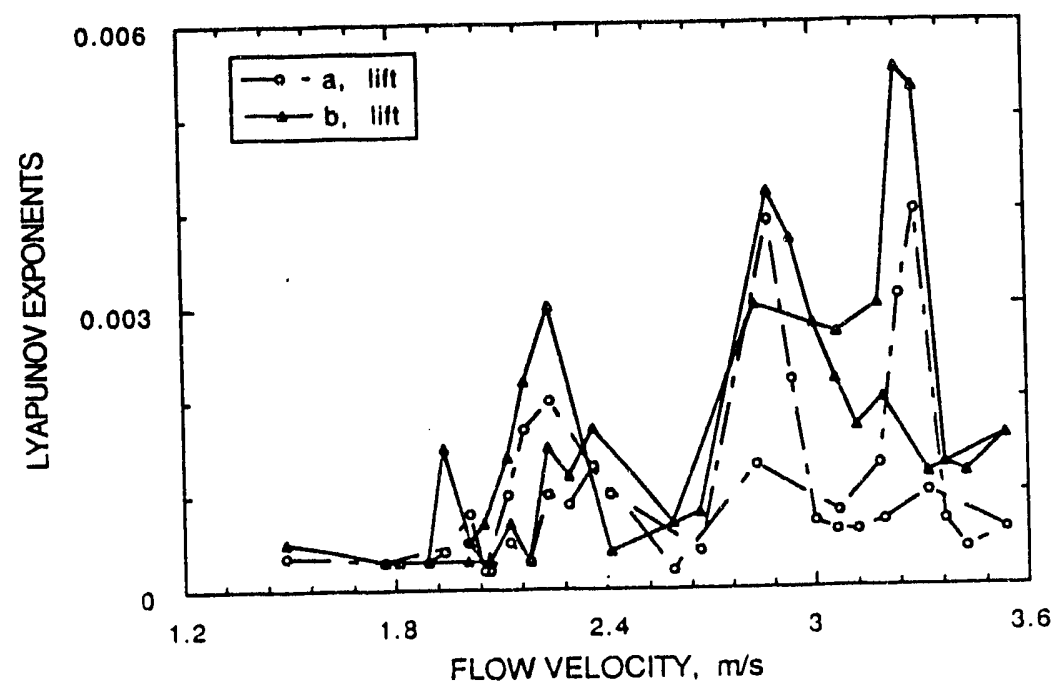

Fig. 46. Lyapunov exponent as a function of flow velocity, Test C.1 


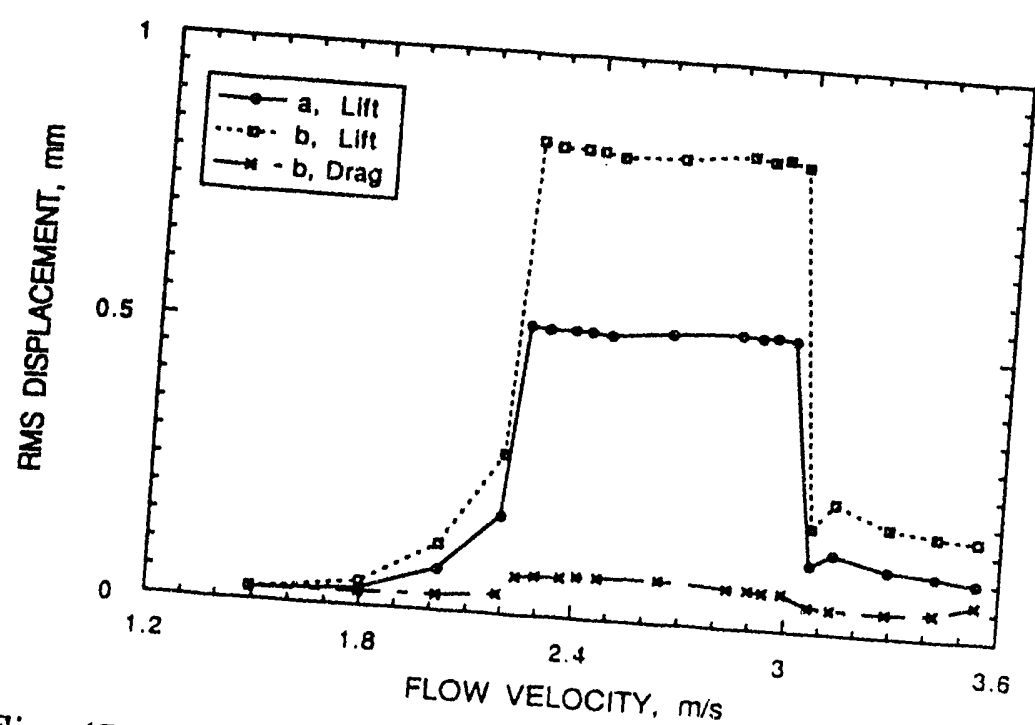

Fig. 47. RMS tube displacement as a function of flow
velocity, Test C.2

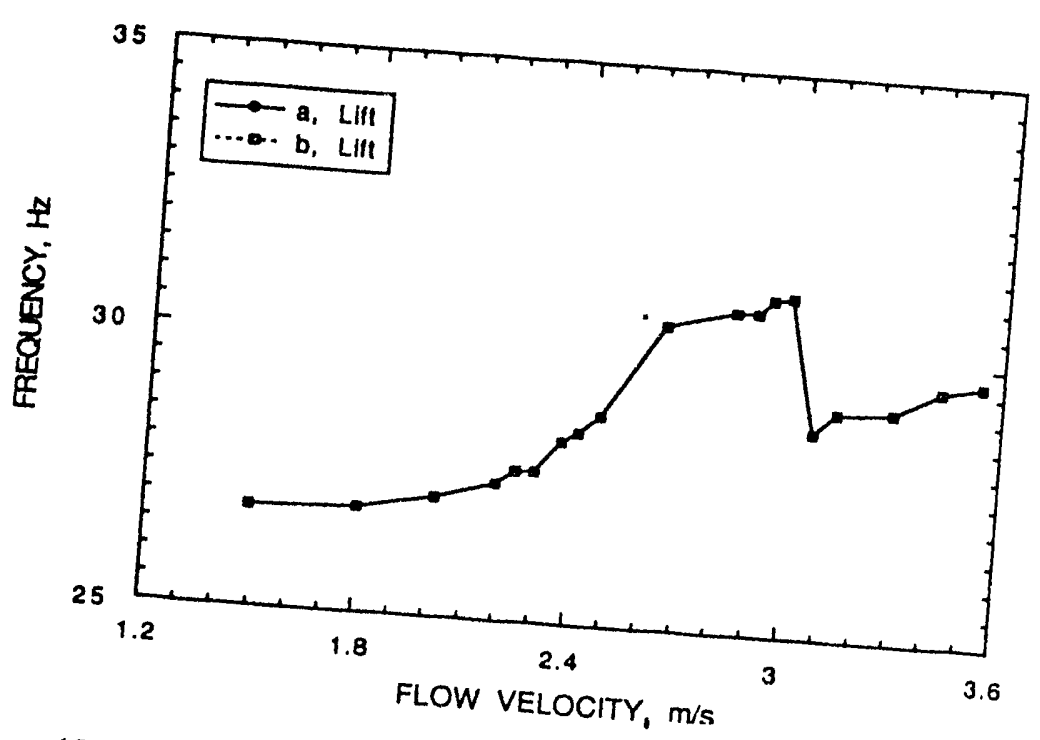

Fig. 48. Dominant response frequency as a function of
flow velocity, Test 


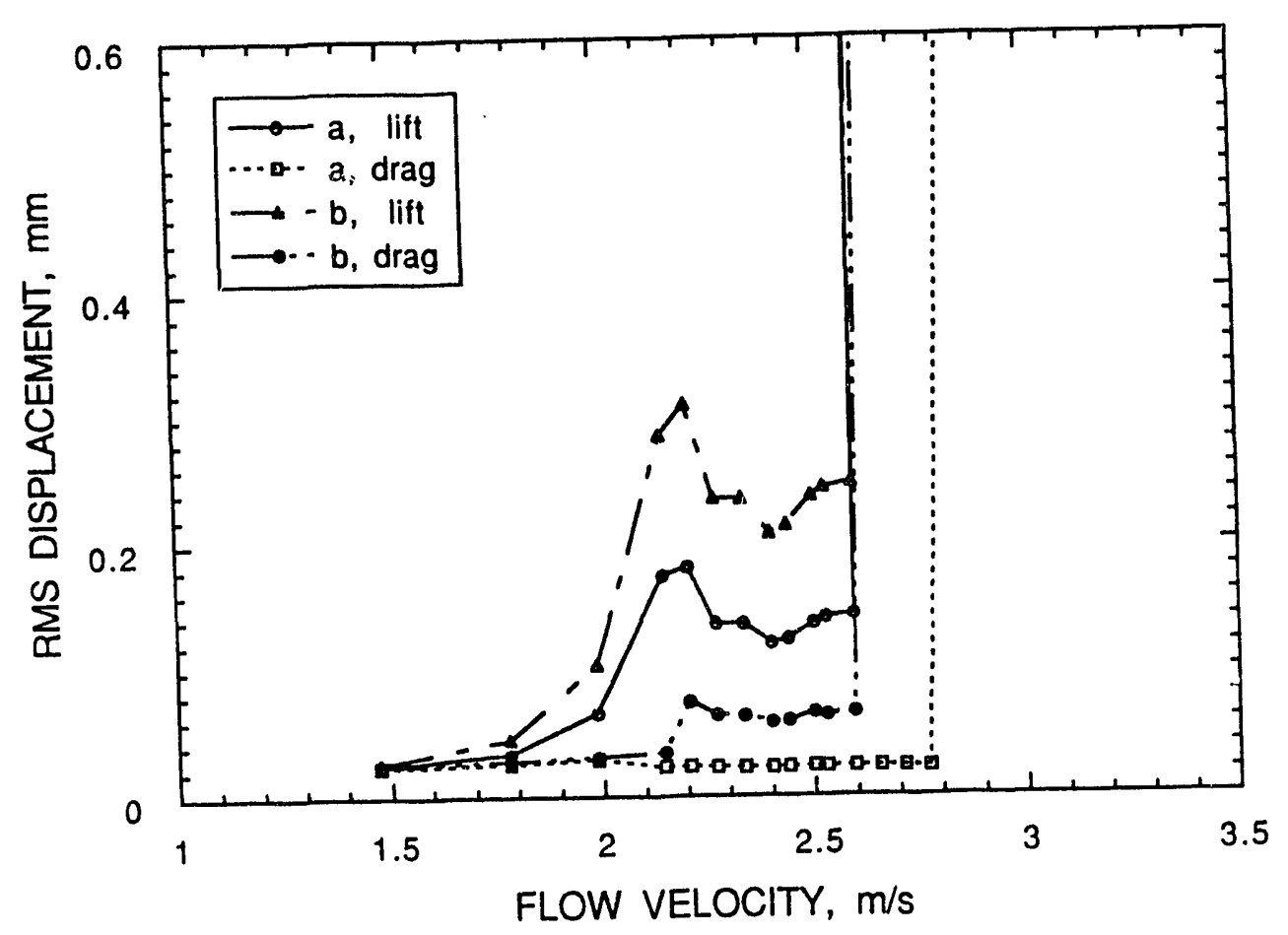

(a)

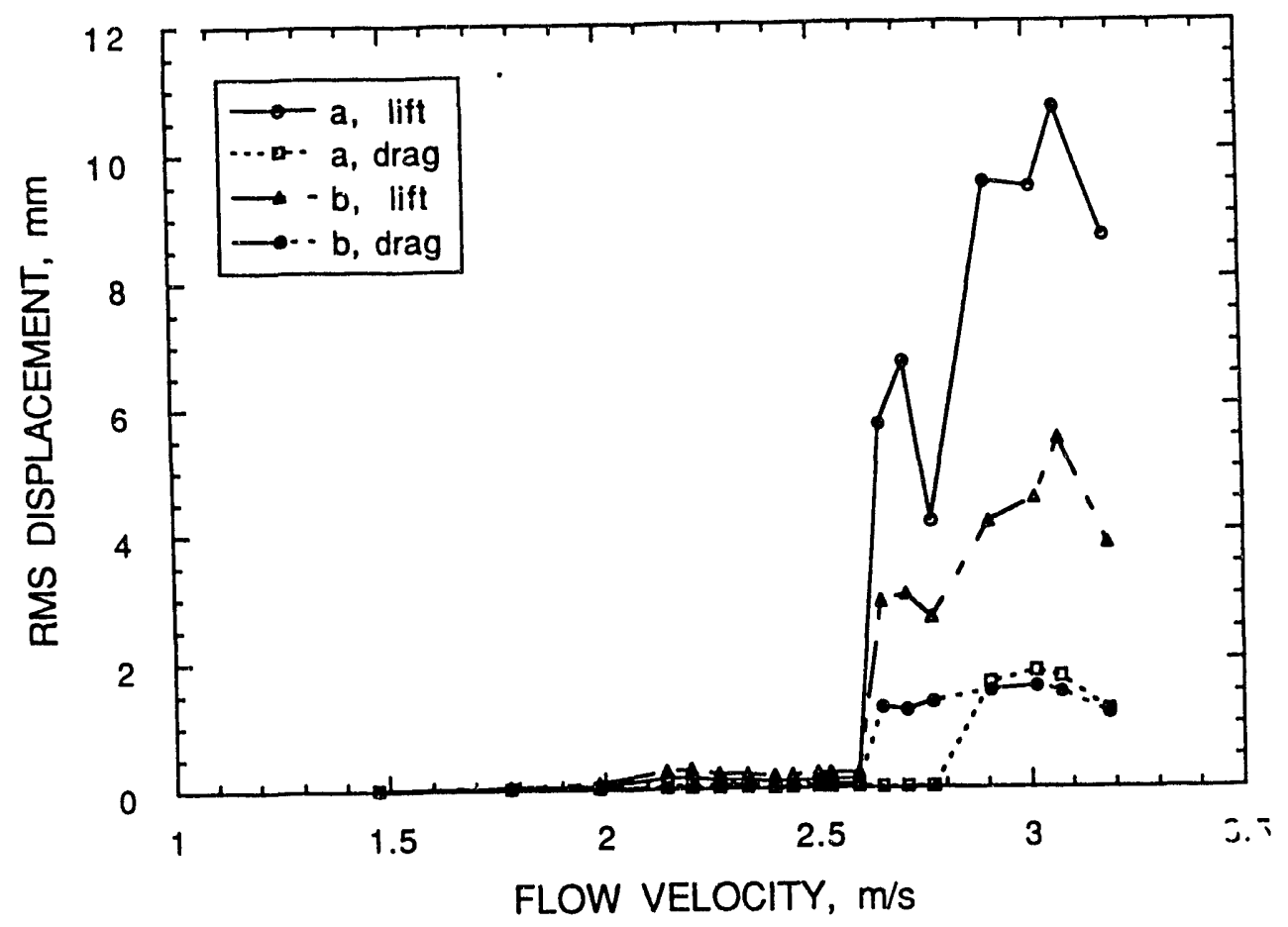

(b)

Fig. 49. RMS tube displacement as a function of flow velocity, Test C.3 


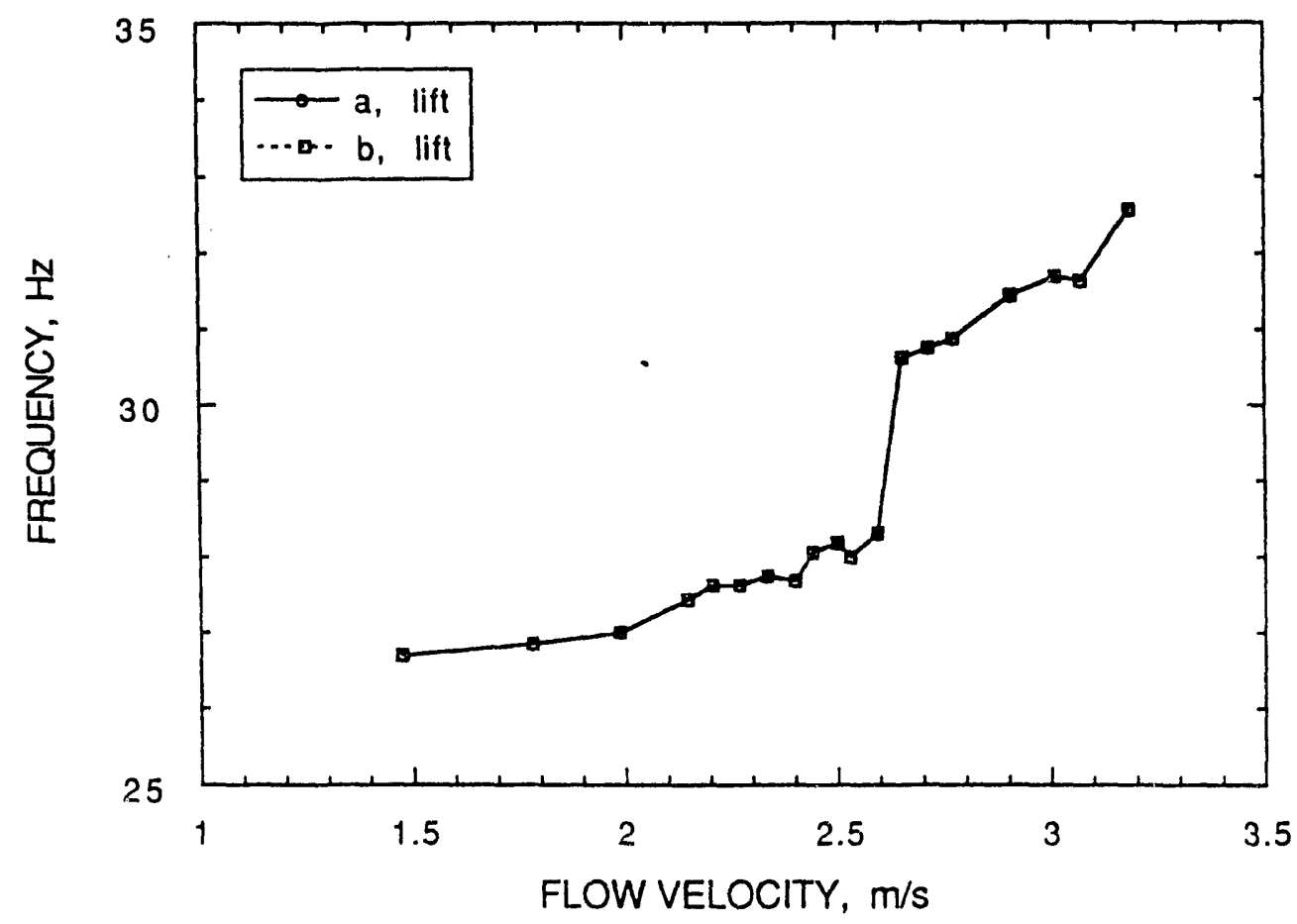

Fig. 50. Dominant response frequency as a function of flow velocity, Test C.3 

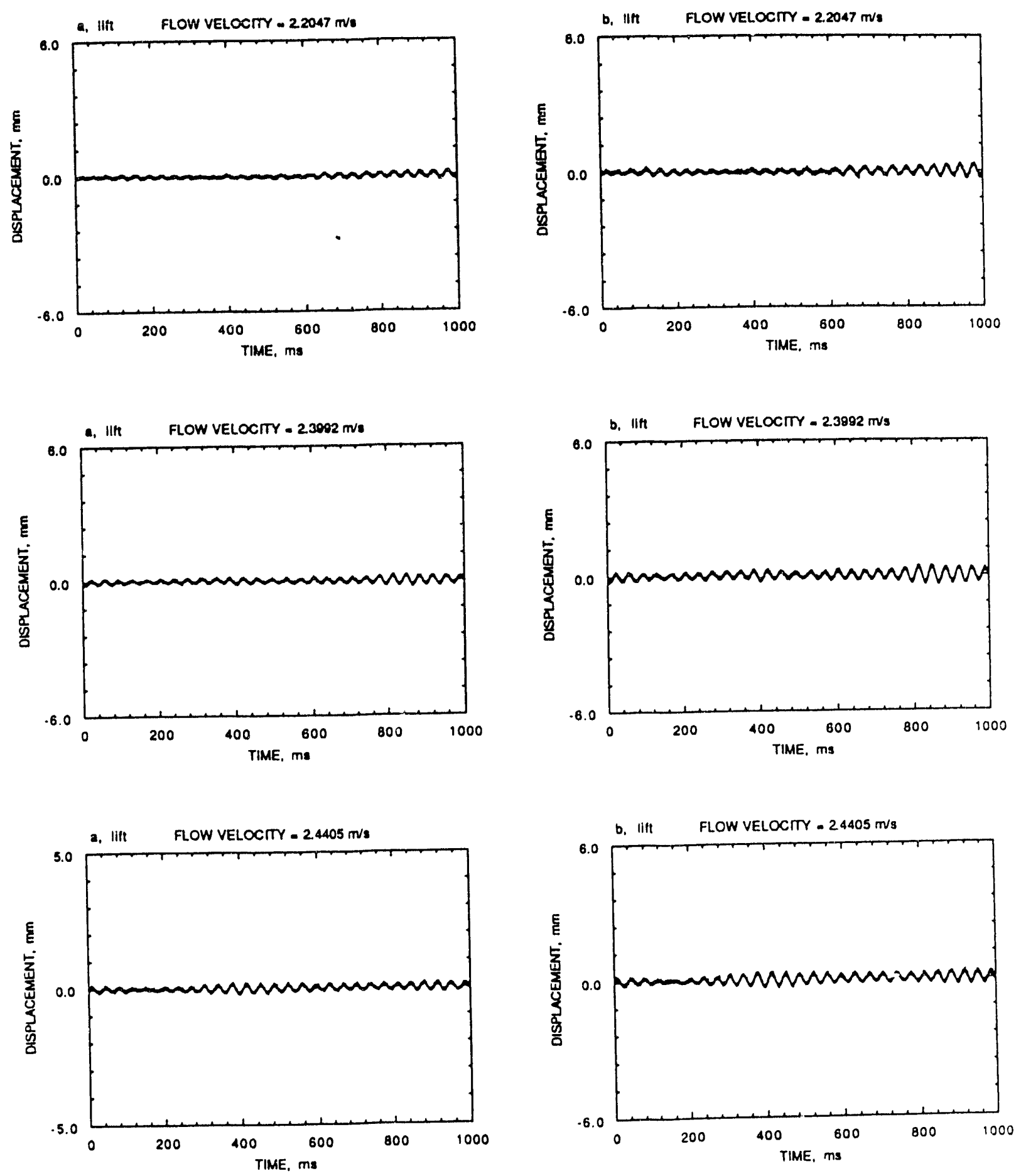

Fig. 51. Time histories of tube displacement, Test C.3 

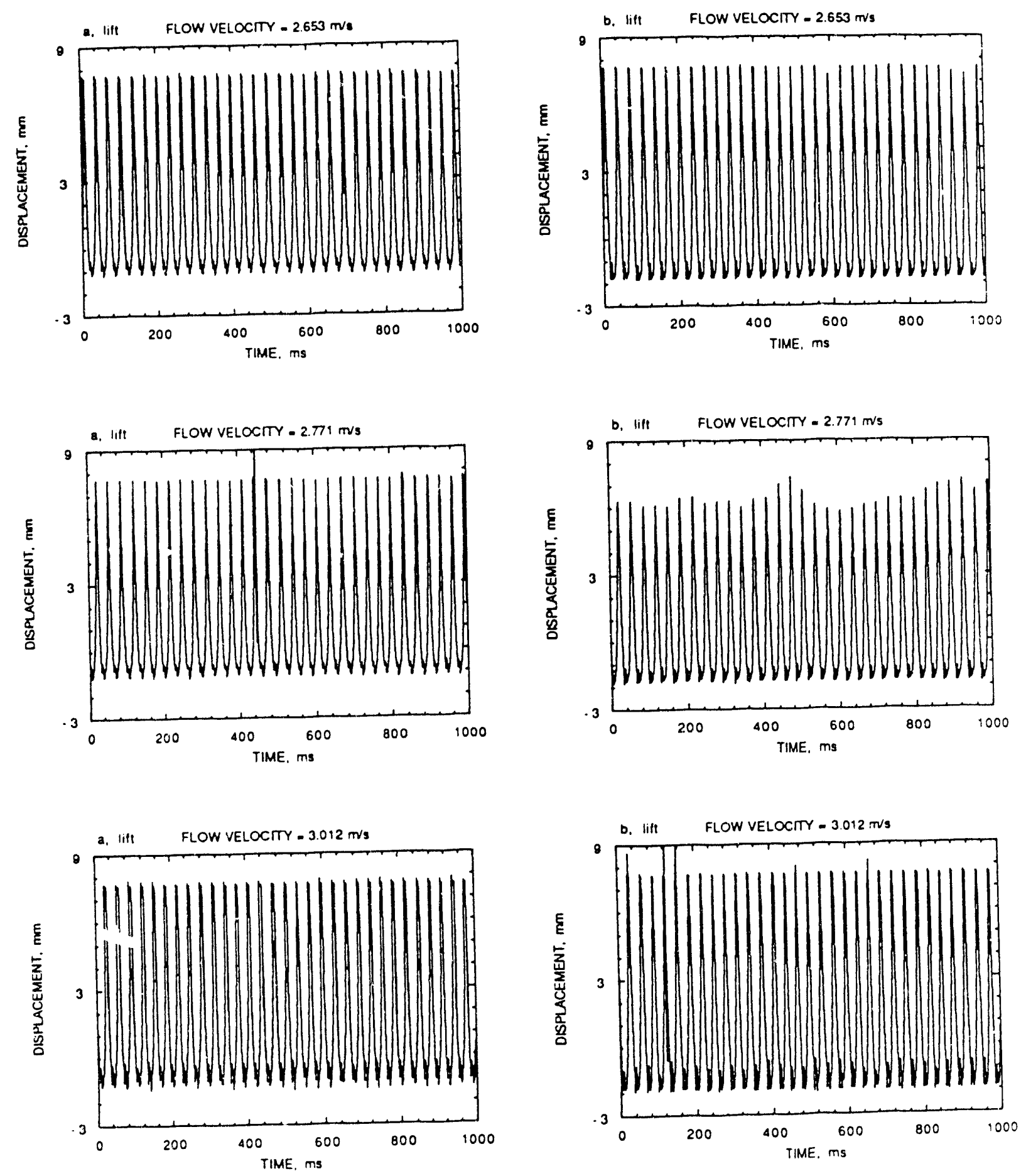

Fig. 52. Time histc. i.es of tube displacement, Test C.3 

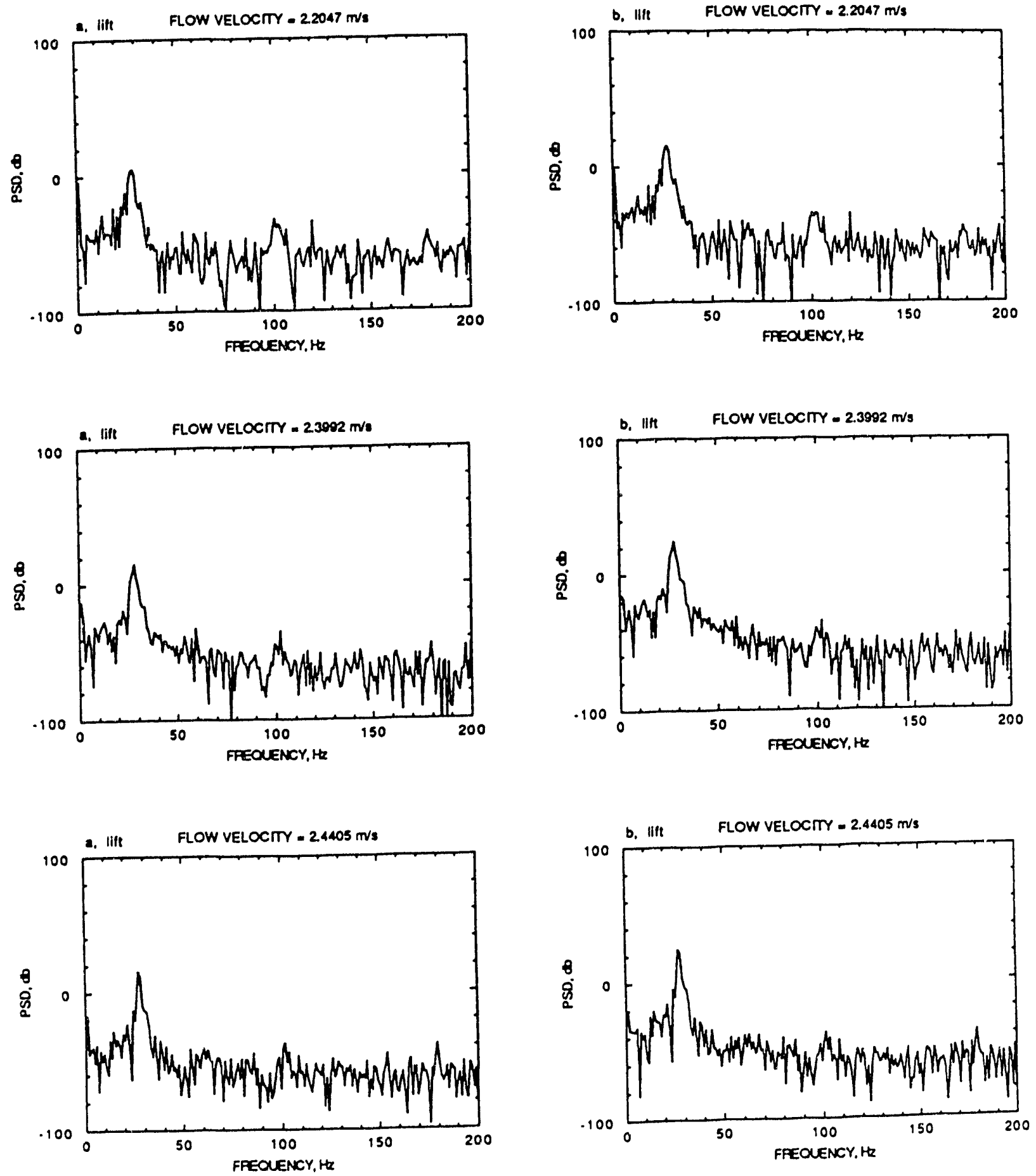

Fig. 53. Pouz. spectral densities of tube displacement, Test C.3 

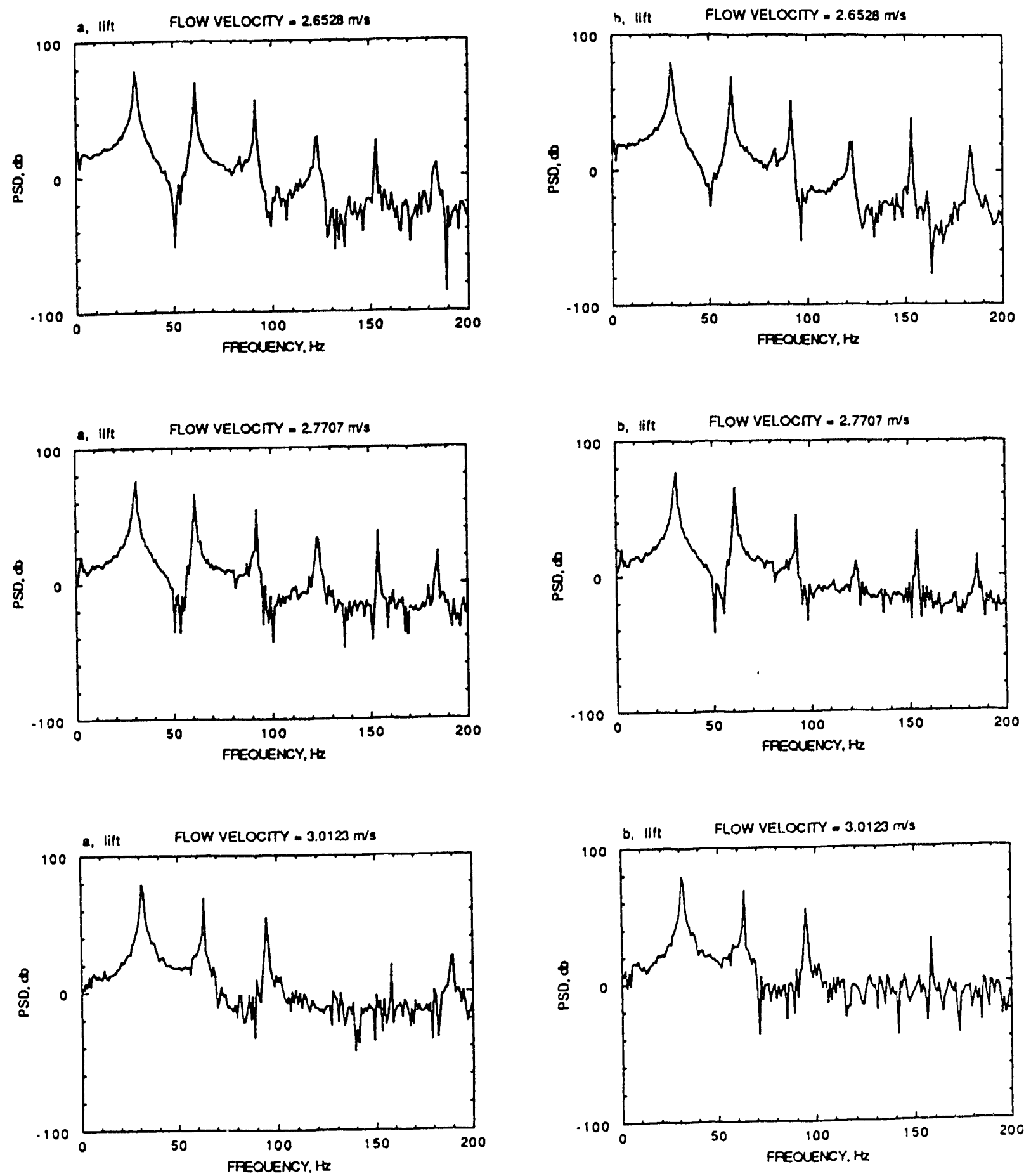

Fig. 54. I zwer spectral densities of tube displacement, Test C.3 

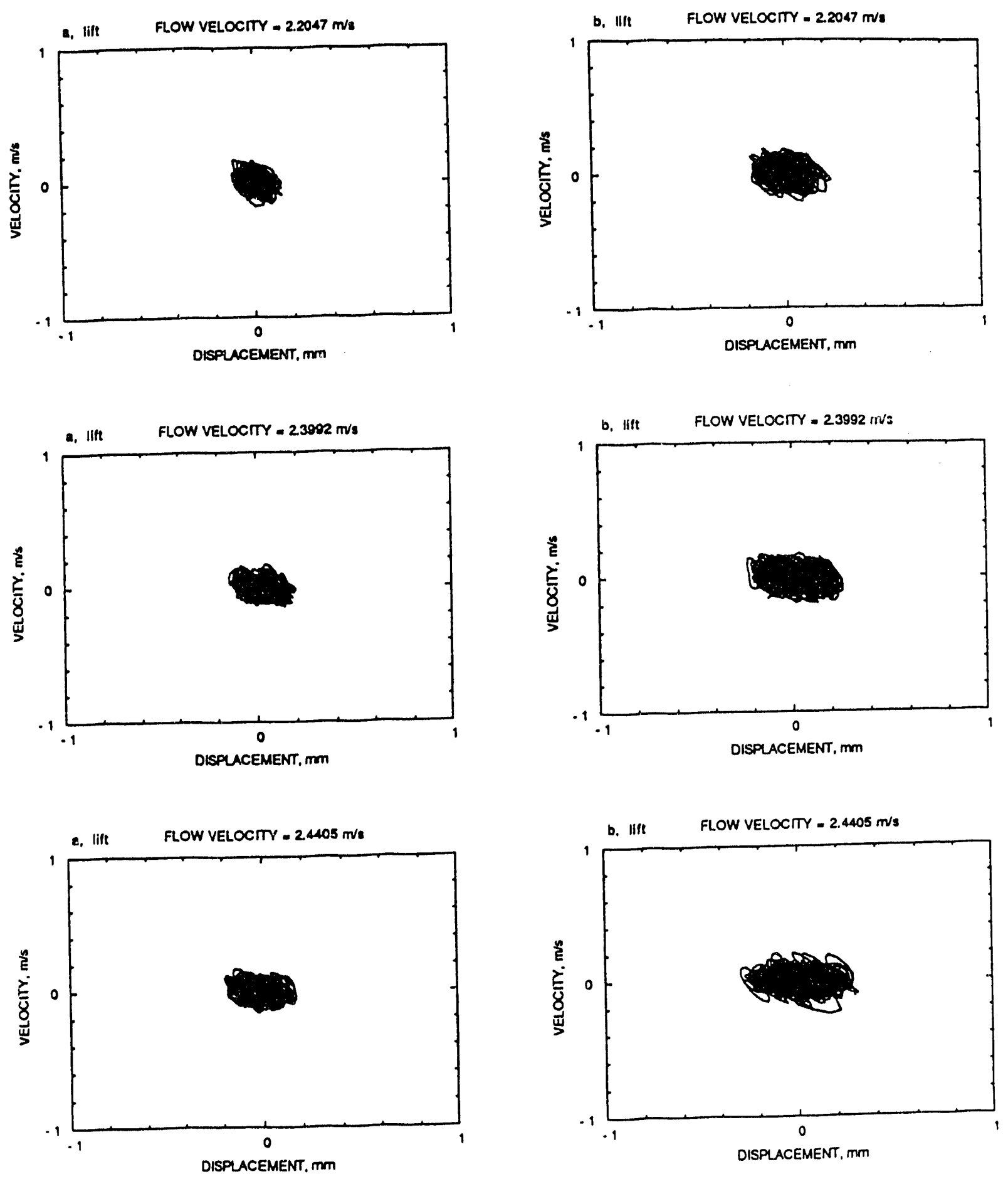

Fig. 55. Phase planes of tube motion, Test C.3 

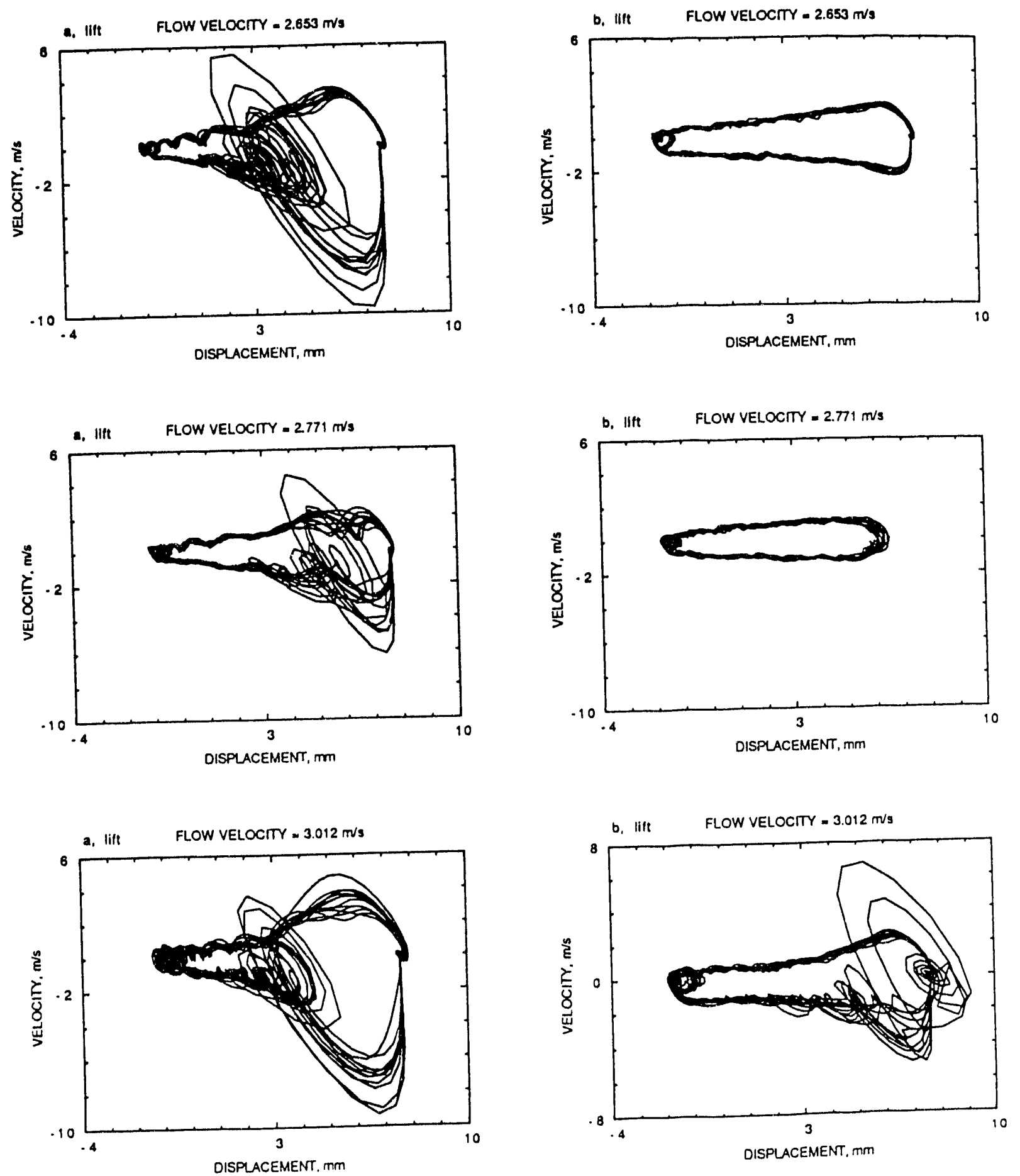

Fig. 56. Phase planes of tube motion, Test C.3 

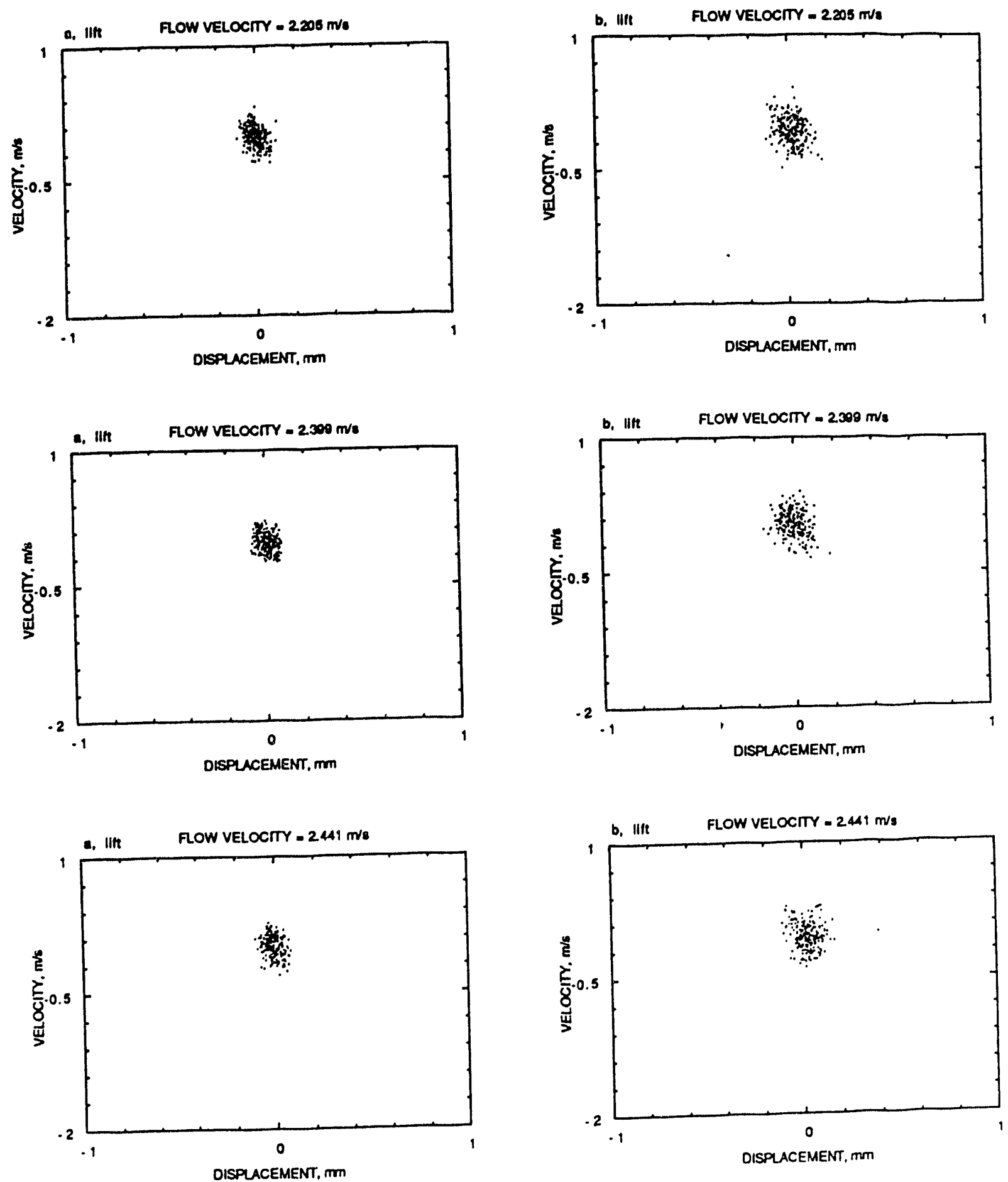

Fig. 57. Poincaré maps, Test C.3 

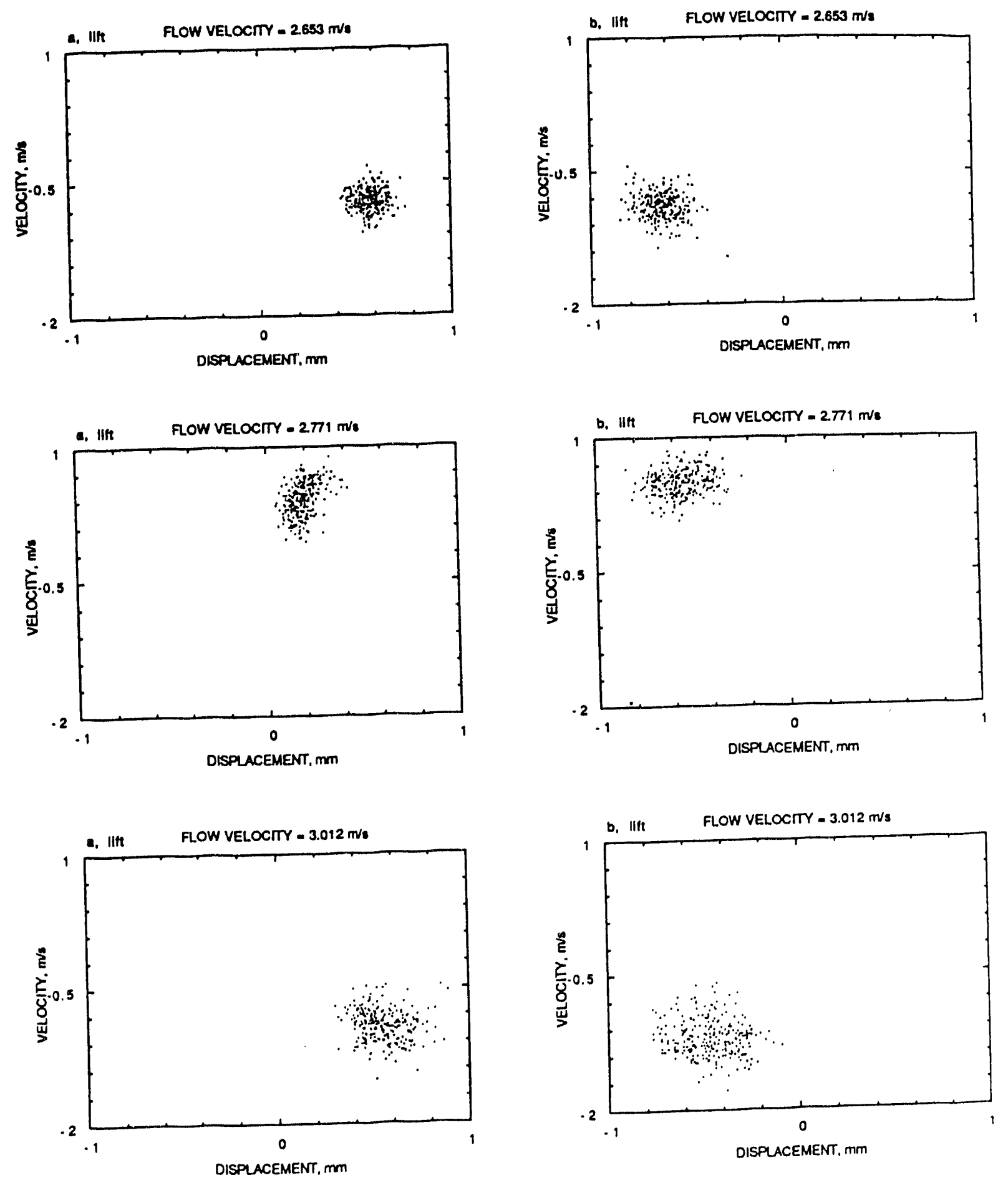

Fig. 58. Poincaré maps, Test C.3 

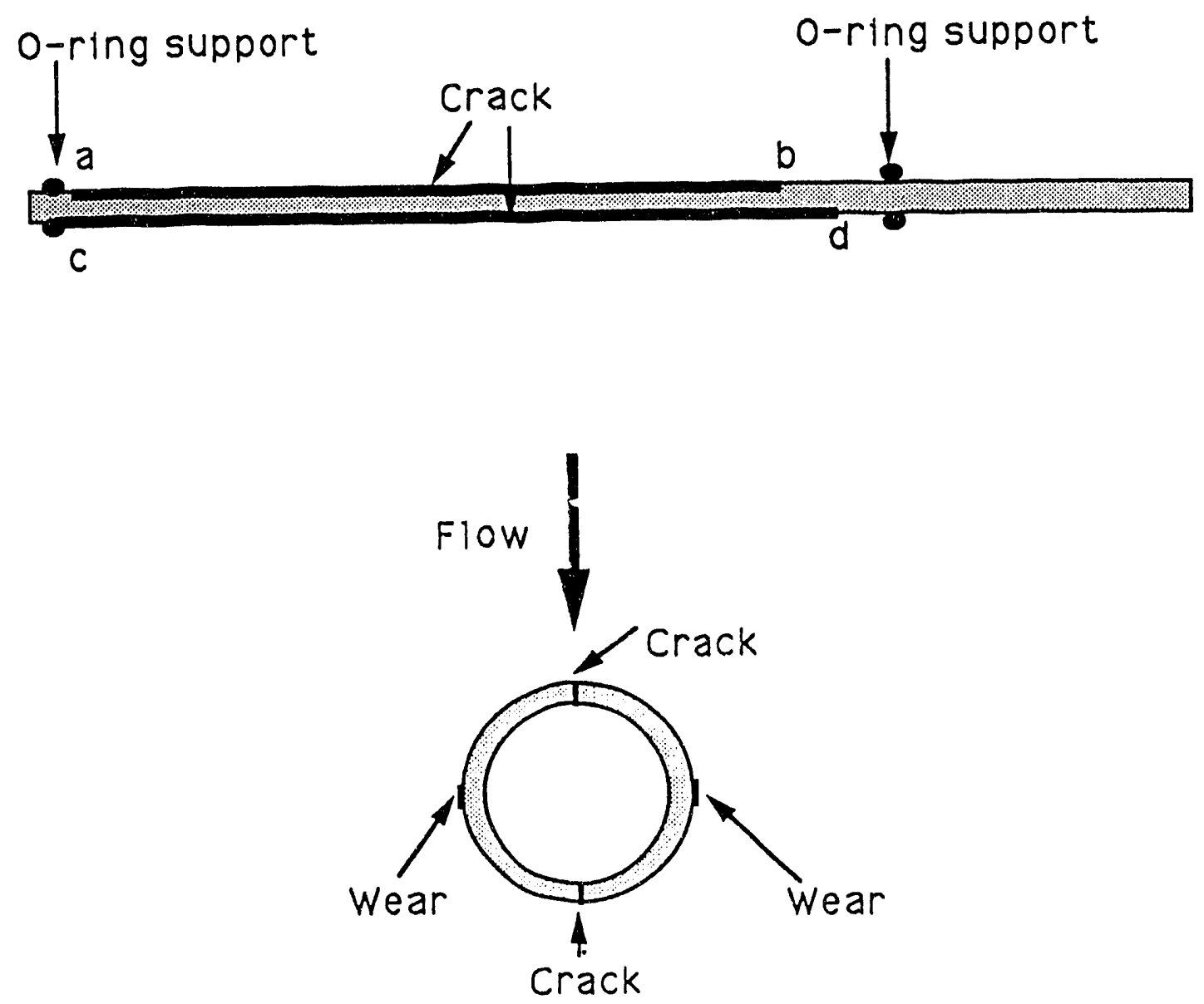

Fig. 59. Tube wear and cracking 


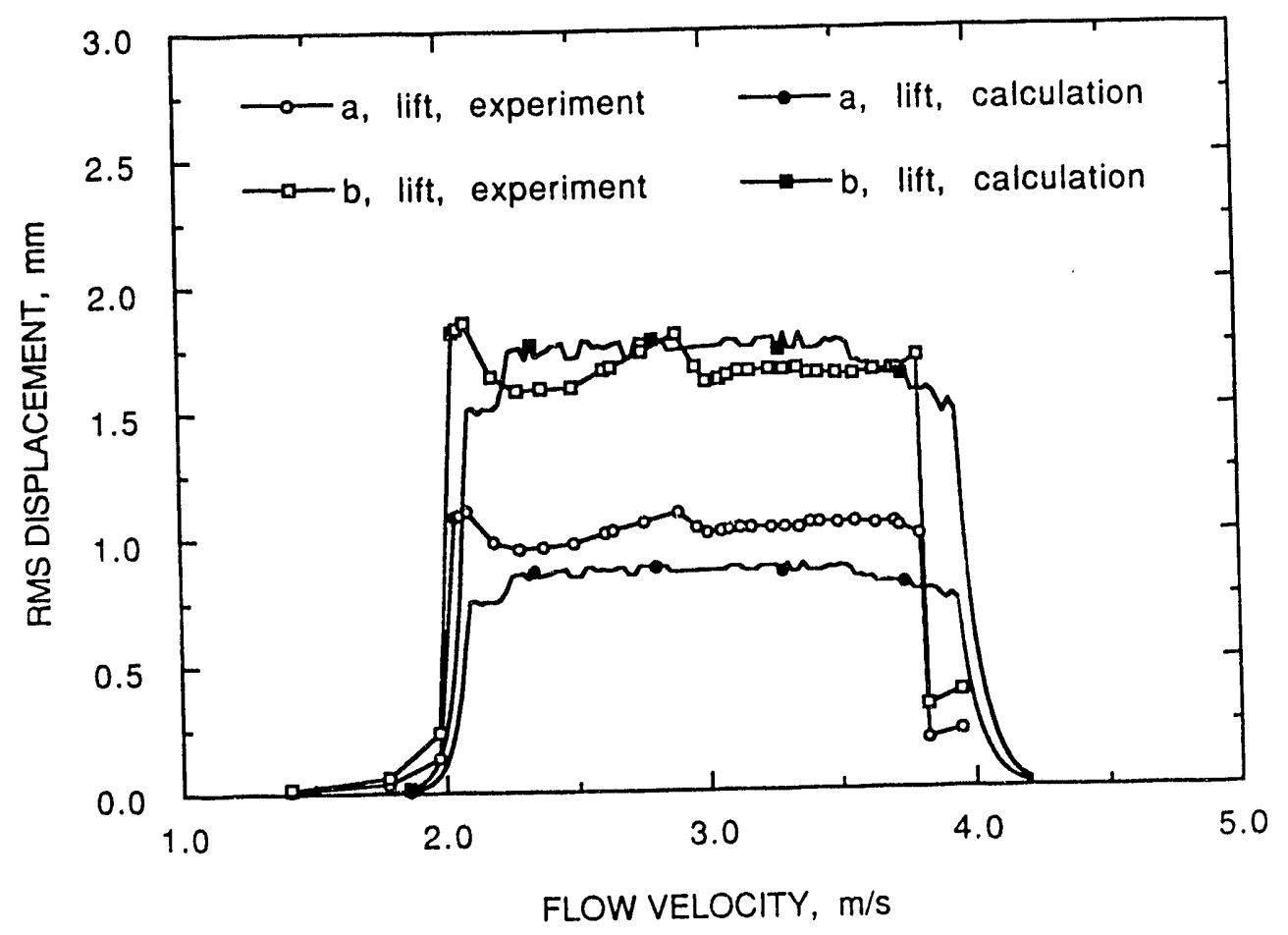

Fig. 60. Comparison of theoretical results and exponent data of RMS tube displacements, Test B.1 

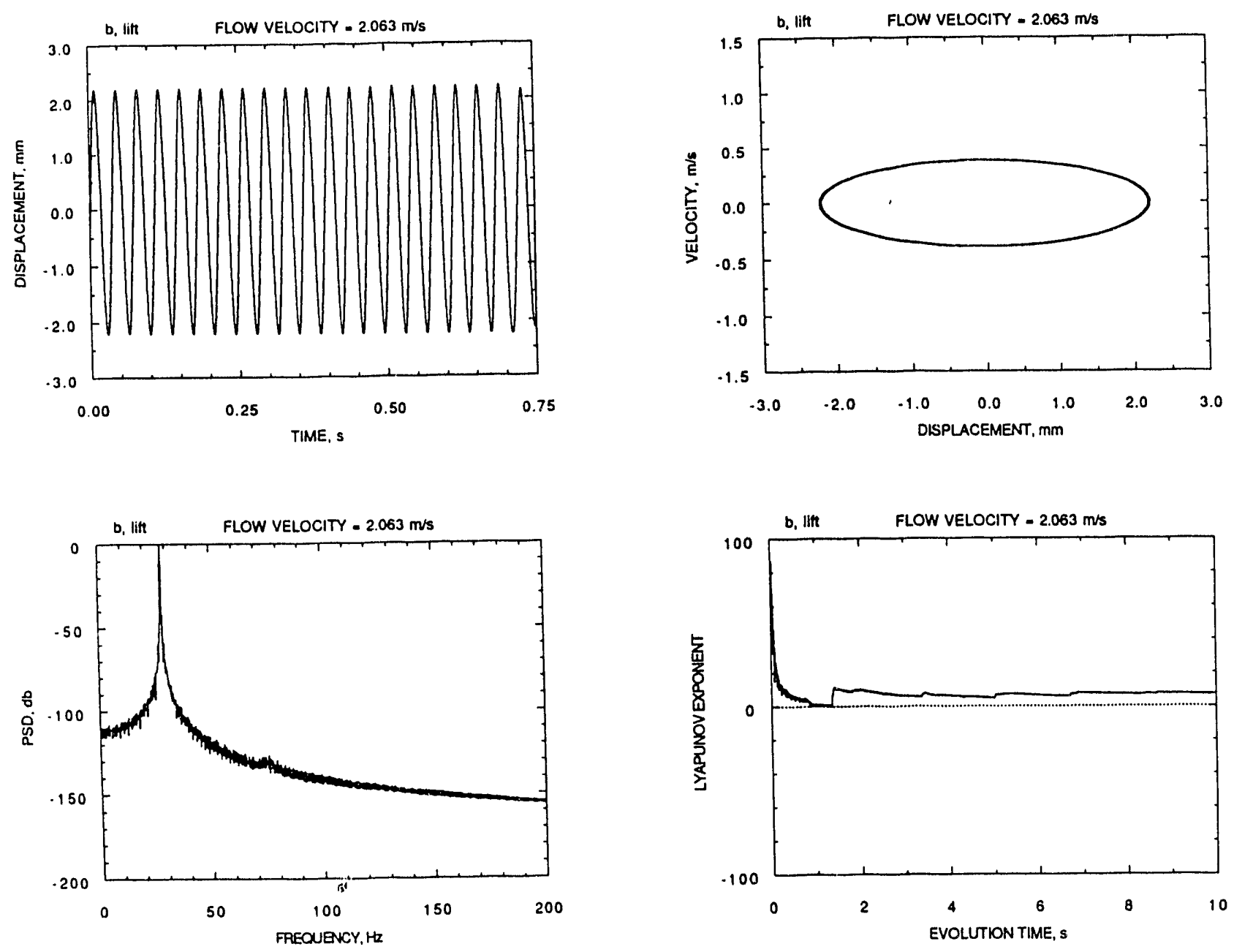

Fig. 61. Time history, power spectral density, phase plane, and Lyapunov exponent at $2.063 \mathrm{~m} / \mathrm{s}$, Test B. 1 

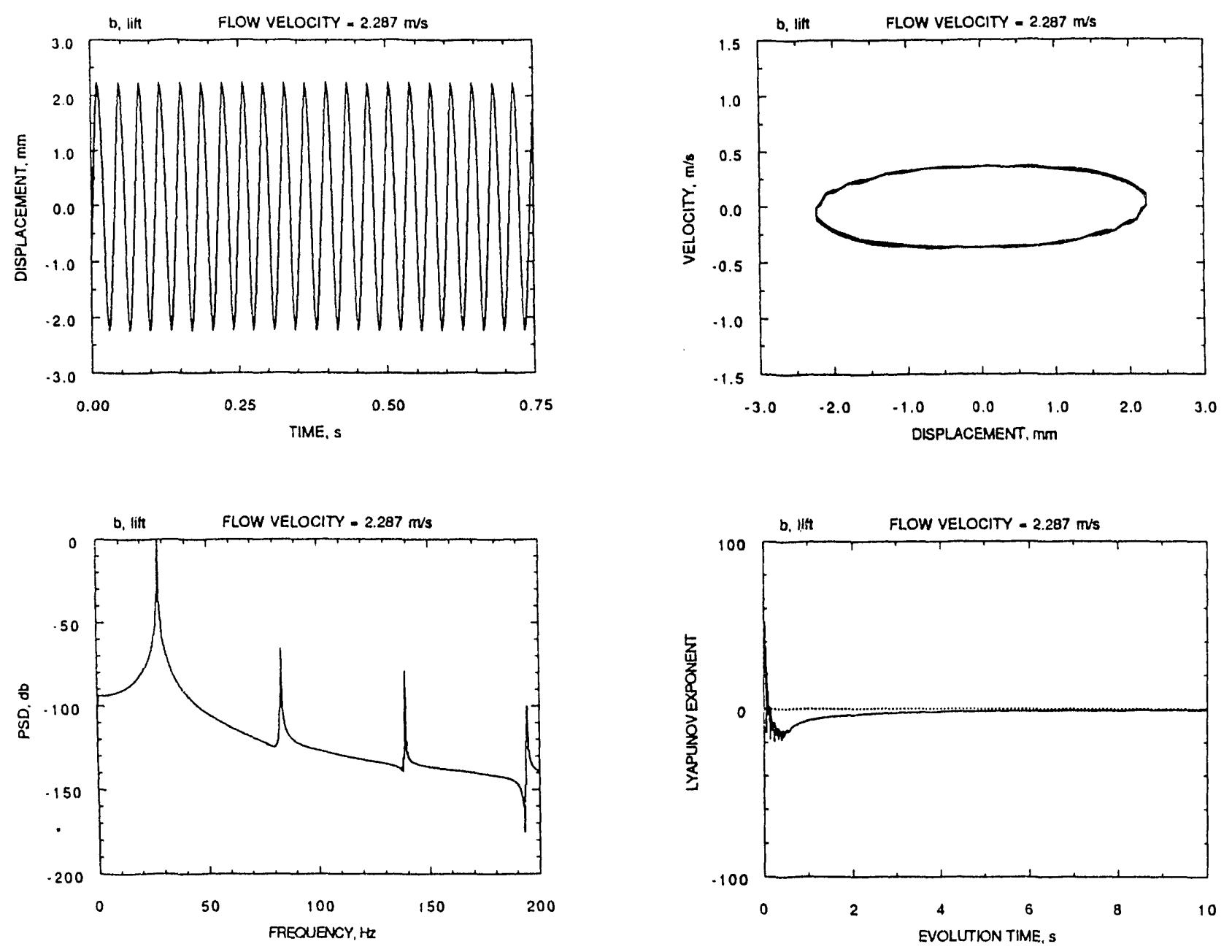

Fig. 62. Time history, power spectral density, phase plane, and Lyapunov exponent at $2.287 \mathrm{~m} / \mathrm{s}$, Test B.1 

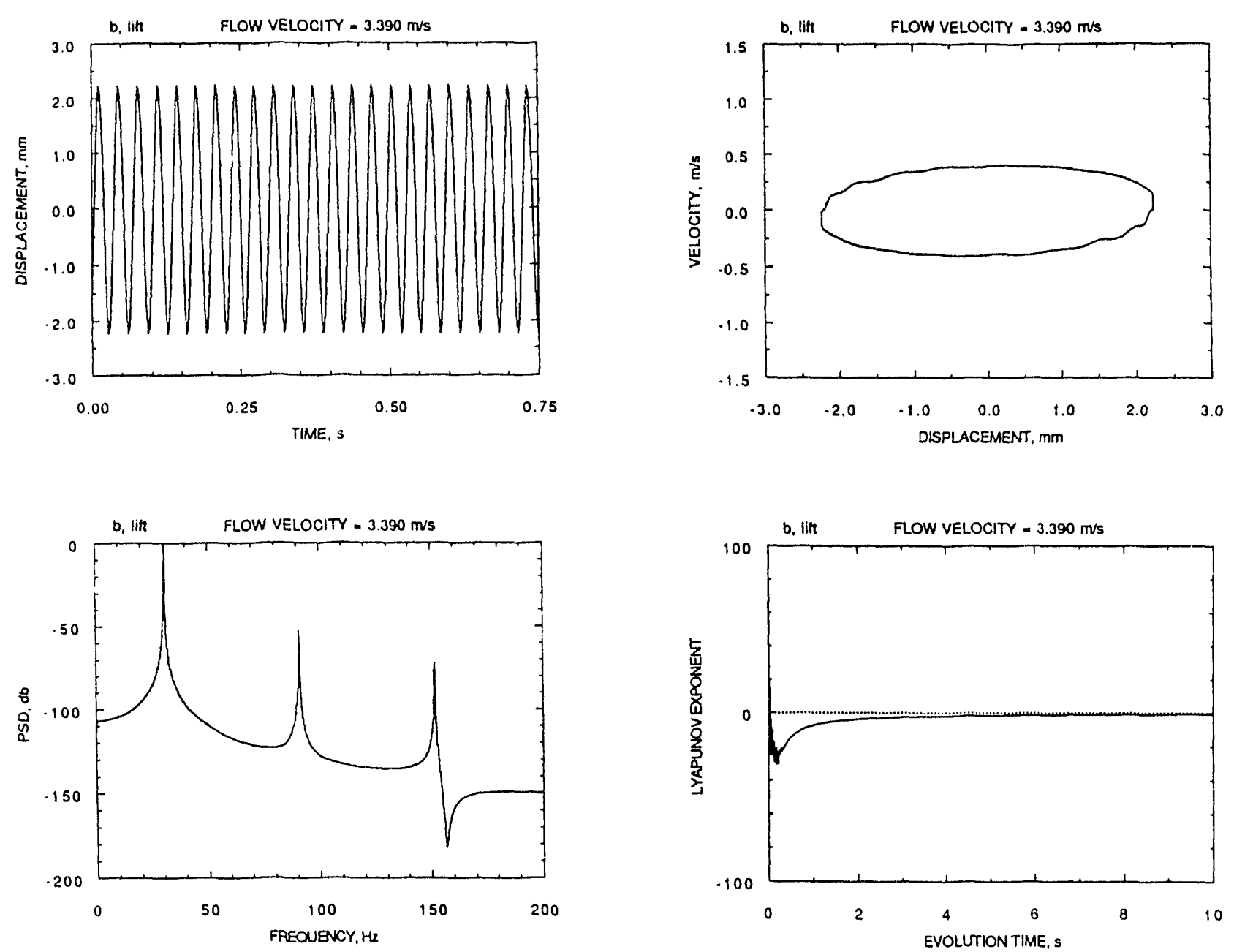

Fig. 63. Time history, power spectral density, phase plane, and Lyapunov exponent at $3.39 \mathrm{~m} / \mathrm{s}$, Test $B .1$ 

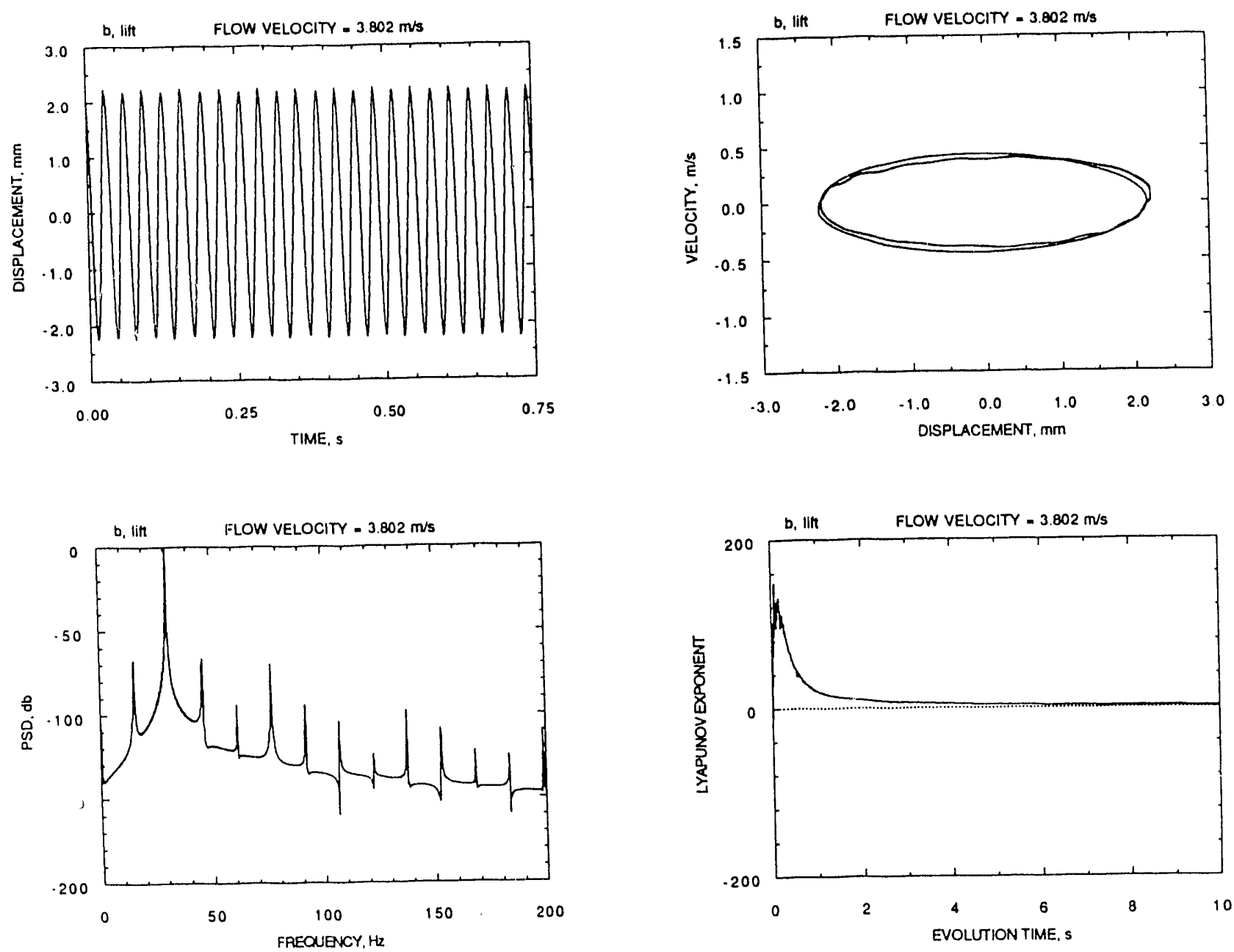

Fig. 64. Time history, power spectral density, phase plane, and Lyapunov exponent at $3.802 \mathrm{~m} / \mathrm{s}$, Test B.1 


\section{Distribution for ANL-93/16}

Internal

Y. Cai (5)

S. S. Chen (20)

H. Drucker

J. A. Jendrzejczyk

C. A. Malefyt (2)

T. M. Mulcahy

R. B. Poeppel
D. M. Rote

R. A. Valentin

M. W. Wambsganss (3)

R. W. Weeks

S. Zhu (5)

TIS Files

\section{External}

DOE-OSTI for distribution per UC-406 (45)

ANL Libraries

ANL-E

ANL-W

Manager, Chicago Field Office, DOE

Director, Technology Management Div., DOE-CH

D. L. Bray, DOE-CH

A. L. Taboas, DOE-CH

Energy Technology Division Review Committee:

H. K. Birnbaum, University of Illinois at Urbana-Champaign, Urbana

R. C. Buchanan, University of Cincinnati, Cincinnati, $\mathrm{OH}$

M. S. Dresselhaus, Massachusetts Institute of Technology, Cambridge, MA

B. G. Jones, University of Illinois at Urbana-Champaign, Urbana

C.-Y. Li, Cornell University, Ithaca, NY

S.-N. Liu, Fremont, CA

R. E. Smith, Engineering Applied Sciences, Inc., Trafford, PA

J. S. Coleman, DOE, Washington, DC

S. K. Datta, DOE, Washington, DC

F. L. Eisinger, Foster Wheeler Energy Corp., Clinton, NJ

Y. L. Liao, Taiwan Power Co., Taipei, Taiwan

O. P. Manley, DOE, Washington, DC

F. C. Moon, Cornell University, Ithaca, NY

K. Srikantiah, EPRI, Palo Alto, CA 

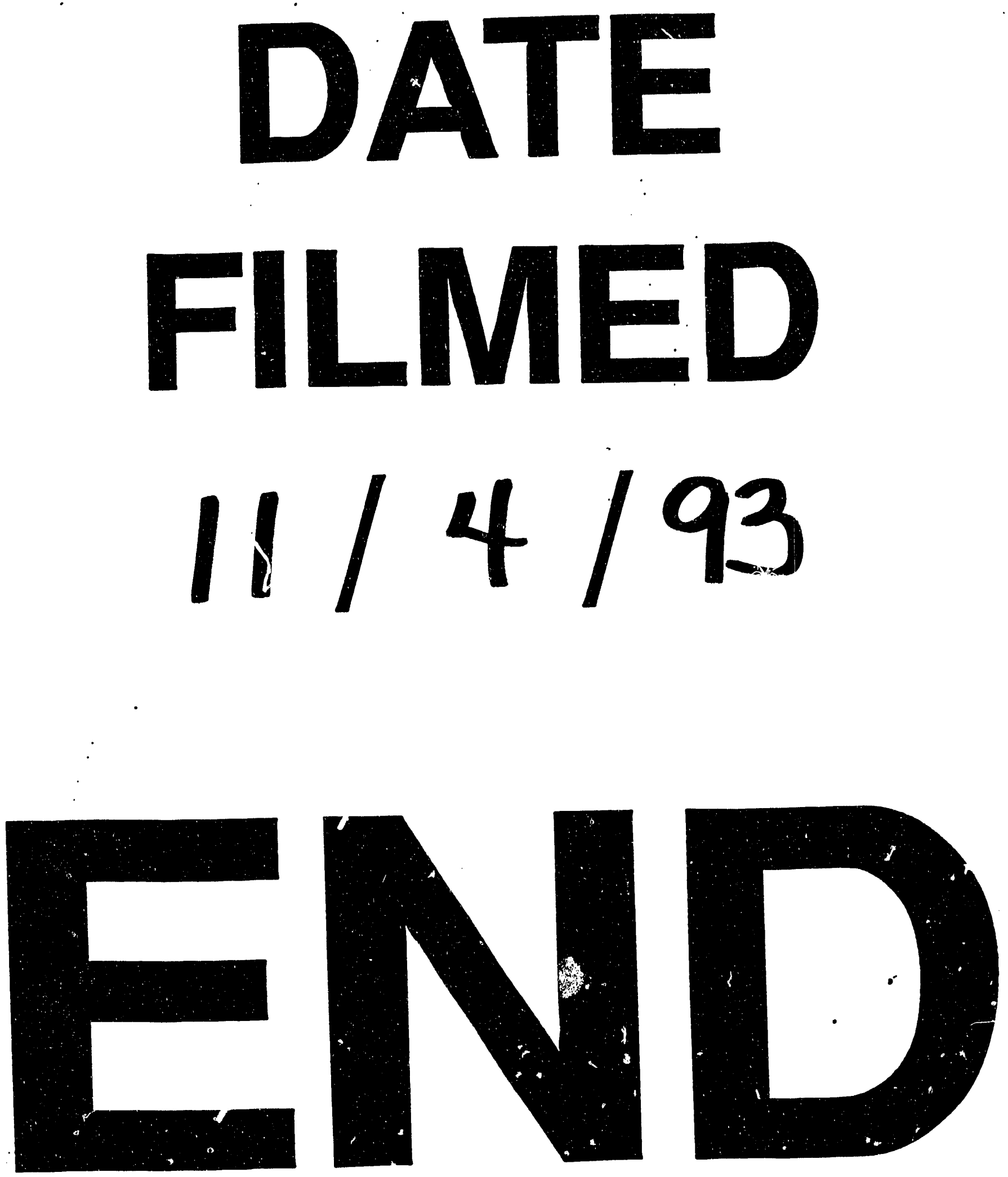

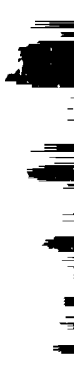


